\title{
Analysis of the Integration of DFM Techniques and Effective Machining Parameter Selection in Metal Parts Manufacturing
}

Omar Ahmed Al-Shebeeb

oaalshebeeb@mix.wvu.edu

Follow this and additional works at: https://researchrepository.wvu.edu/etd

Part of the Industrial Engineering Commons

\section{Recommended Citation}

Al-Shebeeb, Omar Ahmed, "Analysis of the Integration of DFM Techniques and Effective Machining Parameter Selection in Metal Parts Manufacturing" (2019). Graduate Theses, Dissertations, and Problem Reports. 4108.

https://researchrepository.wvu.edu/etd/4108

This Dissertation is protected by copyright and/or related rights. It has been brought to you by the The Research Repository @ WVU with permission from the rights-holder(s). You are free to use this Dissertation in any way that is permitted by the copyright and related rights legislation that applies to your use. For other uses you must obtain permission from the rights-holder(s) directly, unless additional rights are indicated by a Creative Commons license in the record and/ or on the work itself. This Dissertation has been accepted for inclusion in WVU Graduate Theses, Dissertations, and Problem Reports collection by an authorized administrator of The Research Repository @ WVU.

For more information, please contact researchrepository@mail.wvu.edu. 
Analysis of the Integration of DFM Techniques and Effective Machining Parameter Selection in Metal Parts Manufacturing

Omar Ahmed Al-Shebeeb

Dissertation

Submitted to the

Benjamin M. Statler College of Engineering and Mineral Resources at West

Virginia University

in partial fulfillment of the requirement for the degree of

Doctor of Philosophy

in

Industrial Engineering

Bhaskaran Gopalakrishnan, Ph.D., P.E., Chair

Kenneth R. Currie, Ph.D., P.E. Co-Chair

Thorsten Wuest, Ph.D.

Todd R. Hamrick, Ph.D.

Konstantinos A. Sierros, Ph.D.

Department of Industrial and Management Systems Engineering

West Virginia University

Morgantown, West Virginia

2019

Keywords: Design for manufacturing, material properties, process planning, machining, manufacturing cost, production rate

Copyright 2019 Omar Al-Shebeeb 


\section{Abstract \\ Analysis of the Integration of DFM Techniques and Effective Machining Parameter Selection in Metal Parts Manufacturing}

\section{Omar Al-Shebeeb}

This dissertation investigates the minimization of part design with self-locating features. The research focuses primarily on self-fastening characteristics, standardization of parts, and minimal use of fasteners. Further, the present research studies the design for base parts in the construction of a moving joint system, in order to locate potential part and system design improvements. This process may then be extended to industrial applications in the manufacturing industry. Relatively little work to date has examined the significance of Design for Manufacturing Techniques (DFMT), with their inherent machine element systems and machining parameters to investigate which DFMT has the most influence on cost reduction and increasing throughput, and under which circumstances. As such, this dissertation analyzes the inter-operational and synergistic elements of the DFMT, machine element systems, and machining parameters. The parametric specifications for the DFMT are examined and integrated with the cost and productivity-related information. In sum, this research applies DFMT to product design.

The trade-off between cost of manufacturing and productivity in terms of DFM alternatives was subject to preliminary model development and sensitivity analysis. For each DFMT and associated machine element systems and Machining parameters, process planning was used effectively with computer-aided tools to enhance the evaluation impact of the dialogue between the design and manufacturing functions. Expert systems and systematic algorithms are inherently incorporated into the software tools used herein. Generative process planning software is used to measure and analyze sensitivity in plan effectiveness, particularly where material property attributes are changed. The shift that occurs according to process plan attributes is explored. These attributes are presented by manufacturing cost and production rate with respect to variations in specific material properties. The research analyzes four DFMT:

1. Modifying the selection of raw material

2. Modifying quality 


\section{Modifying geometry}

4. Modifying the selection of process/es

In terms of organizing and evaluating the work, a systematic algorithm was developed, discussed, and tested in this dissertation. This algorithm has sequenced elements to investigate and analyze each DFMT. This analysis identifies several potential process plans, from which the plan with the lowest projected cost and highest production rate is selected and constructed. The developed process plans illustrate the importance of alternative DFMT, without impacting product functionality. Each process plan attempts to decrease production cost, maintain quality, and increase throughput. The results of these plans show their respective effectiveness in relation to part utilization, process, and system-level parameters (such as surface finish, tolerance, heat treated condition of the material, geometry, material hardness, melting point, production quantity, cutting tools, cutting fluids, cutting conditions, and machine tools). The criteria for effectiveness include machining cost, tool cost, and throughput.

From this data, the current study determines the most appropriate DFMT and examines underlying alternate machine element systems and machining parameters for each process plan. The effects of DFMT and inherent use of varying machine element systems and machining parameters on cost and productivity-based objectives are also examined. This enables exploration of the selected DFMT choice, according to effective cost reduction and production rate improvement for varying product design. The modified process plan is then compared to the original process plan to highlight areas of improvement. In this comparison, the results of DFMT analysis show significant influence on cost reduction and production rates. These findings suggest that further beneficial outcomes and variety might be obtained by applying this algorithm. 


\section{Dedication}

To my oasis and support

$$
\text { ............... My parents }
$$

To love headspring, immolation and lasting giving

$$
\text { ........My wife "Faihaa" }
$$

To my hope inspiration and the smile in my life

...........My Kids "Mustafa, Jannat, Awaa6,

$$
\text { Tasneem, and Noorhan" }
$$

To immortals light candles

........My passed away brothers "Mustafa and Mohammad" 


\section{Acknowledgements}

I would like to express my deep appreciation and gratitude to my committee chair, Professor Bhaskaran Gopalakrishnan for all his direction and expert insight which he has shared with me, and numerous useful suggestions and invaluable pieces of advice.

I'm very much obliged to my co-advisor Professor Kenneth $R$. Currie, the Chairperson of the Industrial Engineering for his guidance, help, and support throughout my research and for providing me assistantship during my period of study.

I would also like to express my gratitude to all of my professors, my colleagues, and the staff of the Industrial Engineering Department for their help and support.

I would like to express my sincere appreciation to my committee members: Professors Thorsten Wuest, Todd R. Hamrick, and Konstantinos A. Sierros for being my committee members and accepting the heavy task of going through my dissertation.

My work would not have been possible without Mr. Shanti Hamburg, who helped me professionally and personally over the years. I am thankful for his kindness and professionalism.

Finally, I am very grateful and indebted to my family, especially my wife Faihaa for her continuous support for all these years. Their encouragement and inspiration benefit and have enriched my entire life. 


\section{Table of Contents}

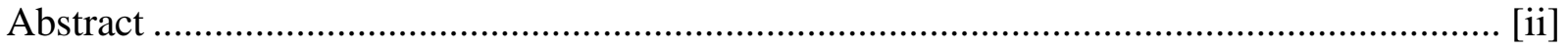

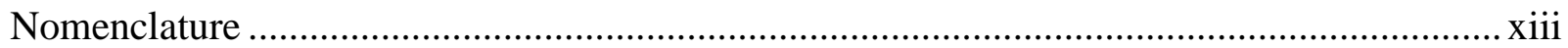

1. CHAPTER ONE: INTRODUCTION........................................................................... 1

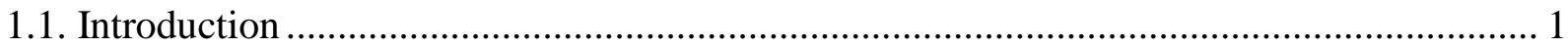

1.2. Technical and economical definition of manufacturing.................................................... 2

1.3. Discrete and continuous Manufacturing ………………................................................. 3

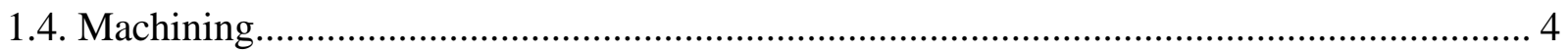

1.5. Machining Process ………………………………………………………………….... 5

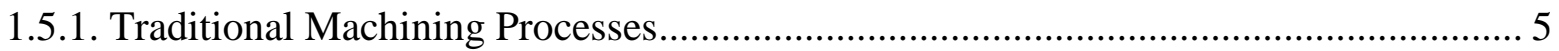

1.6. Concurrent Engineering ………………………………............................................... 5

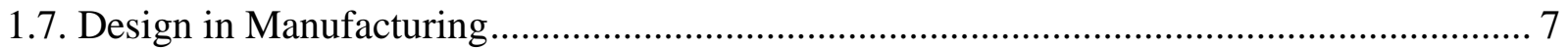

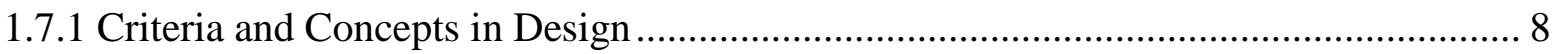

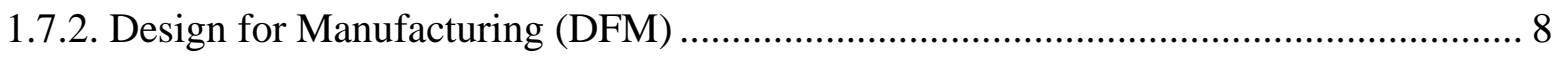

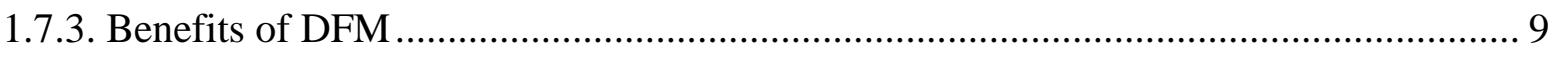

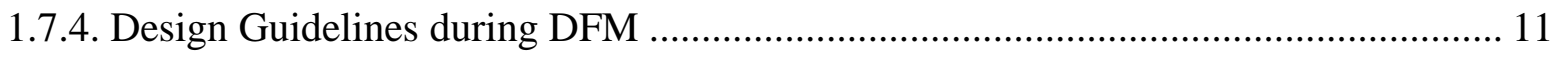

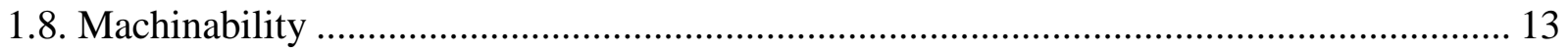

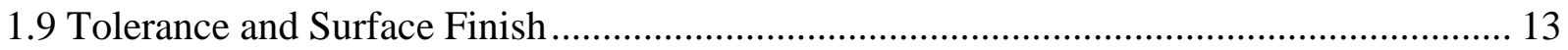

1.9.1 Tolerance in Machining .......................................................................................... 14

1.9.2 Surface Finish in Machining ........................................................................................ 15

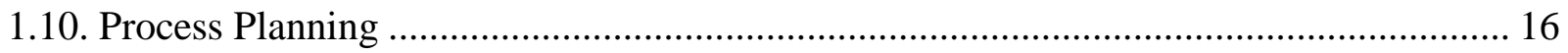

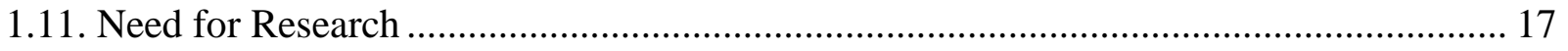

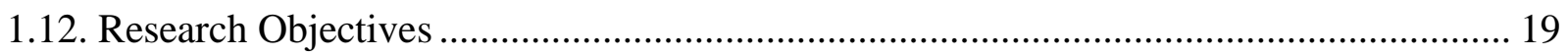

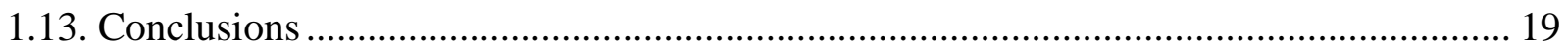




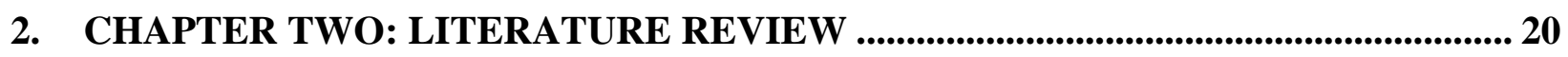

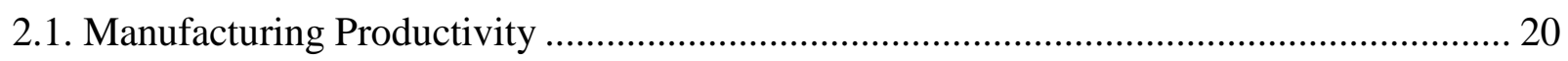

2.2. Machining Productivity in Metal Cutting ...................................................................... 24

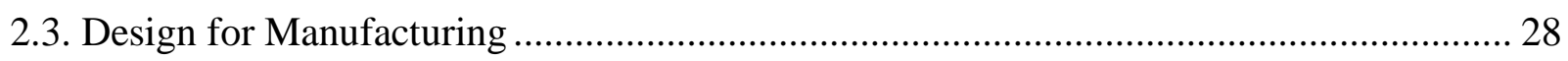

2.4. Design for Manufacturing and Machining Parameters Impacts on Cost and Productivity 33

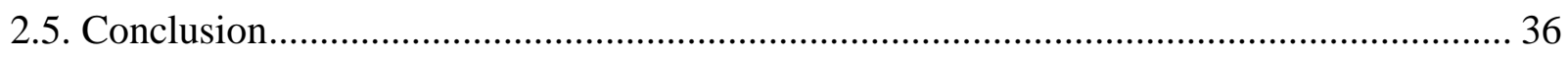

\section{CHAPTER THREE: RESEARCH METHODOLOGY (DATA COLLECTION}

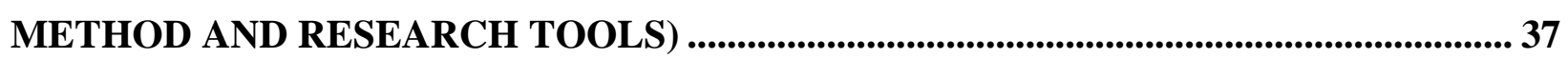

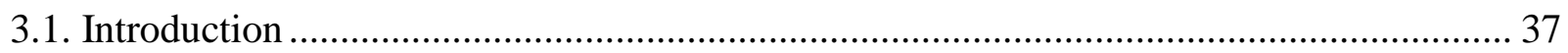

3.2 Systematic Algorithm Structure ……………………………...................................... 37

3.2.1. Design for Manufacturing Techniques (DFMT) ………………………………….... 37

3.2.1.1. Modifying Raw Material.................................................................................... 37

3.2.1.2. Modifying Quality (modifying tolerance and surface finish) .............................. 39

3.2.1.3. Modifying Geometry ……………………………………………………….... 39

3.2.1.4. Modifying Manufacturing Process/es ..................................................................... 39

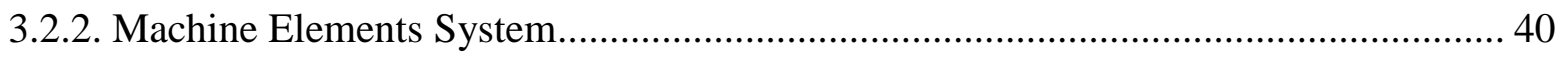

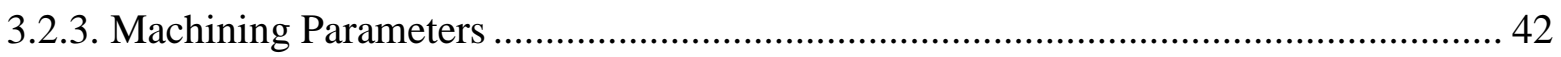

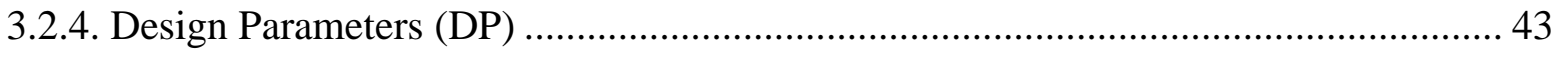

3.2.5. Manufacturing System Parameters (MSP) ................................................................. 44

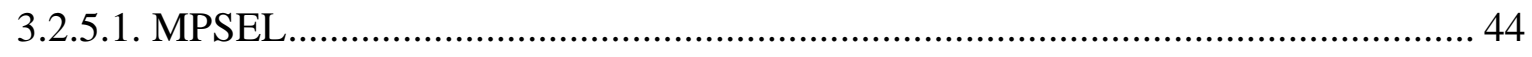

3.2.6. Manufacturing System Data Base (MSDB) .......................................................... 45

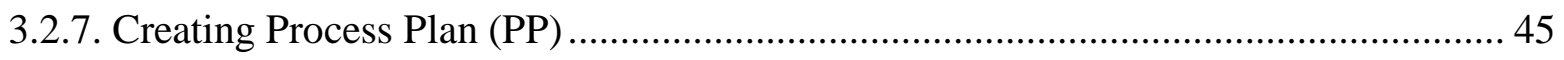

3.2.8. Design for Manufacturing Outputs (DFMO).......................................................... 47

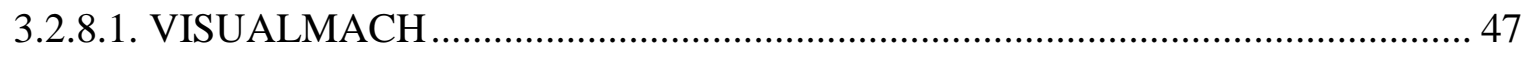

3.2.8.2. Process Plan Attributes Calculator (PPAC) …………………………………...... 47 
3.2.8.3. Economics of Machining and Costing ................................................................. 49

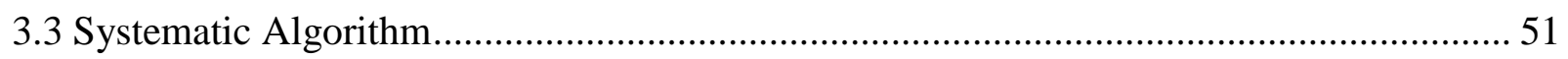

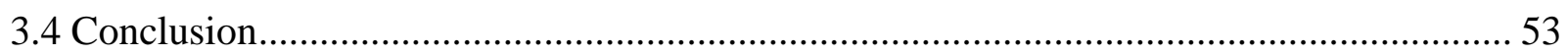

4. CHAPTER FOUR: METHODOLOGY APPLYING AND RESULTS ...........................55

4.1. Using the Systematic Algorithm to perform PPP ........................................................... 57

4.1.1. Description of Quantitative and Qualitative Characteristics of DP............................ 57

4.1.1.1. Quantitative Characteristics of DP..................................................................... 57

B. Final Part Shape, Dimensions, and Features ……………………………………….... 58

4.1.1.2. Qualitative Characteristics of DP.................................................................... 59

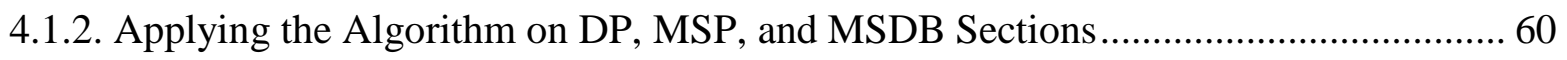

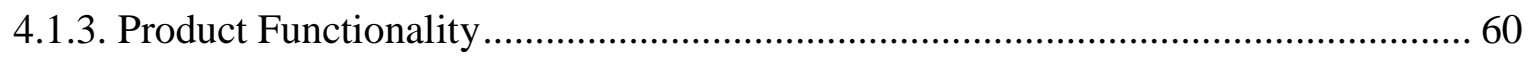

4.1.4. Creating Preliminary Process Plan (PPP) in the PP section ....................................... 61

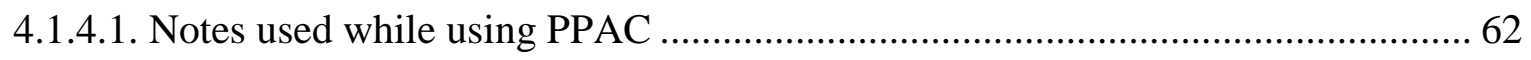

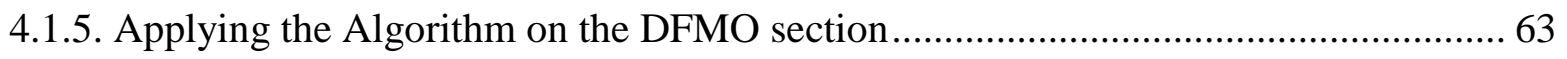

4.1.6.1 Manufacturing Facility Management's (User's) decision ....................................... 66

4.2 Applying the Systematic Algorithm on the DFMT Section................................................ 66

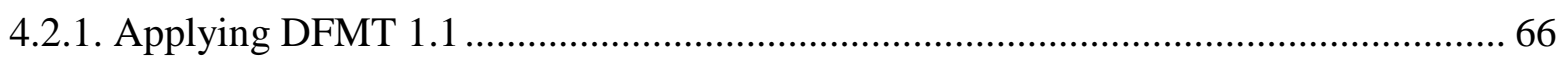

4.2.1.1. DFMT1.1 Using Aluminum Alloy as Raw Material ............................................ 68

4.2.1.2. DFMT1.2 Using Nickel Alloy as Raw Material.................................................. 75

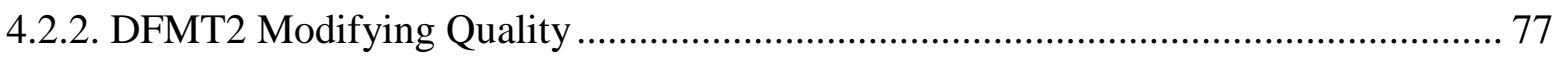

4.2.2.1. DFMT2.1 First Quality Parameters Modification ................................................. 78

4.2.2.2. DFMT2.2 Second Quality Parameters Modification .............................................. 80

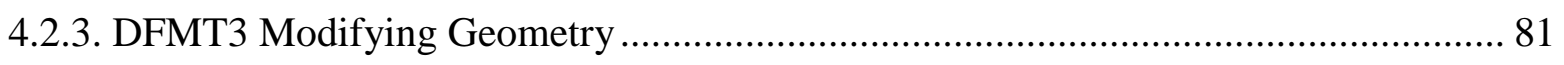

4.2.3.1. DFMT3.1 First Modified Geometry ………………………………………….... 82 
4.2.3.1.1. Modified Workpiece Dimensions ……………........................................ 82

4.2.3.1.2. Final Modified Product Dimensions ................................................................ 82

4.2.3.2. DFMT3.2 Second Modified Geometry .............................................................. 85

4.2.4. DFMT4 Modifying the selection of machining Process/es .......................................... 87

4.2.4.1. DFMT4.1 First Modifications of Selecting Process/es ........................................... 87

4.2.4.2. DFMT4.1 Second Modifications of Selecting Process/es ..................................... 88

4.3 Summarizing the Results and Discussion ...................................................................... 90

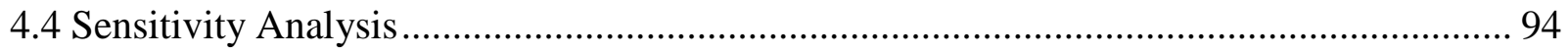

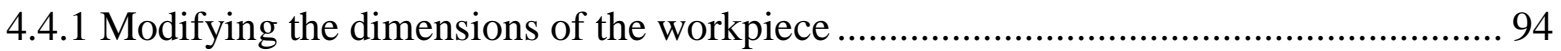

4.4.2. Analyzing L/D ratio ................................................................................................ 96

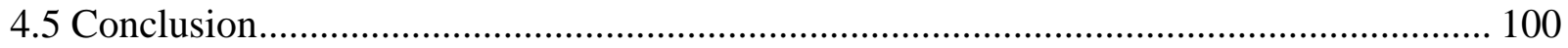

5. Chapter 5: Conclusion, Contributions, Limitations, and Proposed Future Work...... 103

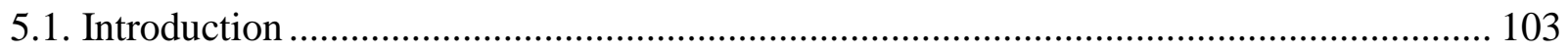

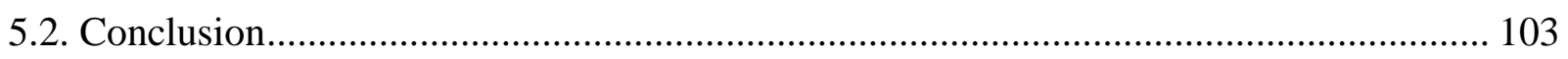

5.2.1. The Findings of the Systematic Algorithm .................................................................. 104

5.2.2. Suggested Method for Modifying the DFMT.......................................................... 105

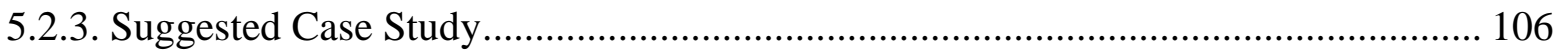

5.2.4. Work Development ............................................................................................ 106

5.2.5. Developed Software in Systematic Algorithm .......................................................... 107

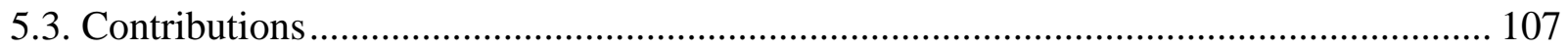

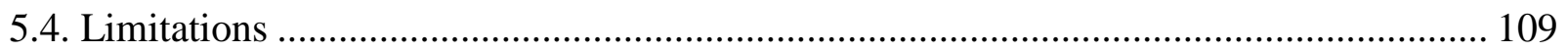

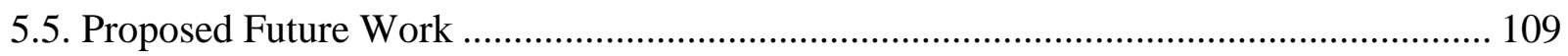

Literature Cited ......................................................................................................................................... 110

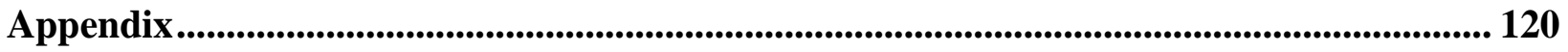

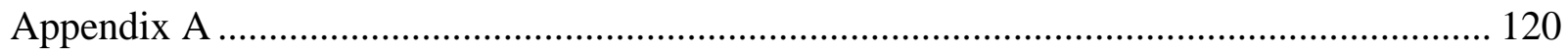


Appendix B

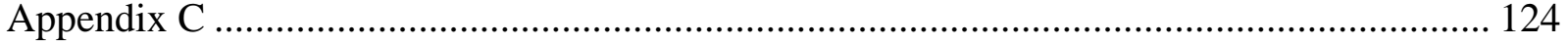

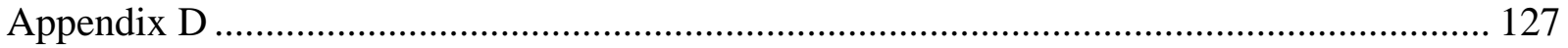

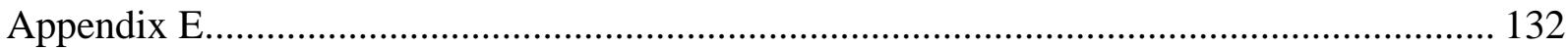




\section{List of Figures}

Figure 1.1. Manufacturing defined in two ways: (a) technical process, and (b) economic

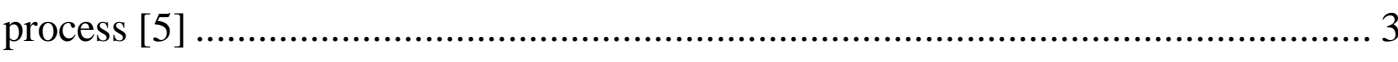

Figure 1.2. The concurrent engineering process [9] ................................................ 7

Figure 1.3. Reducing the cost of the production bracket by changing the design and keeping

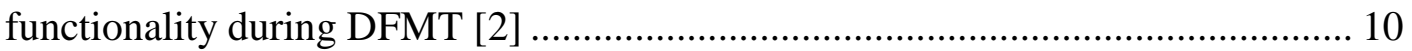

Figure 1.4. Typical sequence of processes required in part fabrication [5] ........................... 17

Figure 3.1. The interface structure of the PPAC software interface ...................................... 48

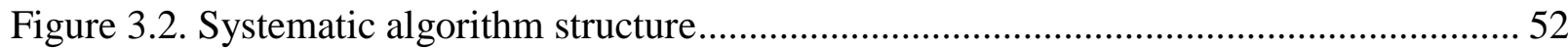

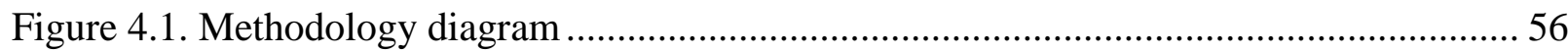

Figure 4.2. (a) Dimensions of the workpiece and (b) 3D drawing of the workpiece ................ 57

Figure 4.3. (a) Dimensions of the final part, and (b) 3D drawing of the final part ................. 59

Figure 4.4. The possible outcomes for facing process 1 after applying DFMT1.1 ................ 71

Figure 4.5. The possible outcomes for facing process 1 after applying DFMT1.1 ................. 72

Figure 4.6. 3D drawing of the modified workpiece ........................................................ 82

Figure 4.7. 3 views and isometric drawing of the final modified part by DFMT3.1 .............. 83

Figure 4.8. 3 views and isometric drawing of the final modified part by DFMT3.2 2.............. 85

Figure 4.9. Comparison of effectiveness of nine process plans ...................................... 93

Figure 4.10. Comparison of effectiveness of three design modifications ............................. 96 


\section{List of Tables}

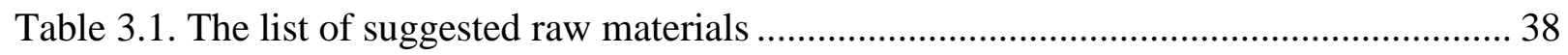

Table 3.2. Example of combinations on turning process ......................................................... 41

Table 3.3. Example of process plan for machining stainless steel part by using HSS tool........ 45

Table 4.1. Machining processes and outputs of the MPSEL for machining stainless steel on PPP .

Table 4.2. Inputs and outputs of PPAC for machining stainless steel 316L by using the HSS tool on PPP 64

Table 4.3. The summarized results of machining stainless steel PPP ........................................ 65

Table 4.4.The possible outcomes for facing process 1 after applying DFMT1.1 …….............. 70

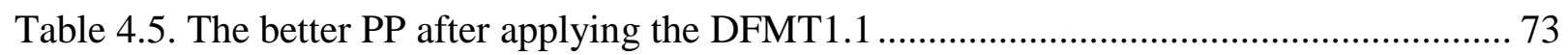

Table 4.6. The summarized results of PP for DFMT1.1 ………………….......................... 75

Table 4.7. The better PP after applying the DFMT1.2 …………………………….............. 76

Table 4.8. The summarized results of PP for DFMT1.2 ………………………………......... 77

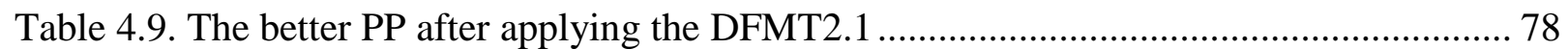

Table 4.10. The better PP after applying the DFMT2.2 ......................................................... 80

Table 4.11. The better PP after applying the DFMT3.1 ………………................................ 84

Table 4.12. The better PP after applying the DFMT3.2 ………………………………......... 86

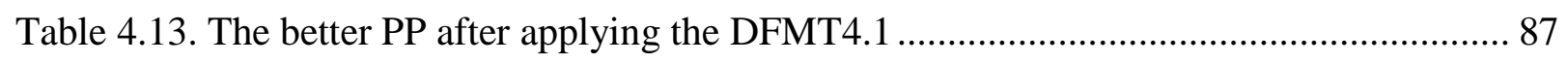

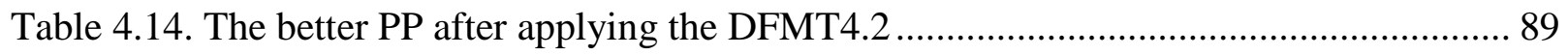

Table 4.15. The summarized results of better nine process plan................................................ 91

Table 4.16. The summarized results of the suggested modifications ......................................... 95

Table 4.17. Changing D and L together in drilling process .................................................... 96

Table 4.18. Fixed $\mathrm{D}$ values and changing $\mathrm{L}$ together in drilling process ................................... 97

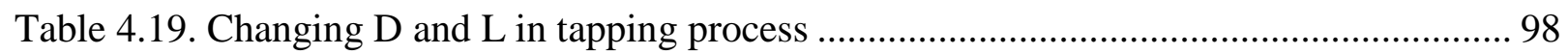

Table 4.20. Fixed D values and changing $L$ together in tapping process................................... 98

Table 4.21. Changing D and L together in drilling process ...................................................... 99

Table 4.22. Changing $\mathrm{D}$ and fixing $\mathrm{L}$ in tapping process.................................................... 100 


\section{Nomenclature}

\begin{tabular}{|l|l|l|}
\hline JIT & $=$ & Just in Time \\
\hline CAD & $=$ & Computer Aided Design \\
\hline CAM & $=$ & Computer Aided Manufacturing \\
\hline CIM & $=$ & Computer Integrated Manufacturing \\
\hline ISO & $=$ & International Quality Standard \\
\hline BTO & $=$ & Build-To-Order \\
\hline GNP & $=$ & Gross National Product \\
\hline CR & $=$ & Customer Requirements \\
\hline DR & $=$ & Design Requirements \\
\hline DFMT & $=$ & Design for Manufacturing Techniques \\
\hline DFM & $=$ & Design for Manufacturing \\
\hline DFMA & $=$ & Design for Manufacturing and Assembly \\
\hline CI & $=$ & Confidence Interval \\
\hline BTU & $=$ & Built up Edge \\
\hline CAPP & $=$ & Computer Aided Process Planning \\
\hline MP & $=$ & Machining Parameter \\
\hline MPSEL & $=$ & Machining Parameter Selection System \\
\hline HSS & $=$ & High Speed Steel \\
\hline nc_mill_mc & $=$ & NC Milling Machine \\
\hline cyl_gr_mc & $=$ & Cylindrical Grinding machine \\
\hline sur_gr_mc & $=$ & Surface Grinding Machine \\
\hline ver_dr_pr & $=$ & Vertical Drill Press \\
\hline hi_sp_steel (M 42) & $=$ & High Speed Steel Grade M42 \\
\hline hi_sp_steel (TiN Coated & $=$ & High Speed Steel Grade Tin Coated \\
\hline Sp_cr_c8_c7_c6 & $=\begin{array}{l}\text { Turning facing, and boring single point tools, as } \\
\text { used in tool grade. Carbide }\end{array}$ \\
\hline PCD & $=$ & Polycrystalline Diamond \\
\hline a & $=$ & Approach of tool to work in inches \\
\hline Cm & $=$ & Total cost of machining one workpiece in \$ \\
\hline Cc & $=$ & Cost of each insert or inserted blade in \$/blade \\
\hline Cp & $=$ & Purchase cost of tool or cutter in \$/cutter \\
\hline Cw & $=$ & $\begin{array}{l}\text { Cost of grinding wheel for re-sharpening tool or } \\
\text { cutter in } \$ / \text { cutter }\end{array}$ \\
\hline d & $=$ & Depth of cut in inches \\
\hline D & $=$ & $\begin{array}{l}\text { Diameter of workpiece in turning, in case of } \\
\text { milling and drilling it is cutter diameter }\end{array}$ \\
\hline
\end{tabular}




\begin{tabular}{|c|c|c|}
\hline $\mathrm{e}$ & $=$ & $\begin{array}{l}\text { Over travel of milling cutter past workpiece in } \\
\text { inches }\end{array}$ \\
\hline Sfpm & $=$ & Surface feet per minute \\
\hline fr & $=$ & Feed per revolution in inches/rev \\
\hline $\mathrm{ft}$ & $=$ & Feed per tooth in inch \\
\hline ipr & $=$ & Inch per revolution \\
\hline in & $=$ & Inch \\
\hline Ipt & $=$ & Inch per teeth \\
\hline G & $=$ & Labor + overhead on tool grinder in $\$ / \mathrm{min}$ \\
\hline K1 & $=$ & $\begin{array}{l}\text { No. of times the tool is re-sharpened before } \\
\text { discarding }\end{array}$ \\
\hline $\mathrm{K} 2$ & $=$ & $\begin{array}{l}\text { No. of times the tool is resharpened before inserts } \\
\text { or blades are re-brazed or indexed }\end{array}$ \\
\hline $\mathrm{K} 3$ & $=$ & $\begin{array}{l}\text { No. of times the blades (inserts) are resharpened or } \\
\text { indexed, before the blades (inserts) are discarded }\end{array}$ \\
\hline $\mathrm{L}$ & $=$ & $\begin{array}{l}\text { Length of workpiece or length of all holes of the } \\
\text { same diameter in drilling }\end{array}$ \\
\hline $\mathrm{m}$ & $=$ & No. of threads per inch \\
\hline $\mathrm{M}$ & $=$ & Labor + Overhead cost on the machines in $\$ /$ min \\
\hline NL & $=$ & No. of workpieces in a lot \\
\hline $\mathrm{r}$ & $=$ & Rapid traverse rate in inch $/ \mathrm{min}$ \\
\hline $\mathrm{tL}$ & $=$ & Time to load and unload workpiece in min \\
\hline $\mathrm{tm}$ & $=$ & Floor to floor time to machine the part \\
\hline to & $=$ & Time to set up machine tool for operation in min \\
\hline ts & $=$ & Time to re-sharpen the tool in minutes \\
\hline $\mathrm{T}$ & $=$ & Tool life measured in min to dull a tool \\
\hline Tc & $=$ & Tool life measured in cubic inches to dull a tool \\
\hline $\mathrm{Tt}$ & $=$ & Tool life measured in inch travel of work \\
\hline $\mathrm{V}$ & $=$ & Cutting speed in feet/min \\
\hline $\mathrm{Z}$ & $=$ & No. of teeth in milling cutter \\
\hline $\mathrm{w}$ & $=$ & Width of cut in inches \\
\hline W & $=$ & $\begin{array}{l}\text { Grinding wheel cost to sharpen tool or cutter in } \\
\$ / \text { cutter. }\end{array}$ \\
\hline$\rho$ & $=$ & Density \\
\hline $\mathrm{E}$ & $=$ & Young Modulus \\
\hline of & $=$ & Strength / Elastic limit \\
\hline Kic & $=$ & Fracture Toughness \\
\hline$\eta$ & $=$ & loss coefficient at $30 \mathrm{C}^{0}$ \\
\hline
\end{tabular}




\begin{tabular}{|c|c|c|}
\hline $\mathrm{CR} \rho$ & $=$ & Relative cost per unit volume \\
\hline $\mathrm{a}$ & $=$ & Thermal Diffusivity \\
\hline $\bar{\lambda}$ & $=$ & Thermal Conductivity \\
\hline$\alpha$ & $=$ & Linear Expansion Coefficient \\
\hline$\sigma \mathrm{t} / \mathrm{E}$ & $=$ & Normalized Strength \\
\hline $\mathrm{T}$ & $=$ & Temperature \\
\hline$\sigma f(\mathrm{~T})$ & $=$ & Strength at Temperature \\
\hline $\mathrm{H}$ & $=$ & Hardness \\
\hline $\mathrm{Ka}$ & $=$ & Wear Rate Constant \\
\hline$q \rho$ & $=$ & Energy Content \\
\hline $\mathrm{T}$ & $=$ & Maximum Service Temperature \\
\hline$\sigma \mathrm{y}$ or $\sigma \mathrm{el}$ & $=$ & Strength \\
\hline Нр.р & $=$ & Production (Embodied) energy per cubic meter \\
\hline рe & $=$ & Electrical resistivity \\
\hline$\sigma \mathrm{ts}$ & $=$ & tensile strength \\
\hline$\sum \mathrm{e}$ & $=$ & Endurance Limit \\
\hline $\mathrm{PP}$ & $=$ & Process Plan \\
\hline PPP & $=$ & Preliminary Process Plan \\
\hline APP & $=$ & Alternative Process Plan \\
\hline Mfg & $=$ & Manufacturing \\
\hline $\mathrm{Wp}$ & $=$ & Workpiece \\
\hline MSP & $=$ & Manufacturing System Parameters \\
\hline DB & $=$ & Data Base \\
\hline $\mathrm{PP}$ & $=$ & Process Plan \\
\hline DFMO & $=$ & Design for Manufacturing Outputs \\
\hline DP & $=$ & Design Parameters \\
\hline $\mathrm{NC}$ & $=$ & Numerical Control \\
\hline $\mathrm{CNC}$ & $=$ & Computer Numerical Control \\
\hline PPAC & $=$ & Process Plan Attributes Calculator \\
\hline VBA & $=$ & Visual Basic for Applications \\
\hline TPI & $=$ & Tooth per Inch \\
\hline
\end{tabular}




\section{CHAPTER ONE: INTRODUCTION}

\subsection{Introduction}

Manufacturing is considered as a process that is used to transform materials into something useful and necessary. According to its common definition, manufacturing represents product development whereby the raw materials can be converted into a wide range of merchandise and goods. The concept of manufacturing does not include the construction of building, street paving, or bridges. Generally, manufacturing refers to the use of human capital, machines, and tools to produce merchandise for use or profit [1], [2]. Manufacturing started before the $19^{\text {th }}$ century with human activities limited to artisans and handmade products and has developed to the higher level of manufacturing we know today [1]. Prior to the $19^{\text {th }}$ century, the first concept of manufacturing was Cost Focus (focusing on low cost of production). Charles Babbage, the inventor of the first computer in 1832, focused on labor specialization [3]. Eli Whitney (1800) created the early popularization of interchangeable parts, which was achieved by using standardization and quality control; he was one of the first inventors to create the cotton gin, thus, beginning the industrial revolution [4]. In the 1910s, Henry Gantt illustrated the project motion and time study for the start and finish dates of terminal elements and summary elements. In the early 1900s, Henry Ford established the Ford Motor Company and developed the assembly line technique of mass production. The focus then changed to quality; Taiichi Ohno introduced the popular lean manufacturing and Just In Time manufacturing (JIT) [1], [2]. In the mid-1900s, Jervis B. Webb Co. created the first electronically coordinated conveyor system. Progressive manufacturing technology and knowledge today includes methods such as Computer Integrated Manufacturing (CIM), Computer Aided Design (CAD), and Computer Aided Manufacturing (CAM), company management philosophy for planning, integration, and implementation of automation, and the Manufacturing Enterprise Wheel [1]. From 1995-2005, the manufacturing process became more customization focused. Inventions and theories helped to improve the manufacturing processes, including the Internet, International Quality Standard (ISO), Finite Scheduling, Supply Chain Management, Mass Customization, and Build-To-Order (BTO). Now (2005-2020), the focus had shifted to Globalization Manufacturing, such as Global Supply Chain and Growth of Transnational Organizations [2], [4]. There are a lot of manufacturing facilities today that use methods such as 
Rapid Prototyping, Work-cell, and Work Envelope to reduce the time of manufacturing and assembly. The manufacturing industry is important to the individual economies of the countries because It influences and can strongly affect the standard of living due to the goods and services available to the populace. The contribution of manufacturing companies is about $20 \%$ of the Gross National Product (GNP). They employ about $18 \%$ of the workforce and account for about $40 \%$ of the exports in the United States [1].

\subsection{Technical and economical definition of manufacturing}

The manufacturing processes can be divided into two major categories, technical and economical processes.

The technical category of manufacturing refers to the physical and chemical processes used to change the geometric properties to result in the final product. Technical manufacturing also includes the assembly of multiple parts to make the final products. Manufacturing is a sequence of operations. The manufacturing processes include a combination of machinery, tools, power, and labor. This idea is illustrated in Figure 1.1 (a). Each process brings the material closer to the desired, final product [5].

Referring to the economic side of manufacturing, it is defined as the transformation of raw materials into final products having more value due to one or more processing and/or assembly operations, as shown in Figure 1.1 (b). Manufacturing process is applied to change the material shape or properties, and/or by assembling it with other materials to create the final product. Thus, a material will be more valuable after manufacturing operations are performed. For instance, when iron ore is converted to steel, the steel becomes more valuable than the original iron ore. One can also consider the example of sand transforming into glass, when wheat is milled into flour, or refining petroleum into plastic. In all examples, the final product is more valuable than the original raw materials. Consider the next step for the plastic, when it is molded into another geometric shape of a plastic product, more value is added and made to be more valuable [5], [6]. Figure 1.1 explains the definition of manufacturing for each of the two categories: technical and economic. 

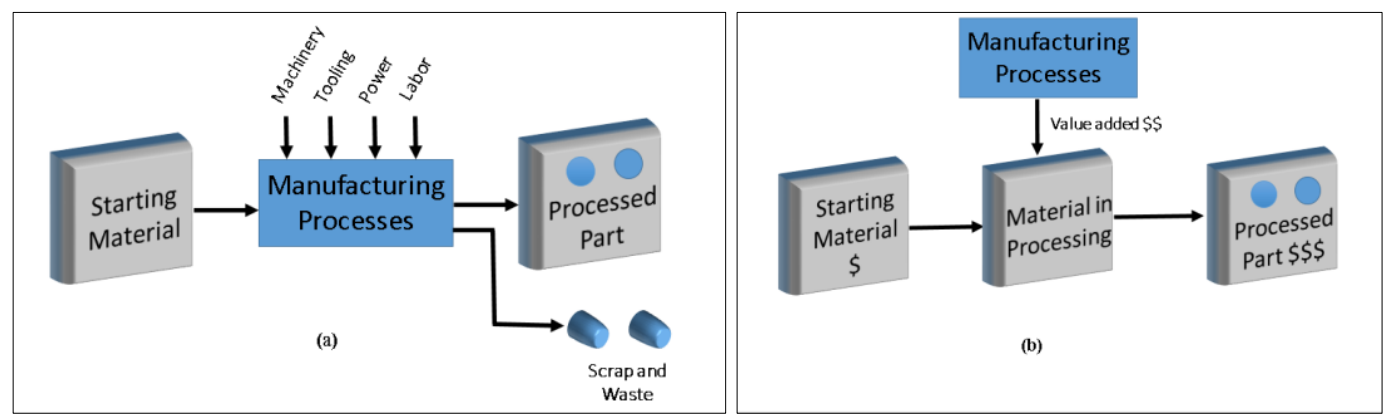

Figure 1.1. Manufacturing defined in two ways: (a) technical process, and (b) economic process [5]

\subsection{Discrete and continuous Manufacturing}

When designing a manufacturing process, one has to choose, one of the two major manufacturing design categories, discrete or continuous. Discrete manufacturing, which is used to produce a specific type of item or product (for example, automobiles, furniture, computers, printer), relates to the assembly of products where the final product is easily identifiable and counted. Discrete manufacturing can be used to produce high volume or low volume with low or high complexity. This type of manufacturing has specific strategies such as the following [1]:

1. Make-to-stock, either highly repetitive or based on work orders

2. Any of the to-orders, including:

- Make-to-order

- Assemble-to-order

- Engineer-to-order

3. Job shop production

Continuous manufacturing is known as manufacturing process. This type of process produces uncountable and continual, but quantitative materials (for example, gas, salt production, oil refining, and milk). Chocolate milk comes in a continuous stream that can control pressure, flow, and temperature, this is considered continuous manufacturing. The chocolate milk will then be placed in boxes onto a pallet making this portion of the process discrete manufacturing.

Most manufactured products have components that required some type of machining usually containing several layers of processes. The list of the major manufacturing processes include [5]:

1. Casting 
2. Molding

3. Forming

4. Machining

5. Joining

6. Additive Manufacturing

7. Injection Molding

8. Vacuum Forming

9. Thermal Forming

10. Composites Manufacturing

This research focuses specifically on machining processes, as machining characteristics have been set as scoped boundaries for this study. This is because the machining domain is dependent on a variety of inter-related processes, which directly impact the cost effectiveness and efficiency of products. The conclusions and theories drawn from analyzing the DFMT can be generalized to all manufacturing processes as suggested future works. Meanwhile, the other listed manufacturing processes represent potential areas for future study.

\subsection{Machining}

Machining can be described as converting raw material into a desired final shape and size obtained by cutting the raw material and controlled metal removal process to remove unwanted material, usually in the form of chips. This could be done by using various machining processes. Machining is usually done after a forming process, such as extrusion, forging deep drawing, or casting. However, the machining processes are one of the most important processes in manufacturing; the value of the final product will be created in these steps and are one of the most expensive steps in manufacturing. A machining process has very low setup cost as compared to forming, molding, and casting processes [6]. Metal is the major raw material used in machining. The metal cutting or removal (machining) processes can be difficult at times because of their properties, such as hardness and toughness. The application of these processes in the industrial world, however, is widespread. Machining is more expensive for high volumes and necessary where tight tolerance dimensions and finishes are required [6]. 


\subsection{Machining Process}

Machining processes can be classified under two categories. They are adopted based on the requirements and the availability of the facilities. They are broadly classified into [5], [7]:

1) Traditional Machining processes

2) Nontraditional Machining processes, such as Chemical and Ultrasonic Machining

This dissertation focuses on the use of traditional machining processes according to the scoped boundaries of this research.

\subsubsection{Traditional Machining Processes}

These types of machining processes are commonly used because they produce most of the necessary machined parts for machining processes. Machining processes, such as turning, drilling and milling, are mostly used in machining operations and are considered "traditional machining." The machining processes that are included in this category are listed below [6], [7].

1. Turning process

2. Drilling process

3. Boring process

4. Milling process

5. Shaping process

6. Broaching process

7. Planning process

8. Grinding process

9. Threading process

10. Tapping process

\subsection{Concurrent Engineering}

Competitiveness has increased day by day due to globalization focus, shortening product life cycles, fast changes in technology, a variety of customer demands, as well as many other reasons during the past decade. Companies struggle to reduce elapsed time involved in producing new products. This involvement includes product development, bring the product to market using customer requirements, design engineering, and manufacturing engineering. Concurrent 
engineering is the best approach that can integrate aspects of product development as well as keep up with high competition in the market. As an industrial engineer, the preferred method is concurrent engineering attached with CAD and CAM applications. In the industrial environment, the main goal is to submit a competitive product to the market while retaining product quality and reliability. This can be done by connecting everyone from the raw material supplier to the product user forming a chain; all of the parts should work as a team [8], [9].

Concurrent Engineering is the better response to satisfying a customer's demands and variability. The expectation is to produce a better product with lower cost in a shorter amount of time [10]. One of the most important parts of concurrent engineering is applying the DFM concept to reduce the development time of a product. DFM is considered as a part of concurrent engineering. In DFM, the simultaneous design is associated with the machining process, tool, and raw material selection; this is the main concept of concurrent engineering. All the requirements of DFM are focused on designing a product with high quality and low cost that will achieve customer satisfaction. DFM, as a part of concurrent engineering, should be applied in early stages of part design and not in the final review of the design. Applying DFM later in the process would make the product more expensive and the product development cycle longer. Hence, there are other benefits of using DFM inside the concept of concurrent engineering including, designing for quality, for life cycle, and for cost [5]. Quality is very important in international competition and it is greatly related to the success of companies who produce their products with high quality. Figure 1.2 shows the three viewpoints that should be applied to make product decisions, the three functional activities should occur simultaneously according to the new style of the concurrent process compared to occurring sequentially in the old style [10]. 


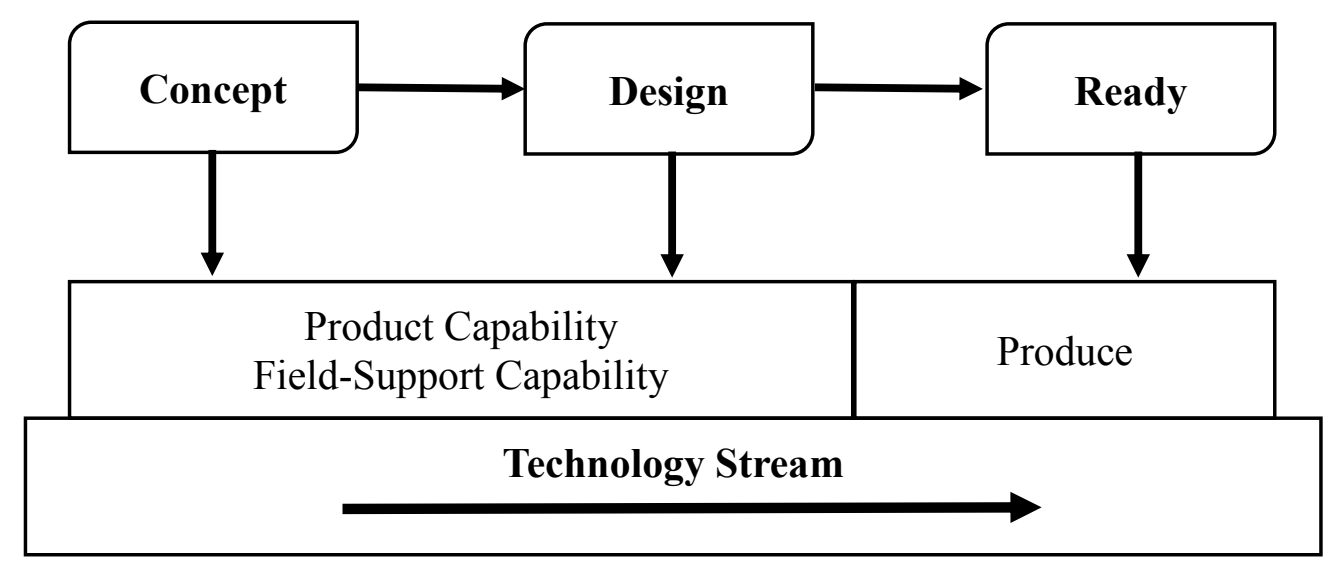

Figure 1.2. The concurrent engineering process [9]

\subsection{Design in Manufacturing}

The main role of engineering design is to transform Customer Requirements (CR) into Design Requirements (DR). Design concepts usually lead directly to the best and most efficient manufacturing results. A design engineer plays a major role in manufacturing planning [11]. This role can be sophisticated, as each product is different in complexity, functionality, and design which needs to be updated periodically. The selection process can be done through finite element analysis or modeling routines to precisely identify material property requirements and the selection of materials can be done by the designers themselves [10]. If a designer fabricates a part that is nearly identical to an existing part and is expected to be used in similar ways, the designer can use the same material for the new part. In the alternative case, the designer can design and select material for a new part without using the information of previous part [10]. It is clear this will require a fair amount of knowledge and work from the designer regarding the load required, stress analysis and environmental condition in addition to other factors such as customer expectations and manufacturing-related factors. Varying production methods and mechanical treatments will cause varying effects on the cost and performance properties of the final product. Often, it becomes critical to understand and accept the manufacturing processes, because there will be a large difference between the cost of using one process instead of another. During the time when the designer developed the design on paper or through a CAD system, the manufacturing processes and their sequences would be specified to produce the product [12]. 


\subsubsection{Criteria and Concepts in Design}

The main criteria that influence the design of manufactured part are governed by the following points [10].

1. To ensure the quality and reduce the cost of production, the design must be efficient. A robust process must be included that will be conducive for statistical control and produce a part within specification limits and avoid variation.

2. Retaining the same or less cycle life cost, this cost includes raw material, production, use, maintenance, disposal or recycling costs.

3. Alternative design or materials will not always lead to a big difference between the previous cost and new cost of the part. However, the failure mode in the product can be avoided or reduced.

4. A product must meet customer requirements regarding the appearance and function of the product to get approval. The customer needs are changing each day and it is very important to satisfy them.

5. The reliability of the part should be considered in the design; a more reliable product reduces the cost of repair, especially with expensive products.

6. Tolerance and surface finish of the product should also be considered; it is very important to retain the functionality of the product if it is considered to have high impact on the cost of manufacturing.

\subsubsection{Design for Manufacturing (DFM)}

Currently, there are rapid advancements in the design of products because of their wide applications and global competition. Design for Manufacturing (DFM) is one of the important methods used to keep up with the global competition in manufacturing. It was used for the first time in the 1970s and has been developing ever since [13]. Designing the product for manufacturing by using the Design for Manufacturing (DFM) can reduce manufacturing time and development cost of parts. Using DFM will allow a quick and smooth transition into production with minimum cost and time of manufacturing while retaining quality, reliability, and the customer's needs. DFM was designed with tolerance close enough to enable interchangeability; it was not only due to high manufacturing efficiency but also to simple and easy repair. DFM is 
applied best by an individual designer who has experience with manufacturing and depends on the designer's intuition. The use of DFM should be inherent with concurrent engineering studies to provide steps to the designer that will assist in the simplification of the product structure; this will reduce manufacturing and assembly cost, leaving the same quality and reliability. For all the above uses, DFM has been considered a component of Lean Manufacturing and as a factor for Global Competition [14].

\subsubsection{Benefits of DFM}

Some benefits of DFM are clear and obvious, such as reducing cost, increasing quality, sustaining reliability, and reducing time. That will lead to lower production costs and lower assembly costs resulting from fewer parts having to be produced after applying DFM and minimum manual labor. Fewer parts in a new design provides high quality parts with less complexity, which leads to less time in manufacturing. At the same time, this means higher quality will be provided in the product from fewer parts, less inspection, and maintenance with better utilization of stable factory process. Using DFM factors will push the product quicker to the market, such as, designing standard parts using a modular design (a design in which the parts are easy to interchange or replaced) [15]. A modular design will reduce both the cost of manufacturing and assembly, and less equipment will be required. The use of standard parts will reduce the setup time to change nonstandard parts; using the same machine will increase the utilization of machinery. Moreover, designing for automatic assembly will reduce the time for assembly and labor cost for manual assembly while increasing the production rate. If the design is satisfactory and possesses all of the requirements, there is no need for redesigning again for manufacturability. Using a robust design (a design whereby a product is insensitive to variation) as a DFM factor, when applying redesign on the product, that should not affect the product functionality, quality or reliability. DFM leads to fewer parts needing to be purchased from fewer vendors, this itself will save the purchasers expense when using standard parts. Fewer parts and robust design with DFM will allow for fewer production problems, making a factory available to produce other products and can increase the production rate. Modern markets are highly competitive and using DFM will allow getting a more competitive product with the same quality and reliability and less cost of production [14], [15].

Briefly, the benefits of DFM can be found in the following points [2]: 
1. Reduce the cost and the time of manufacturing

2. Increase production rate

3. Increase or retain reliability

4. Eliminate or reduce the complexity of the product

5. Improve resistance to environmental impacts

6. Design and produce standard components which are easy to assemble and manufacture

7. Enhance functional aspects of the product

8. Approach to robust design and improve the maintainability of the product

An example of applying DFM on the bracket is shown in Figure 1.3. When the design of the bracket is changed from part a, to part b, to part c, while retaining the quality and functionality of the bracket, the overall cost of the production of the bracket decreased from $\$ 3.50$ to $\$ 2.00$ to $\$ 0.80$. The redesign for the bracket is design 2 and 3. By eliminating the fastener screw and using spots welding, this design can be reduced more by using snap fit instead [2].

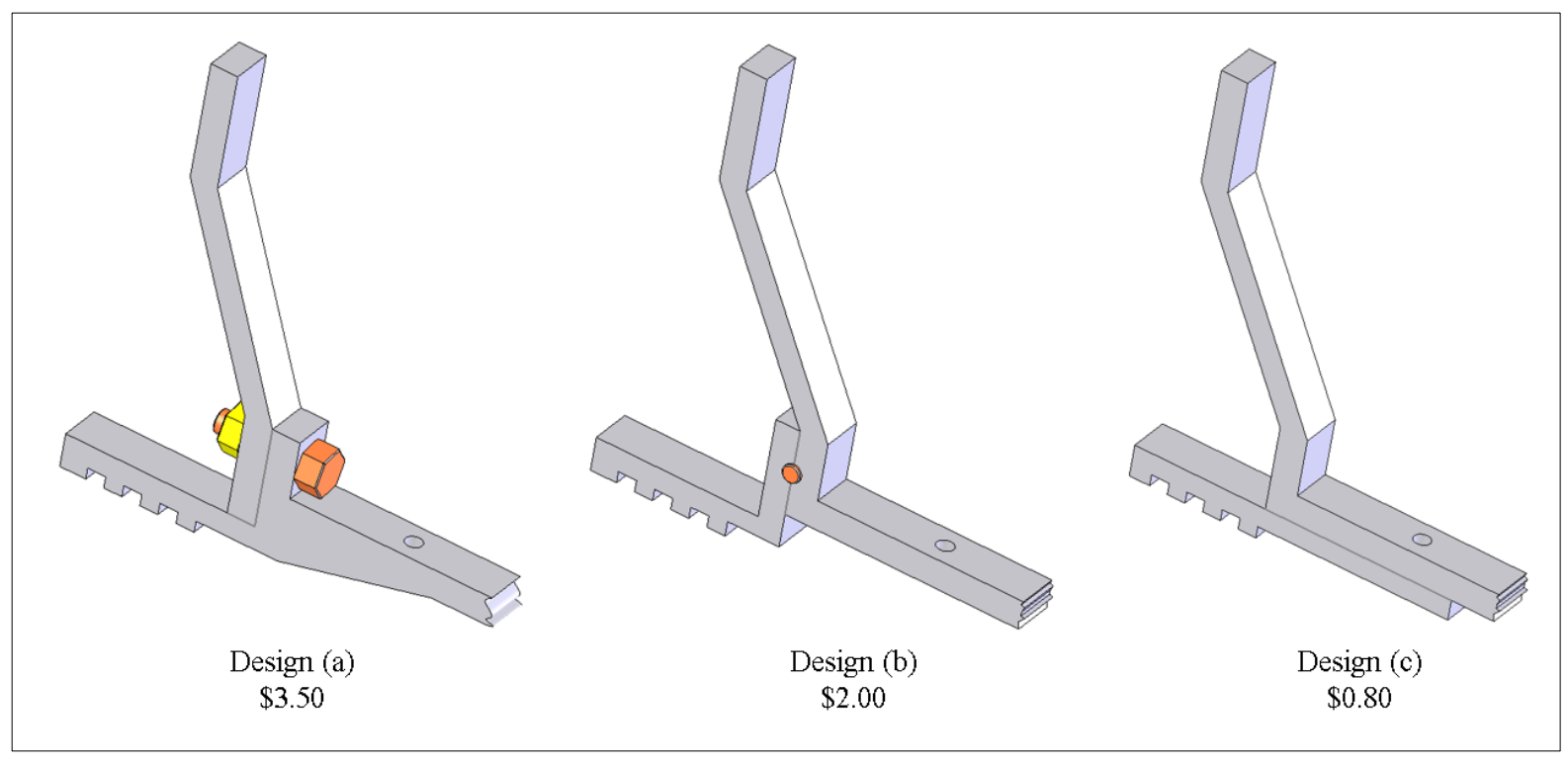

Figure 1.3. Reducing the cost of the production bracket by changing the design and keeping functionality during DFMT [2] 


\subsubsection{Design Guidelines during DFM}

The following DFM factors can be important for providing benefits in this domain [15]:

A) Standardization

1. Design using standard components as much as possible.

2. Modify the pre-shape of the component if possible and appropriate by forming, casting, joining etc. (e.g. casting, forging, and welding).

3. Use standard pre-shape also if possible for workpieces.

4. Apply standard machined features if possible.

B) Raw Material

1. Modify the raw material, if possible, to reduce the components' cost of raw material and machining while keeping the quality, function, and reliability of components.

2. Order the raw materials in the form that can utilize standard forms.

C) Component design for machining [15]

C-1) Generally

1. Try to design components that can be machined by using one machine tool.

2. Try to design components so that it is easy in the machining from its exposed surface when it is gripped in the work holding.

3. Do not put any machined features in your design that the company is not equipped to handle.

4. Avoid interface between tool, tool holder, workpiece, and fixture.

5. Design components that have enough rigidity to withstand the machining force when they are gripped into the workpiece holder.

6. Keep holes and bores cylindrical, straight and with standard L/D for drilling or boring, normal to part axes.

7. Be sure that the end of the blind holes are conical and consider tapping the blind hole.

8. Avoid bent holes or turn holes. 
C-2) Rotational components [16]

1. Confirm that cylinders surfaces are concentric, and the plane surface is normal to the component axis.

2. Ensure that external diameters increase from outer face.

3. The internal diameter should decrease from outer face (exposed face of the workpiece).

4. Internal corners of the components radii equal to the radius of the tool corner.

5. Do not use internal features for long components.

6. Do not design components for a very large or very small L/D ratio.

C-3) Non-rotational components

1. Provide a base for work holding (fixture) and reference.

2. Make the exposed faces of the components have a plane parallel or perpendicular to the base.

3. Ensure that the internal corner normal to the base has a radius equal to the standard tool radius use radii equal or larger to the tool.

4. Avoid cylindrical bores in long components.

5. Get the components with the required surface finish and cross section for long component and an internal surface.

6. Do not design extremely long components.

7. Avoid blind bores in large cubic components.

D) Assembly

1. Make sure that assembly is possible.

2. Make sure that internal corners do not interface with the corresponding external corner during assembly of mating components.

3. Make sure that the mating components have the same surface finish.

E) Accuracy and surface finish

1. Specify widest tolerances possible for the components. 
2. Specify roughest surfaces possible for the components; point 1 and 2 will give the required performance for operating surfaces.

3. Avoid internal corners on the low surface finish [16].

\subsection{Machinability}

Machinability refers to how easy or difficult the materials are to be machined. The main factor affecting the machining operation are the properties of work materials. The properties of these materials directly impact the machinability. According to the machinability, the decision can be made to decide which raw material, tool, and the machine will be used in the process. Therefore, there are several factors used to evaluate the machinability such as [5], [6]:

1. Tool life

2. Forces and power

3. Surface finish

4. Ease of chip disposal.

5. Machining type

6. Cutting condition (feed rate, cutting speed, depth of cut)

7. Mechanical properties (hardness, strength, shear stress, shear strength, tensile strength, etc....)

As work material strength, shear strength, tensile strength, and temperature increase, the machinability decreases, making it more difficult to machine raw materials. For ferrous metals, the percentage of carbon will affect machinability, as carbon content increases the strength and hardness of the steel increases and will reduce the machining performance and machinability, and this problem will be solved by adding alloying elements. This additive will reduce the coefficient of friction between the tool and chip. Therefore, forces, temperature, and built up edge formation will be reduced and better tool life and surface finish result from these effects.

\subsection{Tolerance and Surface Finish}

Product designers define and specify the surface finish and tolerance for the product aiming to retain the functionality and geometries of the product. Tolerance design is very important to set the tolerance on the dimensions of the part. However, tolerance should be specified and set 
whereby the functionality and performance of the product is inside the control limits of the rejection. The cost and the suitability of manufacturing should be considered when specifying the tolerance of the product. Surface finish of the part has the main characteristic of quality and many factories contribute to it in manufacturing. For instance, in the metal forming process or molding, the surface finish of the manufactured part can be obtained by the surface finish of the die. However, the interaction between the microstructure of the raw material and the geometry of the cutting edge will be responsible for the final surface finish in machining processes [17].

\subsubsection{Tolerance in Machining}

It is difficult to obtain the exact desired dimensions of a product using the manufacturing process. There is a certain variability in any manufacturing process. For this reason, the designer should specify a tolerance on a product that will keep the functionality of the product and set a permissible limit on this variability [18]. When the product falls outside these tolerances of this specific limit, the product will be rejected. After specifying this tolerance, the machining processes can be selected; each machining process has a specific tolerance which can be obtained from part drawing. If the machine tool has been used for a long time, then the tolerance is expected to have been exposed to wear-and-tear that will lead to a greater variability than allowed or anticipated. Thus, a machine with advanced capability should be used whenever possible. The question that needs to be answered is "Why does tolerance build up matter?" Tolerance build up matters because designers often specify tighter tolerances than necessary, while a larger tolerance would sustain the required functionality of the product. For example, a designer may specify a tolerance on a dimension of a product as \pm 0.001 when \pm 0.01 may have been sufficient with respect to the functionality of the product. Then, the designer has to specify tolerance based on the functionality of the product that will reduce the cost of machining [18].

Whenever process specifications are important, then the long-range performance becomes the main concern for the manager of the process. There are bounds that should be created by using stochastic analysis. To establish the required bounds, there is a method that determines a Confidence Interval (CI) based on the proportion of the measurements obtained from a random sample from a population. This required bound can be determined from a normal distribution with 
a known mean $(\mu)$ and variance $\left(\sigma^{2}\right)$. For instance, by using the Z-table, the interval that covers the middle $95 \%$ of the population of observations is $\mu \pm 1.96 \sigma$ and represents the tolerance interval. It covers $95 \%$ of measured observations [19].

\subsubsection{Surface Finish in Machining}

Once the designer determines the final surface finish according to the product function, it is then achieved through the manufacturing process (machining). The desired surface finish can be obtained by using modern and well maintained machine tools.

The factors that the roughness of surface finish depends on are [5], [7]:

A. Geometric factors

1. Type of machining operation (e.g. milling versus turning)

2. Cutting tool geometry

3. Feed rate

B. Work material factors, this factor will interact with a tool to effect on machining process. The main defects of work material factors in the surface finish are:

1. Built up edge (BUE) effect: it is periodically created and breaks away, during that particles are transferred to the new work surface, and the result produces a rough surface.

2. Chip causes damage to the surface results returning the workpiece to the work.

3. In machining, ductile material tearing is created on the work surface during chip formation.

4. When the chip formation is not continuously produced that will create cracks in the surface caused, especially when machining brittle materials.

5. According to the type of material, the amount of friction will be generated between the tool flank and the newly generated work surface.

6. Cutting speed and rake angle influence on surface finish whereby increasing cutting speed and rake angle will improve surface finish [5], [7].

C. Vibration and machine tool factors.

The vibration in a machine tool is a large factor that will affect the generated surface finish; this generated vibration, or chatter, is related to machine tools, cutting tools, and setup of 
the operation. Generated vibration will lead to deflection in the fixtures and backlash in the feed mechanism, especially on an old machine.

\subsection{Process Planning}

The goals of the process planner's work are to determine the sequence and the appropriate manufacturing process to produce a specific part by using process planning. In a factory, process planning can be defined as the transformation of product characteristics from the design level to the operating instructions. There is a high probability there are many ways to achieve a product with its required characteristics; hence, process planning will select the best set of process sequences, machines, and tools, while maintaining minimum cost and high quality. The product characteristics should be considered when selecting machines, machine tools, machining parameters, and a cooling fluid [10]. A process plan could not be the same for all industries; they are specific to a particular manufactured part. Process plan can be developed either by an experienced person or more commonly with the help of software. When the process plan is developed with the help of a computer, it is termed as Computer Aided Process Planning (CAPP). There have been tremendous improvements in process planning due to advancement in technology, increased product requirement, cost reduction, customer satisfaction, increase in technical knowledge among customers, and improvement in machines and machining process.

The objectives of the process plan may differ due to following reasons [5]:

1. Manufacturing of a new product

2. Reduce the time of manufacturing

3. Increase productivity

4. More efficient use of existing facility

5. Cost reduction

Many decisions and details should be applied in process planning.

1. Processes and sequence. Process steps should all briefly specify the process plan, for example, part assembly steps should be listed in the order that they can be performed.

2. Equipment selection. Process plan should be developed by a manufacturing engineer that utilizes existing equipment otherwise purchased when it is not possible. 
3. Tools, dies, molds, fixtures, and gages. A duty of a process planner is to decide about which tool, die, mold, and fixture could be used in each process.

4. Cutting tools and cutting parameters for machining operations. Another duty of a process planner, industrial engineer, shop foreman, or machine operator, is to select cutting tools and cutting conditions by the following standard handbook recommendations.

5. Methods. Methods planning are traditionally done by industrial engineers, it includes hand and body motions, workplace layout, small tools, and hoists.

6. Work standards. Time for each operation is established by using work measurement factors.

The sequence of process planning to produce the required part is:

1. Basic process

2. One or more secondary processes

3. Operations to enhance physical properties

4. Finishing operations

Figure 1.4 shows the basic and secondary process used to produce required parts [5].

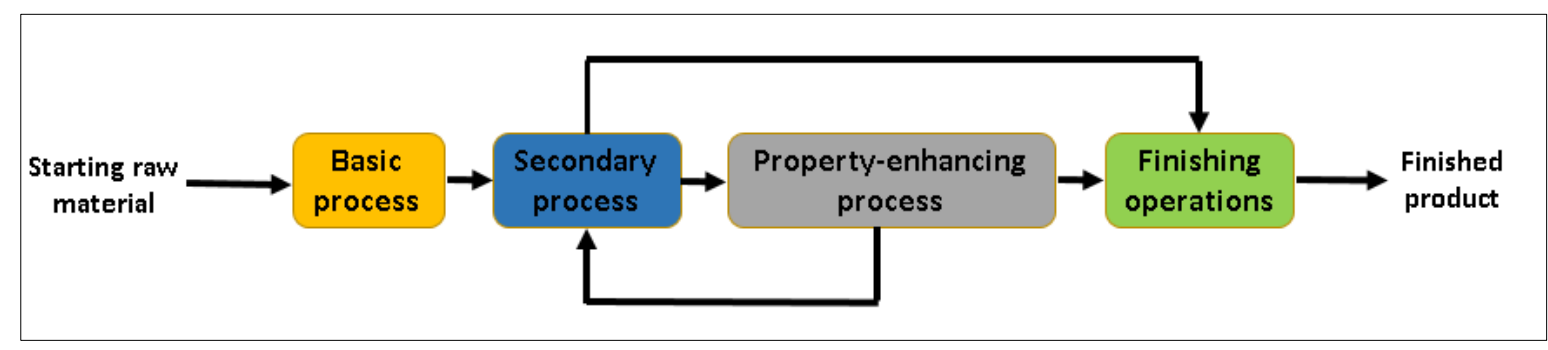

Figure 1.4. Typical sequence of processes required in part fabrication [5]

\subsection{Need for Research}

Over the last century, designers have not focused on redesigning the impact on manufacturing products, especially with regard to quality, cost, and production. Today, competition is extremely high in the manufacturing field to produce parts with high quality and low cost. The Design for Manufacturing Techniques (DFMT) are one of the important tools in the manufacturing industry [20]. The final cost and quality of the final product are completely related to the DFMT. There is a need for research to determine which DFMT impacts the manufacturing cost and production rate. 
When the machining planning is done separately from the design, the product quality and cost will be affected, which is what consumers and manufacturers try to avoid. This research will link the design within manufacturing, specifically the machining processes, to lower costs while retaining quality. The cost aspects related to each of the principles will be evaluated, and preliminary models will be developed to address inherent research issues, including the refining of the design and manufacturability model in terms of operational parameters, financial constraints, and operational effectiveness. A process plan, which is developed for specific machining processes, is responsible for primarily determining the final cost of any machined part, converting raw materials into the final products. Moreover, process planning should be mentioned, due to the fact that it has been applied in this research when reducing the cost of machining, especially dealing with the sequence of the process and its effects on the total machining cost. This research is trying to complement the DFMT, machine element systems and machining parameters that can be selected for the process sequencing, machine and tool selection, and other machining conditions for products to achieve lower costs and higher quality while maintaining functionality.

For example, large manufacturing companies (like General Motors), mass-produce various parts thousands of times per day. If such a company were then to apply the suggested systematic algorithm (with the modifications on the DFMT) to part production, the cost of manufacturing and increasing throughput could improve substantially: perhaps, reducing the cost of manufacturing by $3 \%$ or $5 \%$, increasing the production rate by 0.5 part/hour, and reducing the rejection rate by $2 \%$ on specific parts. The numbers provided in this context may change between specific partsand are hypothetical - but are provided here to show the kinds of improvement manufacturers might expect. While the numbers may be relative, the present research demonstrates that this process will consistently reduce cost and increase throughput, regardless of part.

It is imperative to study and analyze the effectiveness of DFMT, machine element systems, and machining parameters on the throughput and cost of manufacturing; that is the main need for this research. In order to maximize the benefits of this research to machining industries, it is important to redesign the parts using both DFMT and process planning concept. This ensures reduction of manual iterations, which in turn, reduces required processing time and human intervention. To the 
best of the author's knowledge, this type of analysis has not been performed elsewhere, on DFMT (or the associated machine elements systems and machining parameters), in order to study methods for cost reduction and increased productivity.

\subsection{Research Objectives}

1. Analyze and investigate the DFMT, machine element systems, and machining parameters with respect to a specific product and associated product design parameters.

2. Determine the effectiveness of each DFMT, machine element systems, and machining parameters with respect to cost and productivity attributes.

3. Examine the sensitivity of each DFM factor and associated machining parameters with the respect to cost and productivity.

4. Develop a systematic algorithm to organize and perform the work.

\subsection{Conclusions}

Tremendous conceptual shifts in manufacturing began taking place in the early-nineteenth century, in an ever-evolving process that continues today. Over this period of time, the methods for manufacturing parts have shifted from simple handicraft manufacturing processes to advanced automated manufacturing processes. DFMT are central to this progression, because they are imperative for minimizing machining costs and they increase the quality of production in a manufacturing facility. By extension, incorporating process planning, paired with DFMT, presents substantial potential impact to cost reduction and increased productivity. Examination of DFMT with the associated machine elements systems and machining parameters enables alternative process plan development, which leads to improved parts. This improvement may be verified through evaluation of process selections and sequences, as well as machine and tool selections. Several DFMT with the associated machine elements systems and machining parameters have been analyzed to study their impacts on cost reduction and production rate (further discussed in Chapter four). While keeping the functionality and reliability of the product, it is worth paying attention to the DFMT when the goal is to find significant machining cost and productivity impacts (also discussed in Chapter four). 


\section{CHAPTER TWO: LITERATURE REVIEW}

The main objective of analyzing and improving the manufacturing processes is to increase the productivity and reducing the cost of manufacturing. Currently, DFMT plays an important role in improving productivity as compared the simpler systems without DFMT used in the early $19^{\text {th }}$ century. This literature review is based on achievements enhancing manufacturing productivity and metal cutting, including the impacts of the DFM factors to reduce the product cost. The following discussion will demonstrate how the DFM factors are used in process planning within the manufacturing industry.

\subsection{Manufacturing Productivity}

Broadberry [21] showed the influence of labor productivity within manufacturing. The study compared the trend of labor productivity in manufacturing and the labor productivity in overall economic levels since 1820, and it was explained that the difference in productivity levels is related to the selection between mass production and flexible production technologies. The author also discussed how these two choices influenced human capital. This was done by relating the different needs of the two systems, management and research. The author suggested that the structure and structural change of the growth process of manufacturing is important. The labor productivity difference from changes in technological systems in manufacturing since 1820 and the evolution of human capital over time is a more beneficial way to look for standard data to follow manufacturing productivity over the years.

Gunasekaran, A., Cecille, P. [22] implemented a new productivity improvement strategy in a small French company, Valeo, located in the UK, for their wiper production system. The structure of the wiper system includes a container, pump, jet, and hoses. The company followed the strategy of a high variety and low volume with varied customers to aid the improvement. They improved productivity in two cells of the company. The first cell included assembling jets with hoses and hoses with other devices for headlamp cleaning systems. The team suggested multiple recommendations to improve productivity. They worked on the three sides of implementation: improvement of the tools used on the wet-set station to reduce cycle time, applying Kanban system hose cutting with jet and hose assembly stations, and the development of an autonomous cell. One 
recommendation to increase productivity was to analyze the number of changeovers, overtime needed, and the level of complaints. After three weeks, results showed that the cycle time was reduced from 18 seconds to 14 seconds per item.

Wulong, Gu, S., [23] presented international comparison between the growth of manufacturing industries between Canada and the U.S. over the period of 1961-1995. Their conclusion was that the average growth rate of manufacturing decreased dramatically in Canada and the U.S. after 1973 and that the total productivity growth was identical from 1961 to 1973 in the U.S. and Canadian manufacturing. Poor productivity performance of the Total Factor Productivity (TFP) growth in Canadian manufacturing was seen during 1979-1995 for the technology intensive industries. Making changes in the labor composition, such as reasonably more educated and older workers as well as relatively more equipment, helped the growth of manufacturing output in both countries.

Huang et al. [24] explained the significance of achieving productivity improvement at the equipment level, based on Overall Equipment Effectiveness (OEE). The author developed a model for manufacturing productivity using Overall Throughput Effectiveness (OTE). To identify productivity improvement, they applied sensitivity analysis and the theory of constraints. The authors then used a case study describing a production line from a leading glass manufacturer, Pilkington North America, to prove the validity of their work.

Huang et al. [25] presented a systematic methodology for productivity measurement and an analysis at the factory level. The author introduced and developed metrics on Overall Equipment Effectiveness (OEE) and Overall Throughput Effectiveness (OTE) for quantitative measurement of equipment and system productivity. Computer simulations were integrated with these metrics to provide rapid analysis of equipment and manufacturing system productivity. By using a realworld manufacturing case study to employ these factors, they could show improved productivity. By obtaining the results of this research, they are now able to represent factory level productivity and OTE for a quantitative comparison of various factories. 
Md Enamul et al. [26] investigated research using a fan manufacturing company, they proposed a way to improve productivity and quality by improving the existing Six Sigma level of the process; they used the improvement in sigma level as an indicator of productivity improvement. Since it is a methodology used in the process steps, they calculated current sigma level and used a Six Sigma DMAIC (Define, Measure, Analyze, Improve, and Control) cycle. Different improvement tools were used such as 5S (a series of activities designed to organize work environment), supermarket, line balancing, etc. Using these tools leads to reducing the defect rate and improving productivity. They suggested their work to be applied in other companies by applying Six Sigma synchronously among cost, quality, production and control time. The authors have studied new management approaches on improving business processes for both efficiency and consistent quality for customer service benefits.

Hemanand et al. [27] performed a case study in the automotive industry to obtain waste reduction and reduce manufacturing cost by applying Lean Manufacturing. They attempted to reduce motion cost in the shop floor by identifying layout problems using a form of simulation. They proceeded to compare the results of the modified, simulated, layout with the current one. They reached $11.95 \%$ improvement in productivity because of the modified layout. Based on the results, a new material handling system was designed and developed to reduce undesired transportation and motion waste.

Roy et al. [28] suggested a way to improve productivity and quality by introducing Six Sigma philosophy in Bangladesh, specifically in the Manufacturing Industry. They calculated present sigma levels as described from the methodology discussed in the publishing. The production system was observed after applying Six Sigma tools, showing an improvement in the overall production rate. The authors also made a change to the traditional layout using the five major phase of six sigma, Define, Measure, Analyze, Improve, and Control (DMAIC) technique for developing the process. From this technique, they again achieved a significant improvement in the overall productivity. 
Mandloi and Abhishek [29] published a review of a balancing problem in an assembly line design. They studied the number of algorithms made by previous researchers that related to the analyzing of single and multiband mixed-product assembly lines. They figured that many algorithms seek a specific solution determinant on and under specific considerations. Therefore, there was very little flexibility for a general assembly to assembly line design. They gave another analysis for their investigation by using practical design issues, which contain stochastic operation times, parallel workstation requirements, and feasibility for combining the workstations.

Esmaeilian et al. [30] provided a review regarding tangible and intangible elements of manufacturing systems evolution from past and current to future development. This review also presents how the manufacturing systems were classified for this particular study. The author's focus was on advanced manufacturing concepts for the past decade such as Sustainable Manufacturing, Smart Manufacturing, Social Manufacturing, Nano-manufacturing, Semiconductor Manufacturing and Additive Manufacturing. Then they suggested a change in the future direction for manufacturing systems based on their extensive survey.

Sai et al. [31] focused on a motion and time study analyses method for a productivity improvement technique. The aim of the paper is to propose a new system for the production company to enhance their level of productivity. The authors discussed the issue relating to motion and time study implementation as well as assembly line balancing and how they both could lead to an improvement in productivity. They built a simulation system by using Arena ${ }^{\circledR}$ software and proceeded to discuss the output results. The data was gathered from a company manufacturing solar appliances. With this data, they were able to prove the previous simulated theory by showing a positive influence from motion and time study implementation along with assembly line balancing. The theory leads to an improvement in productivity.

Schreiber et al. [32] studied the expensive cost of replacing or exchanging the robot grippers used for material handling because of product variety. They presented soft material ring-grippers for handling which is more flexible in manufacturing grippers. This may be avoided with soft material grippers that principally may handle products with different geometric complexity without 
changing the grippers. The suggested material of soft grippers is cast silicon and they have been made by designing for additive manufacturing. For obtaining more precious results and to avoid the silicon casting process, an Inkjet 3D printer has been utilized. The final result showed that new designed grippers passed the test of maximum pressure and pressure displacement by using FEMsimulation.

Kristjansdottir et al [33] reviewed the literature of reconfiguration manufacturing system and the challenges faced by the configurators in manufacturing companies. Six main challenges have been assigned and categorized which are: IT-related, product modeling, organizational, resource constraints, product-related, and knowledge acquisition. After identifying these challenges, the authors created a survey in manufacturing companies to order these challenges according to their importance then analyzed in depth. The conclusion of this survey in manufacturing companies increased the awareness and knowledge of using configurators and utilized them.

Lameche et al. [34] explained the benefit of Reconfigurable Manufacturing Systems (RMSs) in side manufacturing facilities. The authors discussed the literature of RMSs and how difficult it is to use the RMSs inside the complex manufacturing system. Researchers investigated a method of using modularity to design RMS and they developed an approach by utilizing the Structure Matrix and modular architecture.

Palcic et al. [35] investigated a technical innovation in Slovenian manufacturing companies. Survey with at least 20 employees has been used in this investigation (European Manufacturing Survey). This research analyzed statistically the relationship between the technical innovation and future plans of manufacturing facilities. The results showed the use and the trend of selecting advance technologies in Slovenian manufacturing companies.

\subsection{Machining Productivity in Metal Cutting}

Nishiguchi et al. [36] developed spherical machining technology. Using the stylus method, the technology, with in-situ metrology, improved machining accuracy and reduced machining time. Their work depended on in-situ measurement of machined geometrical accuracy. This allowed 
them to calculate the nominal tool's deviation diameter, tool feed error, and traverse direction. For both spherical grinding and diamond turning processes, the results showed that the machining time could be reduced to a third or even a half by using this approach.

Enache et al. [37] presented a new mathematical model for partial and global machinability. They model is used for selecting the best material for machining by evaluating the characteristics of a material's machinability. Their work formed the guidelines for machining conditions regarding the cutting process to obtain optimal results. The case study was done on machining titanium alloys using turning tools.

Yan et al. [38] discussed a numerical control (NC) program and found some factors relevant in productivity analysis such as, feed acceleration, average per-block feed distance, and command feed rate. They studied the effects of these factors on the quality of the NC program. Moreover, the relationship between feed rate and kinetic factors were studied in parallel with the three, previously mentioned factors. From these factors, the NC program evaluator was developed to track the improvement in productivity. By this evaluator, they could calculate the time of machining even in high machine speeds and high accuracy of machining, typically these cannot be obtained by using the CAM tool or the NC controller. After applying this evaluator, it was concluded that, at high speeds and high precision, they can increase acceleration per block and feed rate, directly influencing the increase in productivity.

Pasko et al. [39] studied the effects of High-Speed Machining (HSM) on productivity as well as accuracy in terms of tools and tool holders. The authors then proceeded to discuss examples of productivity within milling process. These topics showed promising economic advantages. They proved that HSM gives many benefits in the way of improving productivity by reducing the time of machining and increasing the quality by retaining the required surface finish. This study discussed the benefits of reducing the cost of productivity and improving quality.

Veldhuis et al. [40] tested the wear rate and behavior on end milling cutters with mono-layered TiAlCrN and nano-multilayered self-adaptive TiAlCrN/WN Physical Vapor Deposition (PVD) by 
using high performance ball-nose-end-milling conditions. The work material that was used for the machining is a hardened H13 steel. They checked the surface roughness and microhardness distribution around the surface of the work material. The results from the data explained that the high degree tribological compatibility of the work material, or cutting tool system, can have a significant influence on tool life and surface integrity improvement.

Kuttolamadom at al. [41] tested the achievability of surface roughness specifications to reduce the manufacturing cycle time for automotive components by changing the cutting feed. They selected the 6061 aluminum as the material of lightweight automotive material. The paper proceeded to present methodologies for the prediction of surface roughness in machining. Then they discussed the factors that affect surface roughness and how to improve the optimization with machining parameters by practical techniques. They showed the relationship between the feed and surface finish for 6061 aluminum by using controlled milling experiments; the results lead them to obtain recommendations for the machining practice to reduce cycle time and to retain quality.

Kumar [42] performed a procedure that could confirm whether production could continue parallel, off line. To eliminate downtime (waste) for tools, process check was applied on the product part instead of monitors. Before implementing the setup reduction, Single Minute Exchange of Dies (SMED) technique, the author calculated and collected relevant data. The results showed by implementing this setup reduction the time is reduced from 113.75 hours in June 2008 to 59.75 hours in May 2009 with 585.00 hours of machining, leading to an increase in the productivity of the machine from 19 to 44 plates from June 2008 to May 2009 respectively.

Malhotra et al. [43] presented a new micromachining process known as laser-induced plasma micromachining (LIPMM). They used laser beams with plasma to induce liquid at the focal point of the beam, which was used to perform the micro-machining. The results showed that several materials could be machined by using LIPMM, such as metal alloys, polymers, and ceramics. This was done to enhance process productivity and flexibility. 
Agarwal [44] conducted experiments to evaluate several parameters such as the depth of cut, table feed rate, size and density of grit, surface roughness, and surface and subsurface damages. Data from experiments regarding the machining process have been used to develop a mathematical model by considering these significant parameters only. The author developed a Genetic Algorithm (GA) code for the grinding process of ceramic using the manufacturer's constraints. The results showed possible improvement of the grinding process affecting the metal removal rate as well as the improvement of the surface finish by reducing surface and subsurface damages simultaneously.

Baumers et al. [45] created two different models of an Additive Manufacturing (AM) system to evaluate the different production costs. They performed an inter-process comparison of the performance cost. The cost is measured at $£ 2.39$ and $£ 6.18$ per $\mathrm{cm}^{3}$ of material deposited; these two AM systems are used to manufacture end-use metal parts, Electron Beam Melting (EBM) and Direct Metal Laser Sintering (DMLS). The authors concluded that a difference in the levels of productivity system and the observed deposition rates are not sufficient to perform adoption of EBM and DMLS in high volume manufacturing applications. From this analysis, they concluded that an AM on the economic scale can be achievable. The results showed more discussion about varying strategic requirements by the market-pull and technology-push modes of innovation that were found in the AM industry.

Reichler et al. [46] discussed the hybrid manufacturing and explained the need of it in reducing the tools and molds. Hybrid manufacturing is a method of producing products with high volume in two level of manufacturing: first by using a subtractive manufacturing or other manufacturing processes, then finishing it by using the additive manufacturing. This type of manufacturing is increasing the scale of the production and size. The authors developed an approach to reduce the complexity of new design of hybrid manufacturing during the design level of multi-material products.

Costa et al. [47] developed the methodology for design research to serve a service-diamond logic and obtain the human-oriented perspective. Authors included the design models with new PSS approach. From this study, they came out with an application for manufacturing facilities. In this 
research, they explained in details, the need for this application and how it can influence the design of product-service system solutions positively.

\subsection{Design for Manufacturing}

Boothroyd [15] discussed the importance of Design for Manufacture and Assembly (DFMA) in the early stage of product design. The author used a case study to express the philosophy of DFMA methodology and its application. The difference in the cost of products and tools for redesigning were shown. Then, the author explained the history of DFMA in Japan, the United States, and Europe. The new approach has been adopted depending on the published case history. The conclusion was that there are various barriers affecting DFMA techniques and product design for disassembly.

Srinivasan et al. [48] developed a physio-mathematical basis for mechanical tolerances. They studied a tolerance method by the model of profile errors, which has components modified by physical reasoning and estimated using mathematical tools. They presented this methodology as an evolutionary procedure depending on the hardness of the various tools. This methodology will help the designers estimate performance priorities for manufacturing. The main purpose of the functional tolerance methodology is to provide performance simulations of a lathe-head-stock design, focusing on gear transmission.

Bayoumi [49] studied the concept of DFMA, the author showed the advantages of DFMA and discussed how this technique can reduce time and development cost of the product. The author discussed the effect on product assembled and studied the minimum cost and time required to retaining the level of quality to satisfy customers' needs. The advantages of a part designed for easy fabrication in harmony with other designs was explained.

Chiang et al. [50] published a literature review to explain the importance of the functionality of a product and how to provide satisfaction to users. They showed published literature regarding functionality and functional representation that mainly related to mechanical systems design. They concluded that there is an issue affecting daily consumer products in terms of functional 
representation. Their conclusion from this review is that a product is rarely tested in real design or by real designers in manufacturing environments and this issue must be seriously considered. Little attention has been spent on developing tools for evaluating alternative design solutions and most research focuses on how to provide function instead of ensuring function on the product.

Edwards [51] investigated the tactical selection of materials and the manufacturing process itself during the initial design level. The author showed how DFMA is important to engineering for the cost of product design. The author generated a procedure to analyze the function of DFMA in terms of product design based on the application of quantifiable data. Massive information has been collected via this procedure and then computerized to use in future decision making. Using this procedure and information, the author described some methods that affect the integration of quantitative and qualitative materials that can be used during product design. The discussion that focused on the differences between designing new products or redesigning existing products has been presented and displayed how it will influence product cost.

Herrmann et al. [52] published a review regarding how the design for manufacturing (DFM) domain is expanding into new and important areas. The group of authors discussed DFM as well as concurrent engineering. They covered DFM in a variety of different concepts including, "DFM for conceptual design, DFM for embodiment design, DFM for detailed design, design for production, platform design for reducing time-to-market, design for system quality, design for life cycle costs, and design for environment." Then from this study, they suggested general guidelines regarding the development of useful, effective DFM tools within manufacturing firms.

Wong et al. [53] concentrated on how to minimize production cost by optimizing product design. They used the cost of production as a criterion within productivity and defined Design for Production (DFP). DFP is used as a method to minimize production cost by using optimal product design while still retaining a product's functionality. They proposed a DFP methodology which includes three fields. First, productivity was measured by using an Operation-Based Costing method. Second, product design, and activities. Third, integration of product design, production cost estimation, and metamodeling-based optimization combined to get the optimized product 
design. The authors collected the results by applying DFP methodology in many industries, the results proved that the proposed method was effective.

Zhao and Shah [54] simplified DFM analysis across all manufacturing domains. They explained the general steps to perform a shell evaluation on manufacturability. The shell is a software; by using it, they covered several stages of manufacturability analysis as well as different levels of abstraction. Moreover, the shell can provide feedback to the designer during each level of the design. Another advantage of using the shell is that it can be customized and expanded for each project. They presented the architecture of the shell and its applications to manufacturability analysis on sheet metal and injection molding.

Bird and Kochhar [55] conducted a survey in the global automotive organization for manufacturing engineering. They studied the environmental awareness and requirements for design tools which assist in a sustainable process design. They obtained and analyzed results, showing significant differences in the thinking of the engineers but that they also use similar processes for manufacturing similar products. The author then considered the reasons for the difference of opinions amongst the engineers and analyzed the final results.

Kerbrat et al. [56] presented a new approach concerning the DFM focusing on designing a hybrid modular product instead of focusing on one use manufacturing process to obtain the same product competitiveness. This DFM system was created to help the product design level by giving quantitative information. Testing has been applied for industrial products in the automotive industry by using CAD software to help develop and implement a methodology regarding manufacturability in the order of subtractive or additive manufacturing processes.

Ramos and Lorini [57] focused on and analyzed DFM demands/requirements and their influence on the framework of this domain. The authors explained the challenges of both theoretical and technological research advances. They showed how the current approach varies in difficulty and how it is primarily focused on data. The paper proceeded to give the motivation to use frameworks, especially computer-based ones. They proposed work based on ontologies to get a more 
informational, handling approach. Specific, prototype DFM components and architectural aspects requirements have been summarized by using this approach through providing information architecture and its implementation.

Vallhagen et al. [58] measured the impact of the product design of a production system by discussing the definition of productivity and manufacturability. Methodologies and tools have been recommended from the results that have been obtained. These methodologies and tools must follow the product development process to improve producibility. The authors suggested a new approach as the next step is to increase producibility in the manufacturing of aerospace engine components.

Andersson et al. [59] described how a new strategy for the Swedish Aerospace and Defense Company (SAAB), Aero-structures, can be developed. They explained how this new strategy deals with manufacturability issues during the development of airframe composite structures. From the literature review, a DFM strategy was developed. The conclusion was discussed; there will be more contribution to a cost efficient product development and aircraft design by applying important factors, which will lead to a successful DFM management.

Cochran et al. [60] studied the significance of measuring the effectiveness of the system design that, in turn, contributes to the overall system performance. To evaluate the effectiveness of the design of a manufacturing system, they proposed the application of a manufacturing system assessment tool. Manufacturing System Design Decomposition has been used to develop this tool. The efficiency of a system's design is based on the requirements of manufacturing. They proceeded to evaluate the performance of the system based on six physical manufacturing system configurations. The authors' conclusion is that the evaluation of most repetitive, discrete-part manufacturing systems, may be obtained by the proposed Manufacturing System Evaluation Tool.

Sharma et al. [61] presented a mathematical model on known length in a metal matrix to perform compositional gradient to manufacture of Aluminum + Titanium Carbide (Al+TiC). By using the digital image correlation technique, a study was done on mechanical properties; this included 
Young's modulus, strain hardening exponent, and yield stress. Property gradient is caused by particle mixing and matrix grain specific process condition vis-à-vis the number of passes, volume faction, and particle size, instead of initial matrix grains. The result shows that there is an ability for manufacturing of large size from graded composites products.

Song et al. [62] designed and manufactured a titanium alloy beak for an individual Grus Japanese bird. Multiple detailed designs for this beak has been created (A, B, C, D1, D2, and F) and then they have been manufactured. The fabrication processes have been created by using combinations of fused deposition modeling (FDM) with selective laser melting (SLM) which helped for getting a fast response of manufacturing customized titanium alloy beak. After manufacturing and installing the beak, a good result has been obtained, the bird could feed itself after half hour. They suggested that their work could provide veterinary care to animals by using graphic design and additive manufacturing.

From this literature, it can be concluded that some researchers showed the importance of DFM while others showed how it can develop a platform to vary the cost of products. However, minimal work has been done by considering the DFM and the influence of machining parameters on cost reduction and increasing throughput. In conclusion, there is a necessity to analyze the DFM factors and their relationship with machining parameters and machining elements system.

Ostrosi et al. [63] investigated the cloud base design for manufacturing. They used the concept of the Holon and how several CAD design can be manufactured in smart virtual environment in cloud manufacturing. Fuzzy methods were used to model the manufacturing features. The final results showed that the inelegant virtual manufacturing with holonic structure can be adapted and will be successful for cloud manufacturing.

Alabort et al. [64] explored the metal additive manufacturing to manufacture bone, scaffold design has been used to create different bone tissues. Ti-6Al-4V alloy was used in this research with poresize 200 and $500 \mu \mathrm{m}$. Compression experiments were performed to evaluate the collapse load and 
stiffness of the scaffold design. The final results showed that the grids design of the tissues were matching several types of bone stiffness and yield strength.

A. W. Gebisa, H.G. Lemu [65] discussed the importance of the Design for Manufacturing (DFM) in enhancing a design and using alternative material, and pursuing product development. They explained the significance of emerging the Additive Manufacturing (AM) with DFM and how the transition can be achieved from DFM to Design for Additive Manufacturing (DFAM). In this research, the authors analyzed the impact of this transition on optimizing product design.

\subsection{Design for Manufacturing and Machining Parameters Impacts on Cost and Productivity}

Thatcher [66] developed two levels of economic models of duopoly competition. The author developed this model to test the impact of technology investments in product design tools on: product quality and price, a firm's productivity and profits, and consumer welfare. For the first level, product quality has been chosen simultaneously by the firms and for the second level, the price has been set simultaneously. From this model, product quality has been improved and with this improvement, profit is maximized. The conclusion from the results deemed that the company failed to improve the quality and that the author could reduce production cost of tools.

Prasad et al. [67] presented the DFM approach in terms of productivity improvement. This approach is referring to medical devices, being able to make the product easy to build, and reducing the production cost and time. The results obtained from the case study showed that DFM methodologies are appropriate for product design and manufacturing. The final result of this DFM approach showed that the time can be reduced by $75 \%$ and production cost cut by $8 \%$.

Mueller [68] proposed a model that would reduce the cost of the warranty for the product that was under development. Strategies were set by product development teams and the warranty was analyzed to reduce the cost of the warranty. The authors presented a framework to evaluate this 
model for cost reduction strategies throughout the product development cycle. The results obtained by the case study showed that they can reduce the cost of warranty by $35 \%$.

Raja and Baskar [69] investigated the effects of machining parameters for the aluminum material on surface finish. They studied machining parameters such as cutting speed, feed speed, and depth of cut for face the milling process; it showed the influence of each to get the desired surface finish. Their approach was to develop a mathematical model to predict surface roughness using Particle Swarm Optimization (PSO). For optimization validating, the model was applied on PSO depending on the experimental results. After specifying the physical constraints for machining parameters and surface roughness, the authors concluded that the model for predicting roughness is in accordance with the actual roughness.

Qehaja et al. [70] developed a model for surface roughness to evaluate the machining parameters of a dry turning machine, which included the feed rate, tool geometry, nose radius and machining time. With this model, they were able to show how these parameters will affect surface roughness produced by a turning process. The results were obtained after an experiment was performed in a three-level, factorial design. They showed that there is a positive comparison with the previous results, which validates the effectiveness of proposed regression analysis in the model.

Leal-Muñoz et al, [71] presented online method for measuring machining parameters in milling process. This measuring was performed by detecting the minor variation in cutting parameters. A function related to the response time of the input variables has been developed. The influence on machining parameters in mailing process was detecting by cutting force signal which was determined by dynamometric platform using piezoelectric sensors. The depth of cut was one from the tested parameters and the results showed a high precision could be obtained on this parameter.

Lata et al. [72] investigated machining parameters, and tool material such as tungsten carbide and PCD by determining the average chip-tool interface temperature. This work has been applied on turning process for machining IS 733 Gr 63400 aluminum and IS 2062 steel. The average chiptool interface temperature was predicting by using mathematical model obtained from 
experimental observation. The final results showed that the temperature was rising by increasing the machining parameters and the temperature depended on the cutting tool materials in machining ferrous material in contrast of non-ferrous materials.

S Kosaraju et al. [73] studied the influence of process (machining) parameters on machinability of turning Inconel 625. The process parameters were: cutting speed, feed rate, and depth of cut, a surface finish and cutting force were used to investigate the process performance. Design experiment and Taguchi method were utilized to find the optimal level of cutting parameters. Based on the statistical analysis, the feed rate has the most influence among the rest parameters.

Chandra et al. [74] analyzed the effect of machining parameters (cutting speed, feed/revolution, and depth of cut) for turning alloy steels following ISO3685 standards on surface toughness and cutting force. The results showed that surface roughness was low at 350m/min cutting speed and $0.15 \mathrm{~mm} /$ revolution feed. By comparing the turning of $\mathrm{HCHCr}$ alloy steel to EN24 grade alloy steel, the cutting force increased by $35 \%$ when turning $\mathrm{HCHCr}$ alloy steel.

Jacob et al. [75] developed a method can be used by companies to optimize product design parameters and manufacturing technology chain. Specific parameters were used to model a product. Manufacturing parameters and critical product impacts are quantified to enable enabling the optimization of manufacturing technology and product. That will allow the companies of managing their new product and manufacturing technology.

Xuan F Zha, and H Du [76] presented an approach for checking the suitability of manufacturing processes and stock materials for microelectromechanical system (MEMS) in concurrent design. Several issues and strategies of MEMS manufacturing process and material selection has been discussed and addressed. Fuzzy method was used to support this work for decision making problem. The authors developed a web base prototype expert system to support the MEMS from survey conducted on the basis of client response. This approach of selecting the suitability of the manufacturing process and appropriate raw materials showed a good performance and it can be used inside a manufacturing company. 
Kaspar et al. [77] developed an approach for formalizing material selection decisions. They used a material-oriented development methodology to structure their work. The significance material selection on both products and production system. The conclusion about the proposed methodology of materials selection still under processing. However, the material-oriented methodology will be elaborated for future follow-up work. The material selection proposed method will be supported by a software prototype.

\subsection{Conclusion}

The conclusion obtained from reading and summarizing the literature is that Design for Manufacturing Techniques (DFMT) and machining parameters can have a significant impact on cost savings and improving productivity. After reviewing these papers regarding manufacturing, machining, and DFMT, one can say that minimal work has been done considering the influence of DFMT and MP. There is a need to study and analyze DFMT and the associated machining parameters to explain the effects on productivity improvement and cost reduction. None of the papers explained the influence of several DFMT together or applied a comparison between them. The reason could be the researchers were satisfied with the results of just one of the DFMT or they were not aware of combining several DFMT effectiveness. There is no evaluation of the overall effectiveness of an objective for these DFMT and MP. To perform this work, a systematic method needs to be followed. Therefore, a systematic algorithm has been developed and discussed in Chapter three and evaluated in Chapter four of this dissertation. 


\section{CHAPTER THREE: RESEARCH METHODOLOGY (DATA COLLECTION METHOD AND RESEARCH TOOLS)}

\subsection{Introduction}

This chapter deals with a research approach and systematic algorithm adopted in the dissertation. From the literature review, it was found that few studies have been done which analyze Design for Manufacturing Techniques (DFMT), machining parameters, and machine element systems. There is a need to investigate which DFMT with which machining parameter has the most influence on cost reduction and increasing throughput under which circumstances, because little work has been performed on this subject. This study will investigate several DFMT and their relationships with machine element systems and machining parameters, which have not to date been considered adequately within the scientific body of knowledge.

\subsection{Systematic Algorithm Structure}

The systematic algorithm providing the foundation of this study will be explained in this chapter and tested in the next. This systematic algorithm has basic elements that are used as a foundation for critical evaluation. In sum, the algorithm provides guidance for analyzing the DFMT, and presents several outputs that are useful for cost, material, and design comparison. The structure and function of these critical elements of the algorithm will be explained in detail in the following sections and sub-sections of this chapter. The structure of these elements will be integrated in one chart which is represented the scheme of systematic algorithm in Figure 3.2.

\subsubsection{Design for Manufacturing Techniques (DFMT)}

There are several Design for Manufacturing Techniques (DFMT) including raw materials, modifying the quality (surface finish and tolerance), modifying geometry, and modifying the selection of process/es [5]. The DFMT obtained in this dissertation are as follows:

\subsubsection{Modifying Raw Material}

This DFMT includes choosing alternative raw material instead of the one that was used originally in the preliminary process plan. Modifying the selection of raw material is not an arbitrary process and should be done under specific constraints. This modification can be performed by considering 
a specific constrained range of material properties on the preliminary design of the part. The values of these allowed ranges should be specified by the designer, whereby the functionality of the part can be maintained. Further, the material should be selected according to the performance criteria and functionality, in which the material should be compatible with design and process. The list of the materials' properties and their units is shown Appendix D2.

Seven raw materials (alloys) have been selected, including stainless steel 316L, to study the effectiveness of modifying the selection raw materials. The seven alloys selected are shown in Table 3.1.

\section{Table 3.1. The list of suggested raw materials}

\begin{tabular}{|c|l|}
\hline Index & Engineering Alloys \\
\hline 1 & Aluminum Alloys \\
\hline 2 & Stainless Steel Alloys \\
\hline 3 & Copper Alloys \\
\hline 4 & Zinc Alloys \\
\hline 5 & Nickel Alloys \\
\hline 6 & Titanium Alloys \\
\hline 7 & Cast Iron \\
\hline
\end{tabular}

After considering the above alloys as alternative raw materials, the values of material properties for each alloy have been gathered and arranged in Appendix D [78], [79]. These values have been gathered from Ashby's scholarship (plots) to explain the relationships between these alloys, for each pair of material properties [78], [79]. Some of the values related to the current study could not be found within Ashby's work (and do not appear to be published elsewhere) at this time. In such cases, their cells have been nulled until their values can be acquired. For each pair of the material properties of alloys in Appendix D, the minimum and maximum values have been specified. These values are identified by color, from maximum to minimum, ranging from dark red to dark green color respectively. The reason of considering several metal alloys instead of just considering stainless steel and aluminum is to increase the alternative choices of metal alloys that would give more flexibility in analyzing the DFMT. Few materials might not be suitable in most cases, due to the wide ranges of material properties required for different functionalities. User can 
have more options in analyzing materials with respect to DFMT. However, I have chosen only a few materials to illustrate the concept in my dissertation.

\subsubsection{Modifying Quality (modifying tolerance and surface finish)}

Modifying the quality is considered one of the DFMTs. Altering the surface finish and tolerance can establish this modification of quality. In this dissertation, "quality" means the acceptability of the machined part with regard to the specification. The first step in the process of modifying the quality is to follow the part drawing. There are specific ranges of tolerance and surface finish on every joint or contact surface on the machined part. Combinations have been performed between the tolerance and surface finish for the allowable range to obtain minimum cost of machining, which is further explained in the results section of the next chapter.

\subsubsection{Modifying Geometry}

This DFMT can be performed by modifying the shape or the features of the part, for the workpiece and/or the final part. In this study, specific geometric guidelines were selected for modification. Some of these guidelines were modified before starting manufacturing, such as modifying the geometry of the workpiece, while others were modified based on the design of the final part. This may include modifying L/D ratio for holes, modifying some features in the design (such as fasteners and/or modifying the key and keyway to tapped hole and screw), and modifying the shape of the final part. All these modifications must be specified by the designer after analyzing the functionality of the part.

\subsubsection{Modifying Manufacturing Process/es}

Modifying one or more machining processes inside this DFMT has an impact on cost reduction. Several machining process changes, such as switching from the milling process to the turning process or using a milling process instead of expensive surface grinding process. Some process alterations will be inherent in the modifying of another DFMT, such as modifying the geometry (final part shape). 


\subsubsection{Machine Elements System}

Two main machine element systems machine element systems will be modified while applying every DFMT. These two machine elements systems are:

1. Machine tool

2. Cutting tool

For each machining process, there are several machine tools that will be suitable and assigned by MPSEL software (explained further in 3.2.5). For example, to perform the turning process, several machine tools are available, such as the NC lathe, Turret lathe, Engine lathe, and SP lathe. For every type of turning machine, which be selected by MPSEL, several cutting tools are compatible. For instance, with one turning machine (NC Lathe), there are several cutting tools available, such as HSS M Grade, HSS T Grade, Carbide C2.C4, Carbide C5.C8, Ceramic Insert, and PCD Diamond.

The carbide tools can be categorized to several of carbon compounds. Re-grounding carbide tool is difficult, but it is not impossible. The carbide tool can be grounded by using high speed wet diamond or green abrasive wheel establish front and side relief. However, re-sharpening the carbide tools is difficult to be performed manually and might need a professional and specific sharpening machinery to do that. This difficulty of grinding the carbide tool depends on carbide tool grade. The most difficult carbide tool to regrind is the tungsten carbide tool because it is as hard as diamond. Silicon carbide grinding wheel must be used to regrind the tungsten carbide tool [80]. There are several companies available to regrind the carbide tools such as Wolf Tool Technologies and Performance Carbide companies. They recommend to regrind the carbide tool and consider the cost of regrinding carbide inset or round tools to be much cheaper than purchasing new tools [81]. Denkena B. et al. 2018 [82] investigated the crucial of regrinding cemented carbide tools and how that will save the resource of carbide tool. They discussed the defects that inherent the regrinding process and the accuracy of this process. The result of the research showed that $12.5 \%$ percent of the cemented carbide worn tool does not need to be disposed.

The developed systematic algorithm for this dissertation performs the combinations between the machine elements systems (machine tools and cutting tools), shown in Table 3.2 below. These results are an arbitrary example, used in the heuristic analysis for testing the combination and not related to the research results. 
Table 3.2. Example of combinations on turning process

\begin{tabular}{|c|c|c|}
\hline $\begin{array}{l}\text { Machine } \\
\text { Tool }\end{array}$ & Cutting Tool & $\begin{array}{c}\text { Total Turning } \\
\text { Cost }\end{array}$ \\
\hline \multicolumn{3}{|c|}{ Applying the first combinations } \\
\hline NC Lathe & HSS M Grade & 4.57 \\
\hline NC Lathe & HSS T Grade & 4.93 \\
\hline NC Lathe & Carbide C2.C4 & 3.65 \\
\hline NC Lathe & Carbide C5.C8 & 3.67 \\
\hline NC Lathe & Ceramic Insert & 1.76 \\
\hline NC Lathe & PCD Diamond & 1.73 \\
\hline \multicolumn{3}{|c|}{ Applying the second combinations } \\
\hline Turret Lathe & HSS M Grade & 8.48 \\
\hline Turret Lathe & HSS T Grade & 9.28 \\
\hline Turret Lathe & Carbide C2.C4 & 5.91 \\
\hline Turret Lathe & Carbide C5.C8 & 5.95 \\
\hline Turret Lathe & Ceramic Insert & 2.58 \\
\hline Turret Lathe & PCD Diamond & 2.66 \\
\hline \multicolumn{3}{|c|}{ Applying the third combinations } \\
\hline Engine Lathe & HSS M Grade & 23.43 \\
\hline Engine Lathe & HSS T Grade & 26.18 \\
\hline Engine Lathe & Carbide C2.C4 & 11.74 \\
\hline Engine Lathe & Carbide C5.C8 & 11.84 \\
\hline Engine Lathe & Ceramic Insert & 4.23 \\
\hline Engine Lathe & PCD Diamond & 4.38 \\
\hline \multicolumn{3}{|c|}{ Applying the fourth combinations } \\
\hline SP Lathe & HSS M Grade & 7.96 \\
\hline SP Lathe & HSS T Grade & 8.75 \\
\hline SP Lathe & Carbide C2.C4 & 4.53 \\
\hline SP Lathe & Carbide C5.C8 & 4.56 \\
\hline SP Lathe & Ceramic Insert & 1.68 \\
\hline SP Lathe & PCD Diamond & 1.74 \\
\hline
\end{tabular}

After applying any DFMT, then assigning the appropriate machining process, the suitable machine tool and cutting tool will be selected by MPSEL software. In the systematic algorithm and the 
process plan, combinations can be applied for every machining process. These combinations are between the selected machine tools and cutting tools in order to select the process with the minimum cost, as shown in Table 3.2. The turning process performed on machine SP lathe with the ceramic tool has the least cost of machining (\$1.68). This illustrates how the systematic algorithm works with all the machining process outcomes, inside each process plan, after applying any DFMT.

\subsubsection{Machining Parameters}

Several machining parameters are considered in this systematic algorithm as shown below.

1. Cutting speed

2. Feed rate

3. Depth of cut

4. Rapid traverse rate

5. Time to load and unload the workpiece

6. Tool change time

7. Labor cost

8. Machine setup time

9. Tool depreciation cost

The above machining parameters will be simultaneously applied and modified inside each process, with the selected machine tool and cutting tool. For every machine tool, there is a specific, related machining parameters with specific values (Rapid traverse rate, Time to load and unload the workpiece, Tool change time, Labor cost, Machine setup time, and Tool depreciation cost). Meanwhile, for every cutting tool there is also specific related machining parameters with specific values (Cutting speed, Feed rate, and Depth of cut). These related values of machining parameters for every machine tool and cutting tool have been explained in Appendix A and B.

The machining processes have been used in this research because of the extensive applicability and prevalence in use in the manufacturing domain. However, this work can be expanded in order to include more manufacturing processes and parts with different degree of complexity. Moreover, the machining processes are the type of subtractive manufacturing which the whole part can be 
manufactured by it. By the manufacturing processes high precious desired surface finish and tolerance can be obtained and the quality is one of the main DFMT used in this research. All of the above-mentioned reasons made the traditional machining processes as scoped boundaries of this research.

\subsubsection{Design Parameters (DP)}

One aspect of the suggested systematic algorithm is the Design Parameters (DP). The DP represents the qualitative and quantitative characteristics of a part's physical and functional construction.

1. The qualitative characteristics in the systematic algorithm are represented by

A. Surface finish and tolerance of every surface or feature of the part.

B. The raw material information, such as material type and environmental considerations (pressure, temperature, corrosion resistance, stiffness, and strength).

2. The quantitative characteristics

The quantitative characteristics in the DP are represented by:

A. Raw material properties (density, hardness, heaviness, melting point, heat treatment).

B. Raw material and final product measurable characteristics (dimensions, diameter, thickness, length, and width).

C. The shape of the raw material and final part.

D. The features of the final product (holes, fasteners, chamfer, fillet, closed pocket, open pocket, slot with open end, slot, groove, keyway, and snap fit).

All the DP mentioned above has specific ranges and values to maintain the functionality of the product. These values and ranges can be adjusted and reanalyzed, and specified by the designer before applying every DFMT. 


\subsubsection{Manufacturing System Parameters (MSP)}

Before creating any process plan, work should be completed in the manufacturing system parameters section. This involves selecting appropriate machining element systems, including the machine tool, cutting tool, and cutting fluid for each machining process. These parameters can be selected according to their suitability for the machining process, by using the MPSEL expert software. The MSP in the systematic algorithm, is a pool to select suitability of the assigned raw material and machining processes and selecting their machine tools, cutting tools, and cooling fluid by utilizing MPSEL software.

\subsubsection{MPSEL}

MPSEL is software for machining selection, developed by Gopalakrishnan, B, a Professor at West Virginia University [83]; The MPSEL is an acronym for Machining Parameters Selection System. It is an expert system for machining parameter selection in job shop environments. MPSEL was developed to select different machining parameters including machines, cutting tools, cutting fluids and to indicate the different cutting conditions. The different cutting conditions include thermal shock, and high tool chip friction. The expert system considers the following machine shop environment in which engine lathe, NC lathe, turret lathe, single spindle automat, cylindrical grinding machine, surface grinding machine, horizontal milling machine, vertical milling machine, NC mill, Turret drilling machine, vertical drilling machine and radial drilling machine are available. The processes that can be performed in this system are, turning, facing, milling, grinding, drilling, reaming, boring, tapping and threading. MPSEL is a time-saving software; the selection of machines and cutting tools manually is a time-consuming process as it involves a lot of parameters and has constraints including the machine capacity, tool work combination, and surface finish requirements. MPSEL is designed to check the suitability of the machining process with the assigned raw material, and select the appropriate machines and cutting tools for a machining process based on the design and characteristics of the part (type of raw material, hardness, metallurgical structure, desired and required surface finish, tolerance). These outputs of MPSELwill be generated after receiving the information from the design parameters section, then the outcomes will be transferred to the Manufacturing System Data Base (MSDB). The data from MSDB will be sent to the Process Plan (PP) section to generate several process plans. 


\subsubsection{Manufacturing System Data Base (MSDB)}

The suitable machine elements systems will be selected by using MPSEL software. The machining parameters values for every pair of machine elements systems should be specified. These values can be obtained from a specific database represented by tables that includes cutting tool information (tool cost, tool life, tool resharpening cost, and tool resharpening time) and machine tool parameters (machine setup, tool change time, rapid traverse rate, time to load and unload the workpiece, labor cost, machine setup time, and tool depreciation cost). A spreadsheet called "Speed_Feed_Selection" will be used to obtain the values of feed rate, cutting speed, and depth of cut. These values of machine elements systems and machining parameters will be used to create the Process Plan (PP) in the next section.

\subsubsection{Creating Process Plan (PP)}

All the data from the DFMT, DP, MSP, and MSDB sections in the systematic algorithm need to be organized and gathered in one section. All of the information before or after applying the DFMT is used to create the preliminary or alternative Process Plan (PP). PP contains the machining processes sequence and the details for part fabrication. Table 3.3 below shows an example of a process plan for machining stainless steel by using various HSS tools.

Table 3.3. Example of process plan for machining stainless steel part by using HSS tool

\begin{tabular}{|c|c|c|c|c|c|c|}
\hline $\begin{array}{l}\text { Process } \\
\text { Index }\end{array}$ & Process Name & $\begin{array}{l}\text { Type } \\
\text { of Cut }\end{array}$ & $\begin{array}{l}\text { Surface } \\
\text { Finish }\end{array}$ & Machine & Tool & $\begin{array}{l}\text { Required } \\
\text { Tolerance }\end{array}$ \\
\hline 1 & $\begin{array}{c}\text { Face milling side } \\
1\end{array}$ & Rough & 90 & nc_mill_mc & hi_sp_steel (M 42) & \pm 0.05 \\
\hline 2 & $\begin{array}{c}\text { Face milling side } \\
2\end{array}$ & Finish & 90 & nc_mill_mc & hi_sp_steel (M 42) & \pm 0.05 \\
\hline 3 & Turning & Rough & 90 & nc_lathe_mc & hi_sp_steel (M 42) & \pm 0.05 \\
\hline 4 & $\begin{array}{c}\text { Grinding of } \\
\text { cylindrical } \\
\text { surface }\end{array}$ & Finish & 10 & cyl_gr_mc & Grinding wheel & \pm 0.005 \\
\hline 5 & $\begin{array}{c}\text { Surface Grinding } \\
\text { of flat side }\end{array}$ & Finish & 10 & sur_gr_mc & Grinding wheel & \pm 0.005 \\
\hline
\end{tabular}




\begin{tabular}{|c|c|c|c|c|c|c|}
\hline $\mathbf{6 , 7 , 8}$ & $\begin{array}{c}\text { Drilling 5 holes on } \\
\text { cylindrical } \\
\text { surface }\end{array}$ & Rough & 90 & ver_dr_pr & $\begin{array}{c}\text { hi_sp_steel (TiN } \\
\text { coated) }\end{array}$ & \pm 0.05 \\
\hline $\mathbf{9 , 1 0 , 1 1}$ & $\begin{array}{c}\text { Tapping 5 holes } \\
\text { on cylindrical } \\
\text { surface }\end{array}$ & Rough & 90 & ver_dr_pr & $\begin{array}{c}\text { hi_sp_steel (TiN } \\
\text { coated) }\end{array}$ & \pm 0.05 \\
\hline $\mathbf{1 2}$ & End milling & rough & 90 & nc_mill_mc & $\begin{array}{c}\text { mp_hss_t15_m42 } \\
\text { grade } \\
\text { (hss_m2_m3_m7) }\end{array}$ & \pm 0.05 \\
\hline $\mathbf{1 3}$ & T-slot & finish & 90 & nc_mill_mc & $\begin{array}{c}\text { hi_sp_steel (M } \\
\text { grade) Slot mill }\end{array}$ & \pm 0.05 \\
\hline
\end{tabular}

The process plan in Table 3.3 shows the sequence and name of the machining process, as well as the type of cut, surface finish, tolerance with machine, and the tool used for each process. After creating the process plan, the attributes of the PP can be determined.

The High Speed Steel (HSS) cutting tool has been included as one the several cutting tools in this research and used according to its suitability in the machining processes. HSS tools are preferred by manufacturers over several cutting tools because they are the most economical material and easy to fabricate. Furthermore, HSS tools can be used to machine all the materials after improving their performance by coating the cutting tool [84]. The new forecasting statistic records showed that HSS cutting tools market will grow by $\$ 1.88$ billion through the years 2019 to 2023 [85]. Norseman $^{\mathrm{TM}}$ Drill and Tool Company is considering as an America's Finest High-Speed Steel Cutting Tools Manufacturer [86]. Different types of HSS cutting tools have been created for different manufacturing companies inside the United States. Moreover, significant number of companies in the United States are producing the HSS cutting tool [87]. RTS cutting Tool Company is manufacturing custom HSS cutting tools for just about every industry inside the United States. This company considers high speed steel tool as its sweet spot [84]. They have experienced employees for more than 35 years. Despite the slowdown of world economic growth and that influenced on manufacturing HSS cutting tools. The HSS cutting tools are growing annually by $4.94 \%$ and they expected to expand more by 2022 [88]. HSS may have limited scope and use in USA, but it is used prevalently in the third world countries. All of that is an evidence that the HSS cutting tool are important and using prevalently globally. 


\subsubsection{Design for Manufacturing Outputs (DFMO).}

When the PP is completed, the calculations on each machining process should be performed to obtain the attributes of the PP. These attributes are represented by two main outputs: cost of machining and production rate. These two factors will be used to evaluate the process plan by the user in the next section. The outputs of each PP are calculated inside the Design for Manufacturing Outputs (DFMO) section of the systematic algorithm. For calculating the attributes of the PP, every machining process output is determined separately. These outputs are machining cost, tool cost, machining time, and total process cost. The output values of each process are then aggregated, to obtain the total machining cost for the whole part and machining time. Meanwhile, the production rates are calculated from the machining time. Previously, the VISUALMACH software was used to calculate the outputs of each process. For the present study, Process Plan Attribute Calculator (PPAC) was developed as an alternative software in order to improve time and performance.

\subsubsection{VISUALMACH}

VISUALMACH is a spreadsheet application developed by Dr. B. Gopalakrishnan, a Professor at West Virginia University. The purpose of this spreadsheet program is to calculate the machining cost, machining time, and tool cost for a specific machining process. This program was used at the proposal stage of the present research. Thereafter, when the researcher started work on the systematic algorithm, the PPAC software interface for calculating the attributes of a PP was developed.

\subsubsection{Process Plan Attributes Calculator (PPAC)}

The software interface created by the researcher is constructed through coded spreadsheets, using Visual Basic for Applications (VBA®). This interface was used because it is easier and faster to use than VISUALMACH. The user can change any element from inputs directly in one step. After creating several process plans for specific DFMT in the process plan section of the systematic algorithm, they should be evaluated to select the desired one from them. This evaluation can be performed by obtaining several outputs for each process plan, and these outputs are: machining time, machining cost, total tool cost, total machining cost, and production rate per hour. All these outputs can be acquired from utilizing PPAC. All information of the machine elements system 
used for this process and machining parameters, such as tool cost, tool re-sharpening cost, tool depreciation cost, machine tool cutting speed, depth of cut, and feed rate. This information can be gathered from Feed_Speed_Selection spread sheet and the machining parameters data base tables Appendix A and E. Then, by inserting these inputs in the right side of the PPAC input interface shown in the Figure 1 below for turning process. Cutting speed, feed rate, and depth of cut for each process have been calculated by using a spreadsheet called Speed-Feed-Selection, which depends on the process, machines, and tools that are selected by using MPSEL. Figure 3.1 explains the structure of the PPAC for turning process.

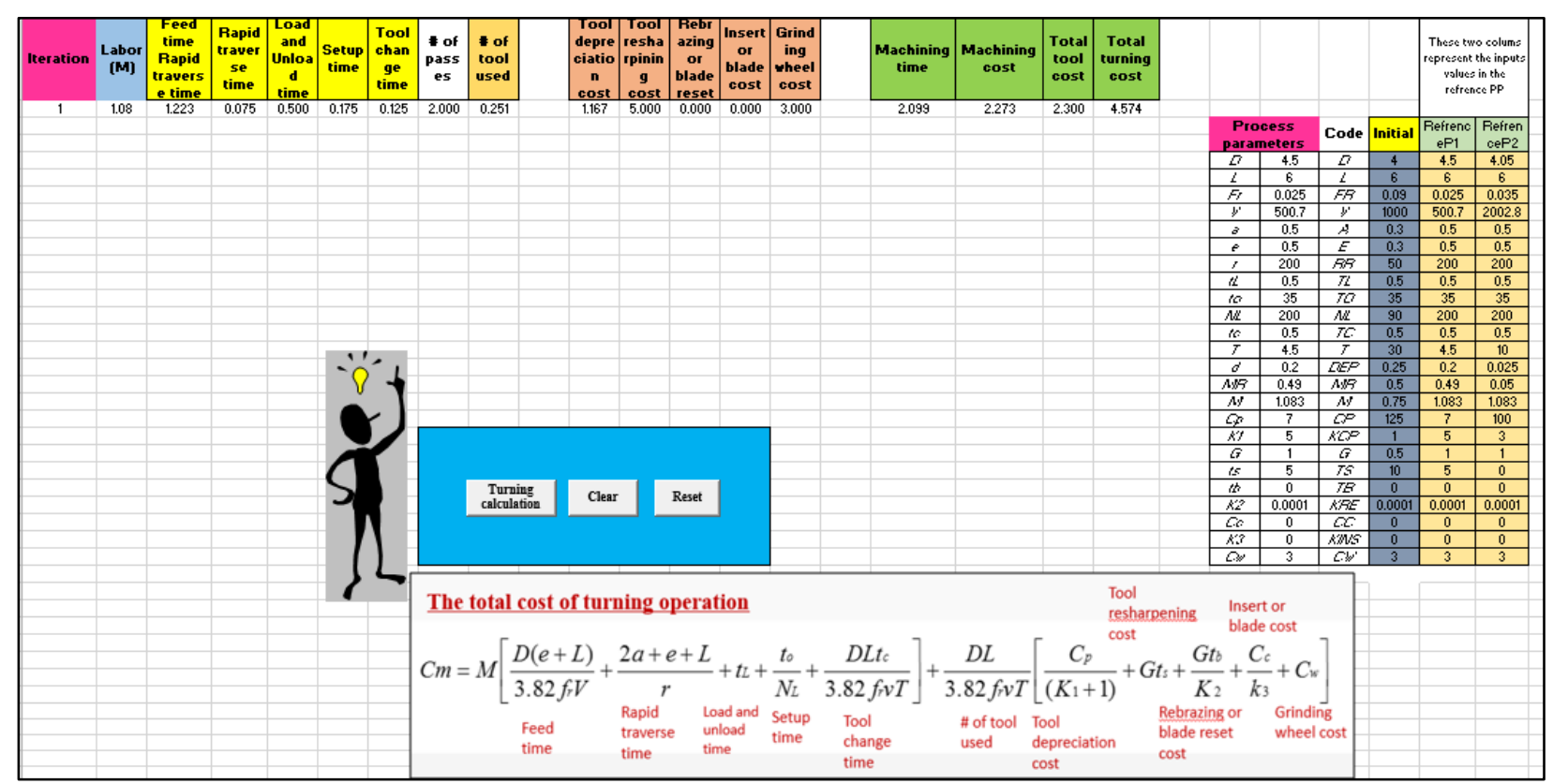

Figure 3.1. The interface structure of the PPAC software interface

Figure 3, user can click on turning calculation to let the PPAC start the calculations. The PPAC will calculate all the machining time elements, tool cost elements from these inputs. From these calculated elements, the desired outputs; machining time, machining cost, total tool cost, total machining cost, and list on the upper row of the interface. These outputs are for one combination of machining process in one from process plans for one DFMT. For other combinations, the input and the calculation procedure are the same. For every combination, the results and the machine tools used will be transferred to the PPAC results interface and arranged in one page. From these combination results, PPAC will select the combination for this machining process with a lower 
cost and time for machining. The steps should be followed for all the suggested machining process for a specific process plan. Finally, the outputs of this process plan will be gathered together and formatted in a table with its total machining cost, total tool cost, total machining time, and total production rate as shown in the Table 1 below. The above-mentioned technique will be used to evaluate all the suggested process plans for specific DFMT. The output of all process plans will be compared and the most viable one between them will be selected.

The verification has been executed in this work on the equations of the PPAC software, represented by the machining equations 1 to 6 in Section 3.2.5.3 of the dissertation. Every equation was tested and evaluated manually by checking every element in the equation and finding the final results from the equation and comparing it with the standard outputs. The results of this validation were perfectly compatible with the standard values.

\subsubsection{Economics of Machining and Costing}

Specific equations have been coded inside PPAC for each machining process. By each equation, the total cost and time of machining can be obtained by calculating the sum of cost and time of machining for each pass. The total cost of machining can be divided into two groups:

1. Machine cost

2. Tool reconditioning cost

The individual time elements, which are involved in finding the total machining time, which is, further used in machine cost are as follows:

1. Feed time

2. Rapid traverse time

3. Load and unload time

4. Setup time

5. Tool change time

The elements that are considered in finding the tool reconditioning costs are as follows:

1. Tool depreciation cost

2. Tool resharpening cost

3. Rebrazing or blade reset cost

4. Insert or blade cost 
5. Grinding wheel cost

The following, general equations give the total machining cost for turning, milling and drilling processes [89]. These equations are developed for different process and used for finding the total machining cost that includes machine and labor cost and the tooling cost, which are adopted in the PPAC spreadsheet.

The total cost of turning process

$C m=M\left[\frac{D(e+L)}{3.82 f_{r} V}+\frac{2 a+e+L}{r}+t_{L}+\frac{t_{o}}{N_{L}}+\frac{D L t_{c}}{3.82 f_{r} v T}\right]+\frac{D L t_{c}}{3.82 f_{r} v T}\left[\frac{C_{p}}{\left(K_{1}+1\right)}+G t_{s}+\frac{G t_{b}}{K_{2}}+\frac{C_{c}}{K_{3}}+C_{w}\right]$

\section{The total cost of facing process}

$$
C m=M\left[\frac{D(e+(D / 2))}{3.82 f_{r} V}+\frac{2 a+e+D}{r}+t_{L}+\frac{t_{o}}{N_{L}}+\frac{D^{2} L t_{c}}{7.64 f_{r} v T}\right]+\frac{D^{2} L t_{c}}{7.64 f_{r} v T}\left[\frac{C_{p}}{\left(K_{1}+1\right)}+G t_{s}+\frac{G t_{b}}{K_{2}}+\frac{C_{c}}{K_{3}}+C_{w}\right]
$$

Equation (2)

\section{Total cost of milling and end milling process}

$$
C m=M\left[\frac{D(e+L)}{3.82 Z f_{t} V}+\frac{2 a+e+L}{r}+t_{L}+\frac{t_{o}}{N_{L}}+\frac{L t_{c}}{Z T_{t}}\right]+\frac{L}{Z T_{t}}\left[\frac{C_{p}}{\left(K_{1}+1\right)}+G t_{s}+\frac{G t_{b}}{K_{2}}+\frac{Z C_{c}}{K_{3}}+C_{w}\right]
$$

Equation (3)

\section{Total cost of cylindrical grinding process}

$C m=M\left[\frac{L}{f t}+\frac{2 a+e+L}{r}+t_{L}+\frac{t_{o}}{N_{L}}+\frac{L t_{c}}{f t T}\right]+\frac{L}{T}\left[\frac{C_{p}}{\left(K_{1}+1\right)}+G t_{s}+\frac{G t_{b}}{K_{2}}+\frac{Z C_{c}}{K_{3}}+C_{w}\right]$

Equation (4)

\section{Total cost of surface grinding process}

$$
C m=M\left[\frac{M R}{f t}+\frac{2 a+e+D}{r}+t_{L}+\frac{t_{o}}{N_{L}}+\frac{D t_{c}}{f t T}\right]+\frac{M R}{T}\left[\frac{C_{p}}{\left(K_{1}+1\right)}+G t_{s}+\frac{G t_{b}}{K_{2}}+\frac{Z C_{c}}{K_{3}}+C_{w}\right]
$$

\section{Total cost o drilling, tapping, and reaming process}




$$
C m=M\left[\frac{D(e+L)}{3.82 f_{r} V}+\frac{2 a+e+L}{r}+t_{L}+\frac{t_{o}}{N_{L}}+\frac{L t_{c}}{T_{t}}\right]+\frac{L}{T_{t}}\left[\frac{C_{p}}{\left(K_{1}+1\right)}+G t_{s}\right]
$$

Equation (6)

\subsection{Systematic Algorithm}

The work's preliminary process plan (PPP) is represented in the first three sections of the algorithm (DP, MSP, and MSDB). For this research, tool-related data is fed into these sections. Concurrently, the part's quantitative and qualitative design characteristics (such as the part's shape and features) are specified in the DP section, to determine which machining processes are most suitable. Each machining parameters then, needs to be checked in the MSP section of the algorithm to decide which machine elements systems and machining parameters will be selected with this process. The same work is repeated on all the candidate machining processes to generate the PPP in the following section, then the DFMO of the PPP is calculated to determine whether the PPP should be performed, or not. If the PPP is not accepted (according to its DFMO), it is time to perform the first DFMT. After that, the modified information is transferred to the relevant sections (DP, MSP, MSDB) to create the alternative PP and its DFMO. This step is then repeated on all the DFMT until user satisfaction is obtained. A flow chart depicting the algorithm is provided in Figure 3.2. 


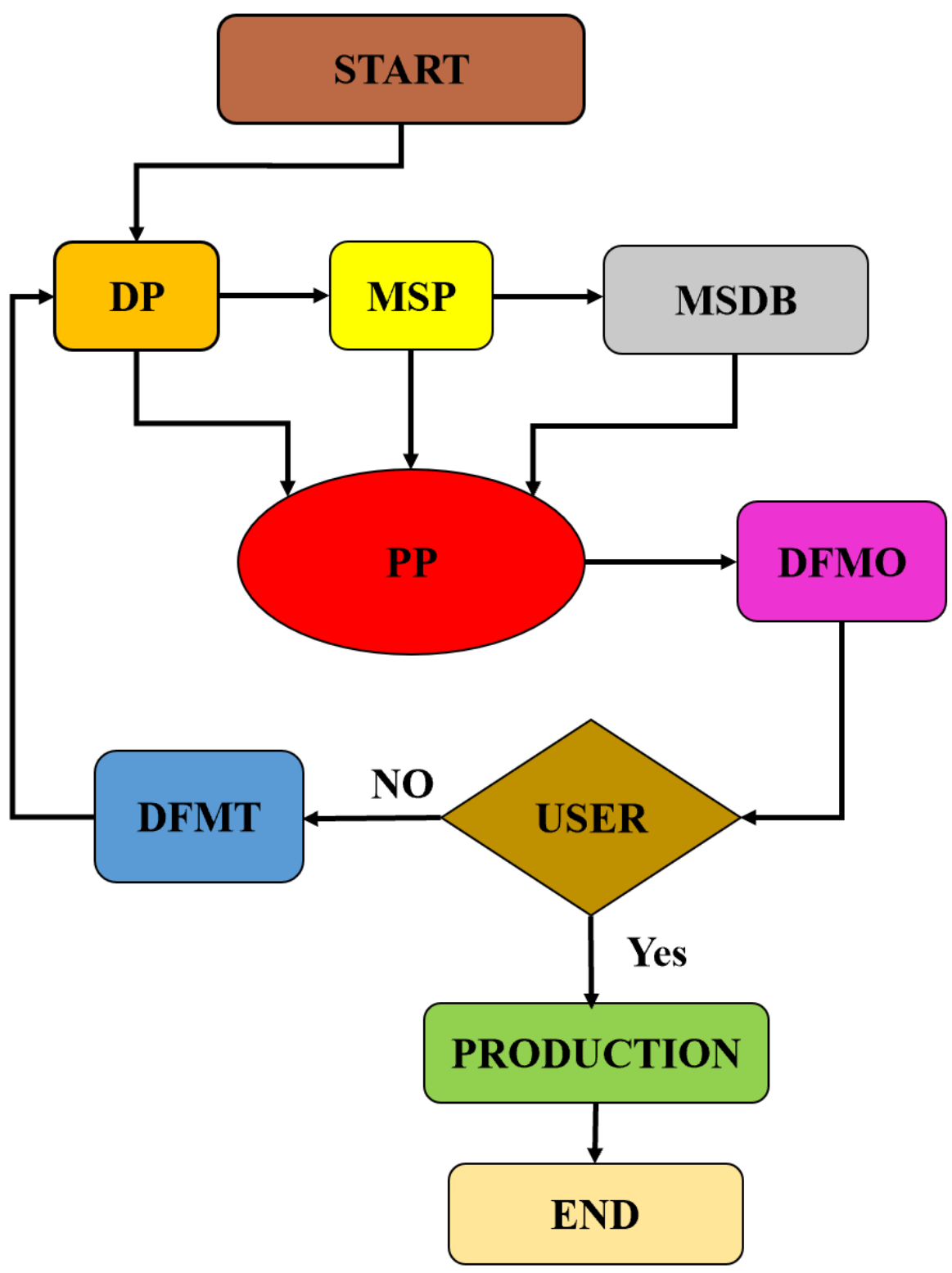

Figure 3.2. Systematic algorithm structure

The scheme of the suggested systematic algorithm is shown in Figure 3.2. The algorithm works using the following steps:

1. The algorithm will start in the three sections (DP, MSP, and MSDB) to create a preliminary process plan (PPP). In the DP section, the quantitative and qualitative design parameters (dimensions, density, hardness, shape of raw material and final part, features) of the part are assigned, and the machining process will be specified. 
2. A check will be done on the suitability of every process, and then the machine elements systems (machine tool and cutting tool) will be assigned inside the MSP section.

3. The information will be transferred simultaneously for each machining process to the (MSDB) section for determining the values of MP.

4. This information will be collected together and entered into the PP section to create the PPP.

5. The attributes of the process plan are calculated inside the DFMO section to obtain the cost of manufacturing and the production rate of a PPP, by using the PPAC interface.

6. The decision is made for accepting the PPP (or not) by the user or by facility management.

7. If the decision is to accept the PPP, notification will be sent to the production section to start the manufacturing; otherwise, the sequence of the algorithm will move to the DFMT section.

8. The first DFMT will be applied (changing raw material) when the user is not satisfied with the results of PPP. The procedure of selection alternative process plan is discussed in section 3.2.1.

9. The new DP, MSP, and MSDB are calculated to create the alternative process plan and calculate DFMO, by following the same steps from 1 to 5 , listed above.

10. The same actions should be applied for steps 7 to 9 for the rest the DFMT (modifying geometry, modifying quality, and changing machining process/es) in order, according to significance. The conditions of this significance will be explained in the next chapter.

11. In this way all the DFMT will be applied in sequence and the DP, MSP, and MSDB will be changed with every DFMT, until the user is satisfied with one of the PP and its DFMO.

*Note, if the result of applying the DFMT does not produce convincing results, a combination can be applied between the DFMT to acquire better results.

\subsection{Conclusion}

The work in this chapter discusses the details of the systematic algorithm constructed for this study. The structure of the systematic algorithm was explained in detail, then a schematic drawing of the algorithm was depicted in Figure 3.2. The method for applying this algorithm was also discussed 
in this chapter. Four DFMT were suggested for analysis in the next chapter (modifying the selection of raw material, modifying quality, modifying geometry, modifying the selection of process/es).

The systematic way to move from one DFMT to another was discussed, as well as how new DP can be generated. Then, alternative selection of machine elements systems and machining parameters was explained, and how the combinations between the machine elements systems (machine tool and cutting tool) are applied to generate the alternative PP. After that, the method for obtaining DFMO was explained, which allows a user to make decisions about accepting this PP (or not). To move from one DFMT to another, the same steps will be repeated on the all DFMT in the next chapter. For checking the algorithm and applying all the DFMT, a case study was suggested and performed, which is described in the next chapter.

The steps of performing the systematic algorithm on all the DFMT were specified and arranged by the researcher. These steps were listed and sequenced after heuristic study made by the researcher. Every section in the systematic algorithm has a specific duty as explained in this chapter. For instance, in the DP section, the quantitative and qualitative characteristics design parameter should be described for the PPP, then these DP will be modified after modifying each DFMT. After performing the DFMT, the DP will be updated according to the modifications on the DFMT. In the DFMT section, the suitable and applicable alternative DFMT will be selected whenever the algorithm executing reaches this section.

This systematic algorithm organizes all the work for finding alternative solutions, to reduce the cost and increase the production rate of machining metal parts. After testing the systematic algorithm and evaluating its impact on the manufacturing attributes, the algorithm could be extended to general manufacturing processes, rather than limiting the algorithm use for machining processes. By utilizing the two software platforms, MPSEL and PPAC, the work on this algorithm will be simplified and considerable time will be saved, proven in the next chapter. 


\section{CHAPTER FOUR: METHODOLOGY APPLYING AND RESULTS}

This chapter explores applying and testing the algorithm that was discussed in Chapter three. A case study (moving joint part) was assigned with a preliminary process plan. The systematic algorithm was applied by modifying the four DFMT (modifying the selection of raw material, modifying quality, modifying geometry, and modifying the selection of process/es). The results of applying the systematic algorithm and the work involved are included in this chapter followed by the conclusion.

In order to clarify the steps of the systematic algorithm, Figure 4.1 represents how it works in more detail. This flowchart illustrates how to perform the systematic algorithm. In the first step, the user inputs data (such as workpiece and part dimensions, raw material properties, features, and workpiece and final part shapes), which are represented by DP. Then, the preliminary process plan can develop by transferring the DP information to the MPSEL software, represented by MSP. Each machining process is reviewed in this section to determine related machine elements systems and machining parameters suitability. In the next block, the PPAC software calculates process plan attributes, which are represented by cost of machining and production rate. The above work is then related to the process planner and manufacturer. If the DFMO remains unsatisfactory, the first DFMT is applied - thereby modifying the DP. The designer executes this work, and alternative process plans can be generated through the collaboration of the process planner and manufacturer, to determine the DFMO of APP. The same steps are then, repeated on all identified DFMT. Data extracted from modified DFMT is aggregated and reviewed to evaluate which PP is most acceptable. These results are then, listed and presented to the customers in to obtain their approval, which allows manufacturing of the preferred process plan to proceed. 


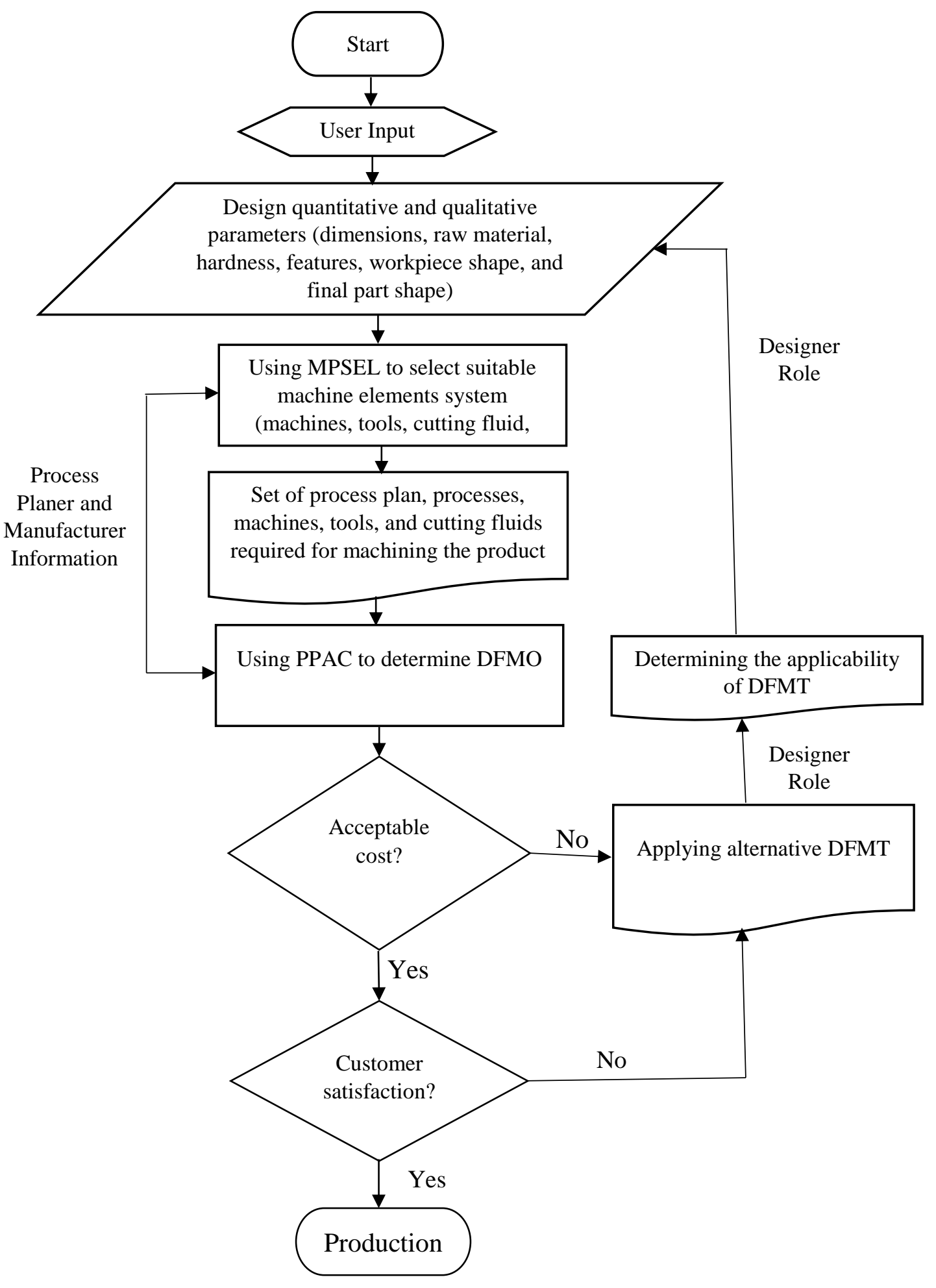

Figure 4.1. Methodology diagram 


\subsection{Using the Systematic Algorithm to perform PPP}

A case study was made to analyze the DFMT effectiveness on cost reduction and productivity inside the algorithm. The base design of the part to be considered in this chapter is shown in Figure 4.1 (a) and (b) below.

\subsubsection{Description of Quantitative and Qualitative Characteristics of DP}

In this section to perform and evaluate the PPP, the quantitative and qualitative characteristics of design parameters are specified in the DP section, shown next.

\subsubsection{Quantitative Characteristics of DP}

The quantitative characteristics of DP, as represented by the workpiece dimensions and shape, as well as the final part dimension, shape, and features are explained below.

\section{A. Workpiece Shape and Dimensions}

The bar dimensions of the workpiece are explained in Figure 4.2 below
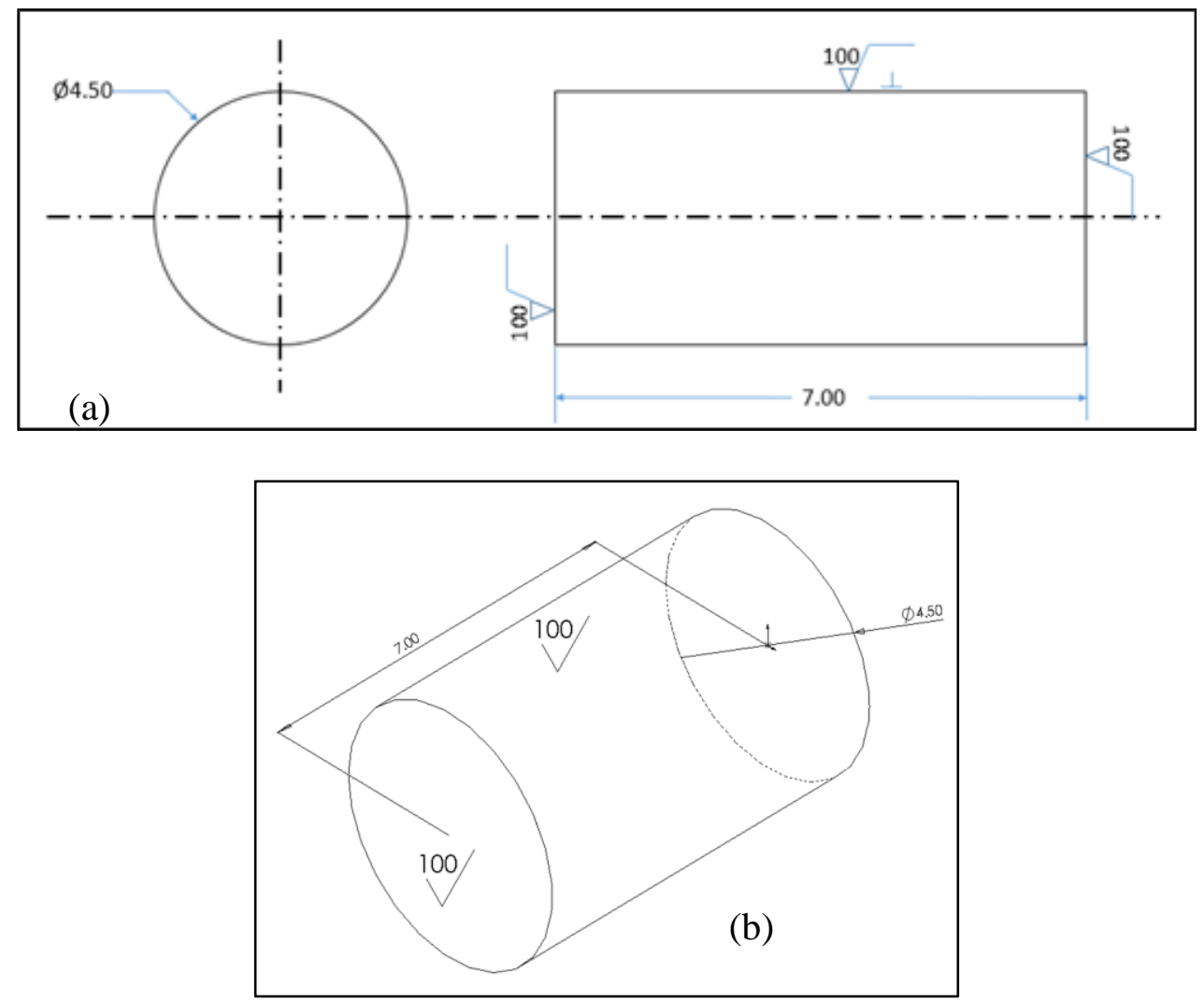

Figure 4.2. (a) Dimensions of the workpiece and (b) 3D drawing of the workpiece 
The workpiece is a cylinder with a diameter of 4.5 inches and a length of 7 inches with a surface roughness of 100 micro inches.

\section{B. Final Part Shape, Dimensions, and Features}

The final product has the following required features and dimensions that are shown in Figure 4.2 (a) and (b) below, the following part characteristic was used to specify the Design Parameters (DP) of the part and select suitable machining processes:

1. Five holes on the cylindrical surfaces as shown in the drawing. A hole diameter is 0.30 inch and the length is 0.5 inch. All holes have the same dimensions. The holes are threaded (12 TPI), and the inside surface finish of the holes should be $90 \mu \mathrm{in}$. Tolerances can be held to 0.05 inch.

2. A T-slot on the cylindrical surface of the cylinder. The slot width is 0.75 inch and depth is 0.3 inch. The slot neck has a depth of 0.25 inch and width of 0.3 inch. The slot length is 2.5 inch as shown in the drawing. The surface finish on the slot surfaces can be $90 \mu$ in and tolerances can be maintained at 0.05 inch.

3. The cylindrical surface must have a final diameter of 4 inches and a length of 6 inches. The surface finish on the cylindrical surface and one of the flat surfaces, as shown in the drawing, must be maintained at 10 micro inches. The tolerances on the length and diameter are 0.005 inch.

4. The two sides of the cylinder have a different surface finish and tolerance. Side 1 has a surface finish of $90 \mu$ in and a tolerance of 0.05 ; side 2 has a surface finish of $10 \mu$ in and a tolerance of 0.005 . 

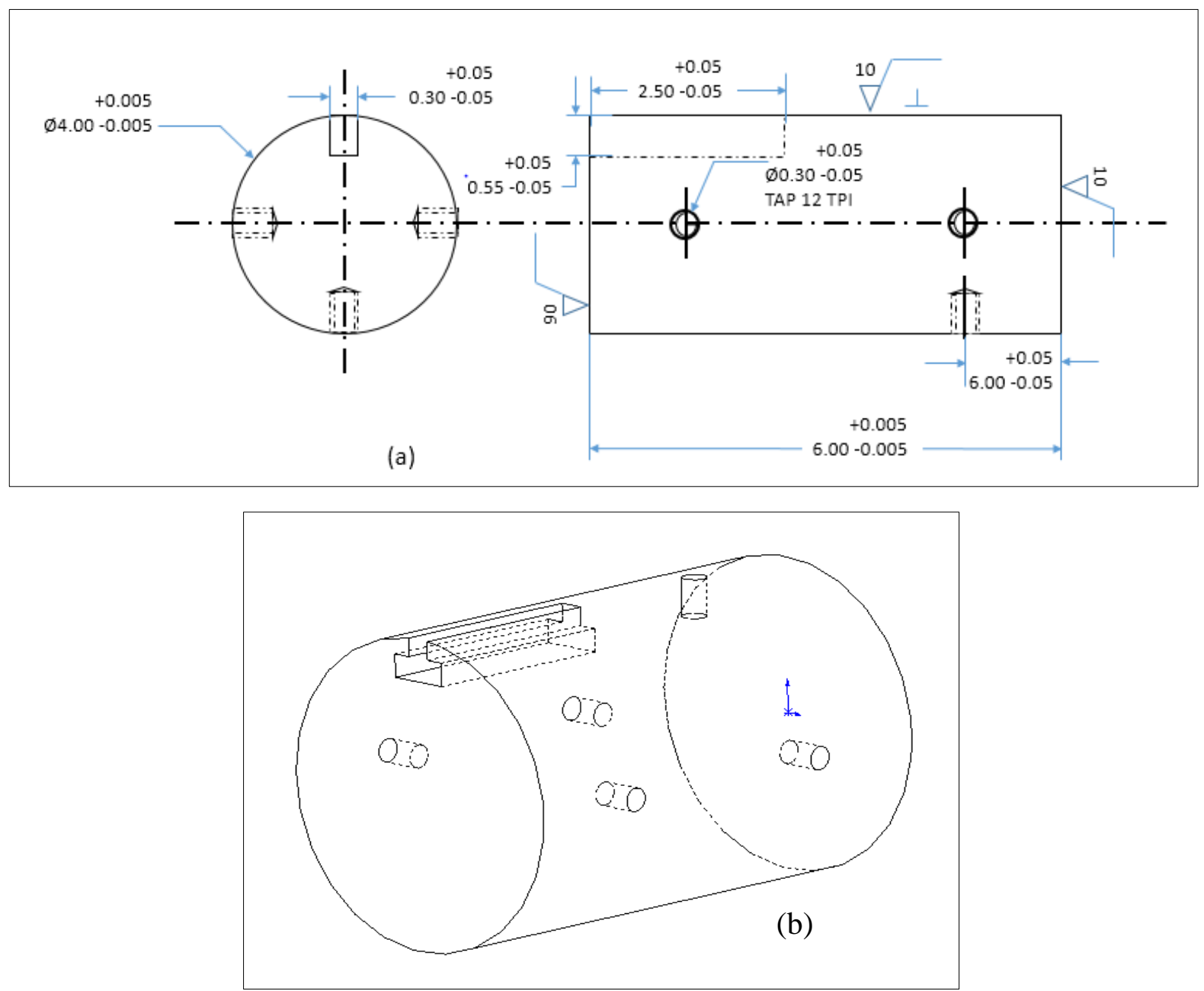

Figure 4.3. (a) Dimensions of the final part, and (b) 3D drawing of the final part

\subsubsection{Qualitative Characteristics of DP}

The first suggested material, which was used primarily to produce the above part, was stainless steel $316 \mathrm{~L}$ with the following details, this information is used in the DP section of the systematic algorithm:

Workpiece material type

Workpiece material

Heat treatment condition

Melting Temperature

Hardness (BHN)

Initial length
$=$ Ferrous

$=316 \mathrm{~L}$ Austenitic Stainless-steel alloy

$=$ Hot rolled / Annealed

$=2510 \mathrm{~F}^{\mathrm{o}}-2550 \mathrm{~F}^{\mathrm{o}}$

$=149$

$=7^{\prime \prime}$ 


$\begin{array}{ll}\text { Initial diameter } & =4.5 ” \\ \text { Lot size } & =200 \\ \text { Density of stainless steel } & =0.29 \mathrm{lbs} / \mathrm{in}^{3} \\ \text { Material cost of stainless steel } & =\$ 4.56 / \mathrm{lb} \\ \text { Bar stock volume } & =3.14 / 4 \times 4.5^{2} \times 7 \\ & =111.33 \mathrm{in}^{3} \\ \text { Total mass for stainless steel alloy } & =111.33 \mathrm{in}^{3} \times 0.284 \mathrm{lbs} / \mathrm{in} 3 \\ & =31.62 \mathrm{lbs}^{\circ}\end{array}$

Total material cost for stainless steel alloy $=31.62 \mathrm{lbs} \times \$ 4.56 / \mathrm{lb}$ $=\$ 144.21$

The material density and cost information is obtained from [90].

\subsubsection{Applying the Algorithm on DP, MSP, and MSDB Sections}

After obtaining all this information from the designer about the workpiece and the finished part, the raw material has been selected according to the functionality of the part. This information has been transferred to the manufacturer and process planner to create the preliminary process plan (PPP) to obtain the cost of manufacturing the product.

The first three sections (DP, MSP, and MSDB) of the systematic algorithm are utilized in this work, the MPSEL program was run, and the selected machining parameters and conditions of the machines, cutting tool, and cutting fluid were obtained. From the outputs of MPSEL, the preliminary process plan has been created and named PPP. Then, the PPAC software has been used to calculate the machining time, machining cost, and tool cost for each process based on the type of work material used and the dimensions of the part.

\subsubsection{Product Functionality}

The product depicted in the drawing above is a part of a Floating Joint. The Floating Joint assembly is used in mechanical applications for absorbing any "off-centering" or "loss of parallel accuracy" between the cylinder and the driven body. Both centering and a high level of machining accuracy are unnecessary. The installation time is dramatically reduced, and it is compact and suitable for high tensile stresses. The floating joint assembly is an alignment coupler that protects against 
cylinder misalignment. Its compact design allows high loading and aligns the connecting product based on deflected loads. The floating joint assembly can be anchored in many ways to a substructure and the type of product depicted in the drawing is anchored using a total of five screw type threaded fasteners.

\subsubsection{Creating Preliminary Process Plan (PPP) in the PP section}

All the information above and the output in section 4.1.1 data have been arranged in Table 4.1. Table 4.1 represents some of the inputs and the output of the MPSEL program. Multiple outputs have been obtained from the MPSEL program about the selected machines and tools. The NC machine has been chosen above all of the selected machines allowed by MPSEL, because it provided the minimum cost of machining. It is related to higher cutting speed, feed rate, and depth of cut. After studying the various results from PPAC, it was found that the feed rate has the maximum impact among the machining parameters on cost. After obtaining all of this information from MPSEL, the speed and feed have been calculated from Speed_Feed_Selection spreadsheet (Appendix C). PPAC was used to calculate the total cost of one of the parts in the lot that has size 200 workpieces. The various values have been calculated by PPAC are: total machining cost, total machining time, total tool cost, and total process cost for each process. All this information is shown in Table 4.2 below. 
Table 4.1. Machining processes and outputs of the MPSEL for machining stainless steel on PPP

\begin{tabular}{|c|c|c|c|c|c|c|}
\hline $\begin{array}{l}\text { Process } \\
\text { Index }\end{array}$ & Process Name & $\begin{array}{l}\text { Type } \\
\text { of Cut }\end{array}$ & $\begin{array}{c}\text { Surface } \\
\text { Finish } \\
(\mu \mathrm{in})\end{array}$ & Machine & Tool & $\begin{array}{l}\text { Required } \\
\text { Tolerance }\end{array}$ \\
\hline 1 & $\begin{array}{l}\text { Face milling side } \\
1\end{array}$ & Rough & 90 & nc_mill_mc & hi_sp_steel (M 42) & \pm 0.05 \\
\hline 2 & $\begin{array}{c}\text { Face milling side } \\
2\end{array}$ & Finish & 90 & nc_mill_mc & hi_sp_steel (M 42) & \pm 0.005 \\
\hline 3 & Turning & Rough & 90 & nc_lathe_mc & hi_sp_steel (M 42) & \pm 0.05 \\
\hline 4 & $\begin{array}{l}\text { Grinding of } \\
\text { cylindrical } \\
\text { surface }\end{array}$ & Finish & 10 & cyl_gr_mc & Grinding wheel & \pm 0.005 \\
\hline 5 & $\begin{array}{l}\text { Surface Grinding } \\
\text { of flat side }\end{array}$ & Finish & 10 & sur_gr_mc & Grinding wheel & \pm 0.005 \\
\hline $6,7,8$ & $\begin{array}{l}\text { Drilling } 5 \text { holes on } \\
\text { cylindrical } \\
\text { surface }\end{array}$ & Rough & 90 & ver_dr_pr & $\begin{array}{c}\text { hi_sp_steel (TiN } \\
\text { coated) }\end{array}$ & \pm 0.05 \\
\hline $9,10,11$ & $\begin{array}{l}\text { Tapping } 5 \text { holes } \\
\text { on cylindrical } \\
\text { surface }\end{array}$ & Rough & 90 & ver_dr_pr & $\begin{array}{c}\text { hi_sp_steel (TiN } \\
\text { coated) }\end{array}$ & \pm 0.05 \\
\hline 12 & End milling & rough & 90 & nc_mill_mc & $\begin{array}{l}\text { mp_hss_t15_m42 } \\
\text { grade } \\
\text { (hss_m2_m3_m7) }\end{array}$ & \pm 0.05 \\
\hline 13 & T-slot & finish & 90 & nc_mill_mc & $\begin{array}{l}\text { hi_sp_steel (M } \\
\text { grade) Slot mill }\end{array}$ & \pm 0.05 \\
\hline
\end{tabular}

\subsubsection{Notes used while using PPAC}

In the case of drilling operation, the re-orientation time to align the workpiece to drill the next hole can be taken as 0.12 min.

- The diameter of a grinding wheel used for tool re-sharpening is 5 inches.

- All HSS tools are solid tools.

- All tapping operations are to be done in a single pass.

- The drilling of axial holes or the facing operation on a lathe can have the same tool approach parameters as for the turning operation.

- The grinding attachment is not possible on any of the lathes.

- In the case of using tool inserts, discard the tool after using all the edges in the insert (no re-sharpening needed). 
- When doing one or more operations on the same machine without changing the orientation of the part, the job setup time will be incurred only for the first operation, and subsequent operations will have a job setup time of zero.

\subsubsection{Applying the Algorithm on the DFMO section}

HSS tools were used for most of the machining processes $(1,2,3,6,7,8,9,10,11,12$, and 13), as shown in Table 4.1. The NC milling and turning machine have been used because they have been selected by MPSEL. A vertical drilling press was used for drilling and tapping because it has the maximum feed rate appropriate to the specified drilling machines for this experiment. To obtain the $10 \mu$ in on the finished cylindrical and flat surface of the cylinder, cylindrical and surface grinding have been used according to the machines selected by MPSEL to machine 316L stainless steel. Finally, the speed, feed, and depth of cut have been selected from the Feed_Speed_Selection spreadsheet, and a sample from it is also shown (Appendix C). After applying PPAC and collecting the results, Table 3.2 was created. 
Table 4.2. Inputs and outputs of PPAC for machining stainless steel 316L by using the HSS tool on PPP

\begin{tabular}{|c|c|c|c|c|c|c|c|c|c|c|c|c|}
\hline $\begin{array}{l}\text { Process } \\
\text { Index }\end{array}$ & $\begin{array}{c}\text { Depth } \\
\text { of } \\
\text { Cut }\end{array}$ & $\begin{array}{l}\text { Diameter } \\
\text { of Cutter } \\
\text { or WP } \\
\text { Diameter }\end{array}$ & $\begin{array}{l}\text { Cutting } \\
\text { Speed }\end{array}$ & $\begin{array}{l}\text { Feed } \\
\text { Rate }\end{array}$ & $\begin{array}{c}\text { Max } \\
\text { Material } \\
\text { that can } \\
\text { be } \\
\text { Removed }\end{array}$ & $\begin{array}{c}\text { Number } \\
\text { of } \\
\text { Passes }\end{array}$ & $\begin{array}{c}\text { Depth } \\
\text { of } \\
\text { Cut } \\
\text { for } \\
\text { the } \\
\text { Final } \\
\text { Pass } \\
\end{array}$ & Final D or $\mathbf{L}$ & $\begin{array}{c}\text { Total } \\
\text { Machining } \\
\text { Time }\end{array}$ & $\begin{array}{c}\text { Total } \\
\text { Machining } \\
\text { Cost }\end{array}$ & $\begin{array}{l}\text { Total } \\
\text { Tool } \\
\text { Cost }\end{array}$ & $\begin{array}{c}\text { Total } \\
\text { Cost } \\
\text { for } \\
\text { One } \\
\text { process }\end{array}$ \\
\hline & (in) & & (sfpm) & (ipr/ipt) & (in) & & (in) & (in) & $\min$ & $\$$ & $\$$ & $(\$)$ \\
\hline 1 & 0.2 & 4.5 & $3,298.67$ & 0.008 & 0.9 & 5 & 0.1 & $\mathrm{~L}=6.1$ & 2.43 & 2.64 & 0.82 & 3.46 \\
\hline 2 & 0.09 & 4.5 & $3,298.67$ & 0.008 & 0.09 & 1 & 0.09 & $\mathrm{~L}=6.01$ & 1.13 & 2.30 & 0.16 & 2.46 \\
\hline 3 & 0.2 & 0 & 500.69 & 0.025 & 0.49 & 2 & 0.045 & 4.01 & 2.05 & 2.22 & 2.22 & 4.44 \\
\hline 4 & 0.005 & 8 & $2,099.63$ & 0.02 & 0.01 & 1 & 0.005 & $\mathrm{D}=4$ & 2.60 & 2.38 & 0.35 & 2.73 \\
\hline 5 & 0.01 & 8 & $3,500.00$ & 2.5 & 0.01 & 1 & 0.01 & $\mathrm{~L}=6$ & 6.63 & 5.08 & 1.02 & 6.1 \\
\hline $6,7,8$ & & 0.29 & 102.88 & 0.004 & 0.5 & 5 holes & 0 & 0.29 & 2.88 & 1.42 & 4.02 & 5.19 \\
\hline $9,10,11$ & & 0.3 & 50 & 0.004 & 0.5 & 5 holes & 0 & 0.3 & 1.6 & 1.53 & 5.26 & 6.11 \\
\hline 12 & 0.2 & 0.3 & 219.91 & 0.008 & 0.55 & 3 & 0.1 & $\mathrm{~L}$ of cut $=2.5$ & 2.41 & 2.61 & 1.13 & 3.74 \\
\hline 13 & 0.2 & 0.75 & 549.78 & 0.008 & 0.3 & 2 & 0.1 & $\mathrm{~L}$ of cut $=2.5$ & 2.29 & 2.48 & 0.76 & 3.23 \\
\hline
\end{tabular}

The results in the last four columns of Table 4.2 represent the outputs of the PPAC for every machining process. The machining cost for one part includes total tool cost and total machining cost; however, the total machining time has been used to calculate the machining cost by multiplying it with the labor rate. Similarly, the tool recondition cost was used to determine the total tool cost by multiplying it with the number of tools used to perform one process. The summation of these two costs has been used to calculate the total cost for machining the part as explained by equations $1,2,3$, and 4 in Chapter three. 
According to the output of the MPSEL, the surface finish is $10 \mu$ in on one face from the flat surfaces of the part, and this surface finish can be obtained only by using the surface grinding process. The values for each of the last four columns in Table 4.2 have been added and these added values were used to create the summarized Table 4.3 below.

Table 4.3. The summarized results of machining stainless steel PPP

\begin{tabular}{|l|c|}
\hline Total Machining Time (min) & 24.02 \\
\hline Total Machining Cost (\$) & 22.07 \\
\hline Total Tool Cost (\$) & 15.74 \\
\hline Production rate per hour & 2.499 \\
\hline Total Cost of Machining One Part (\$) & 37.81 \\
\hline Material Cost (\$) & 144.21 \\
\hline Total Cost for Producing One Part $\mathbf{( \$ )}$ & 182.03 \\
\hline
\end{tabular}

These summarized results are represented by cost of production (\$182.03) and hourly production rate (2.5) for producing one part from 316L stainless steel; the results were not satisfactory due to the high cost, and an alternative process plan was suggested to reduce this high production cost and increase the production rate.

Some of the used data has been taken from the dimensions of the part, such as the length of the workpiece. Other data has been taken from prepared tables, including specific information relating to cutting and machine tools, as shown in Appendix A (1, 2, 3, 4, 5, 6, 7) and Appendix B. In Appendix A, the tables (1-7) display information about cutting tools according to the machining processes, and include information about tool cost, tool life, and other tool factors. In Appendix B, information about machining has been collected for the different types of machines for different processes. Appendix B includes information on paramaters, such as the rapid traverse rate, setup time, load and unload time, which have been used in the input interface of PPAC. Feed rate, cutting speed, and depth of cut, meanwhile, have been calculated from a prepared spreadsheet called Speed_Feed_Selection, shown in Appendix C. 


\subsubsection{Manufacturing Facility Management's (User's) decision}

The summarized Table 4.3 was shown to the manufacturing facility management. After discussing the final results of PPP, the PPP was rejected by the facility management. The designer, manufacturer, and process planner were notified in order to find an alternative solution. The next step was to apply the Systematic Algorithm on the modified DFMT.

\subsection{Applying the Systematic Algorithm on the DFMT Section}

With the unsatisfied results obtained in PPP, the decision was taken to apply the systematic algorithm on the alternative DFMT. This algorithm is performed in four levels, according to the number of DFMT. DFMT have been applied in the following sequence:

1. Modifying the selection of raw material

2. Modifying quality

3. Modifying geometry

4. Modifying the selection of process/es

This sequence has been arranged according to DFMT significance DFMO and applicability, which has been assigned by the researcher according to the heuristic work performed by the researcher. It was concluded that this sequence should be followed when applying DFMT within the systematic algorithm. For every DFMT, two experiments were performed. It is not necessary that all the DFMTs should be applied, because the algorithm will stop as manufacturing begins, whenever the user (facility management) is satisfied with the results.

\subsubsection{Applying DFMT 1.1}

The first DFMT is applied to reduce cost of production. This approach is completely dependent on the designer and manufacturer. This attempt included applying the first DFMT on a part to reduce the cost of production. The selected DFMT was implemented by modifying the raw material of the workpiece. Keeping the functionality of the part is necessary when the work material is one of the implemented DFMTs. After reconsidering the design and functionality of the part, it was concluded that keeping the same geometry of the part using the suggested raw material would retain the functionality of the part. This is 
dependent on whether the following material part properties remain in the ranges shown below.

Young Modulus (E) between 80 Gpa to $250 \mathrm{Gpa}$

Strength / Elastic limit ( $\sigma$ f) between $500(\mathrm{Mpa})$ to 950(Mpa)

Production energy per cubic meter between $500000\left(\mathrm{MJ} / \mathrm{m}^{3}\right)$ to $700000\left(\mathrm{MJ} / \mathrm{m}^{3}\right)$.

The selection of the alternative raw materials (instead of the stainless steel 316L) must be within the range of the above three material properties. To select an alternative material, a procedure was developed in the systematic algorithm. This procedure was performed by generating data tables identifying the values of material properties for several types of ferrous and nonferrous alloys (these tables are represented in Appendix D). The material properties have been selected from different domains, including environmental, mechanical, electrical, and manufacturing, as shown in Appendix D2 [78], [79]. After viewing the tables in Appendix D1, it has been concluded that two alternative raw materials can be used instead of stainless steel 316L: aluminum alloy multipurpose 6061 T6 and nickel alloy. Both alloys are inside the property range, keeping the functionality of the part without changing its design. The two materials were assigned to DFMT1 and were named DFMT1.1 and DFMT1.2.

And the material properties range of aluminum alloy (6061 T6) were:

Matt BergenstockYoung Modulus (E) between 78.8 Gpa to 89.5 Gpa.

Strength / Elastic limit ( $\sigma$ f) between $55(\mathrm{Mpa})$ to $718(\mathrm{Mpa})$.

Production (Embodied) per cubic meter between $706122(\mathrm{MJ} / \mathrm{m} 3)$ to $761224(\mathrm{MJ} / \mathrm{m} 3)$.

Therefore, the aluminum alloy could be used as an alternative material for manufacturing the moving joint part because the aluminum alloy material properties ranges fit inside the required ranges to keep the functionality of the moving joint

In the same steps specified in section 4.1, the quantitative and qualitative characteristics of DP will be entered into the DP section of the systematic algorithm. Then, this work will be transferred to the MSP, MSDB sections to generate the alternative process plan in the PP 
section. DFMO of APP will be created to make the decision of accepting the alternative process plan or not by the user; these steps will be repeated on all DFMT until the final decision is obtained. User can do an iterative database search determining materials that pertain to the desired properties.

\subsubsection{DFMT1.1 Using Aluminum Alloy as Raw Material}

The information about the aluminum alloy has been gathered as shown below.

$\begin{array}{ll}\text { Workpiece material type } & =\text { Non-ferrous } \\ \text { Workpiece material } & =\text { Aluminum alloy multipurpose } 6061 \mathrm{~T} 6 \\ \text { Heat treatment condition } & =\text { as cast } \\ \text { Elastic modulus } & =10 \text { ew elastic } \\ \text { Melting Temperature } & =95-97 \\ \text { Hardness (Bhn) } & =7 " \\ \text { Initial length } & =4.5^{\prime \prime} \\ \text { Initial diameter } & =200 \\ \text { Lot size } & =0.098 \mathrm{lbs} / \mathrm{in}^{3} \\ \text { Density of stainless steel } & =\$ 1.81 / \mathrm{lb} \\ \text { Material cost of aluminum } & =3.14 / 4 \times 4.5^{2} \times 7 \\ \text { Bar stock volume } & =111.33 \mathrm{in}^{3} \\ & =111.33 \mathrm{in}^{3} \times 0.0975 \mathrm{lbs} / \mathrm{in}^{3} \\ \text { Total mass for aluminum alloy } & =10.89 \mathrm{lbs} \\ \text { Total material cost for aluminum alloy } & =10.891 \mathrm{bs} \times \$ 1.81 / \mathrm{lb} \\ & =\$ 19.71\end{array}$

The material density and cost information is obtained from [90].

After listing the information about the aluminum alloy multipurpose $6061 \mathrm{~T} 6$, the corresponding data has been transferred to the DP, MSP, and MSDB sections. In the DP section all the above information about the aluminum alloy has been gathered, after that the machining processes were assigned to check them in MSP section, then the outputs of MSP were transferred to MSDB section, this work could be performed by following the steps from 1 to 3 in the systematic algorithm which are mentioned in the end of the previous chapter. Steps 4 and 5 in the sequence algorithm were performed to obtain the PP and DFMO after 
applying DFMT1.1. As explained before, in Suction 3.2.2, for every machine tool selected by MPSEL, all suitable cutting tools were considered to acquire the process with minimum cost. For instance, the first machining process for machining aluminum alloy involved the facing process. Table 4.4 below shows how this iteration was executed. 
Table 4.4.The possible outcomes for facing process 1 after applying DFMT1.1

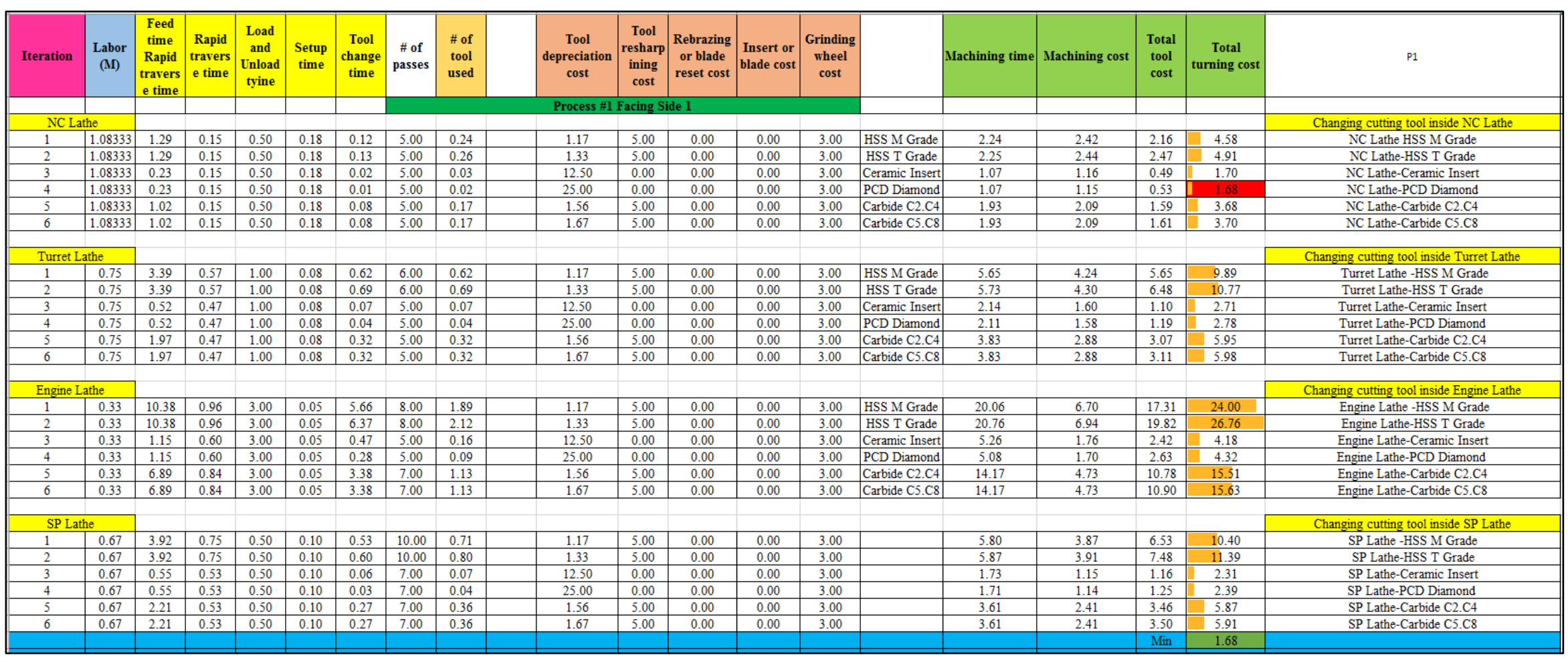

All outputs in Table 4.4 and explained in Figures 4.4 and 4.5 were obtained by using the PPAC interface, saving a significant amount of calculating time. Then, the minimum cost of all outcomes will appear in the last row of the table. This procedure is the same for all machining processes in each PP after applying every DFMT. It is noteworthy, again, that after selecting the machine elements systems by MPSEL, the machining parameters related to these machine elements systems are changed simultaneously with the machine elements systems according to their suitability and these changes are not arbitrary. 


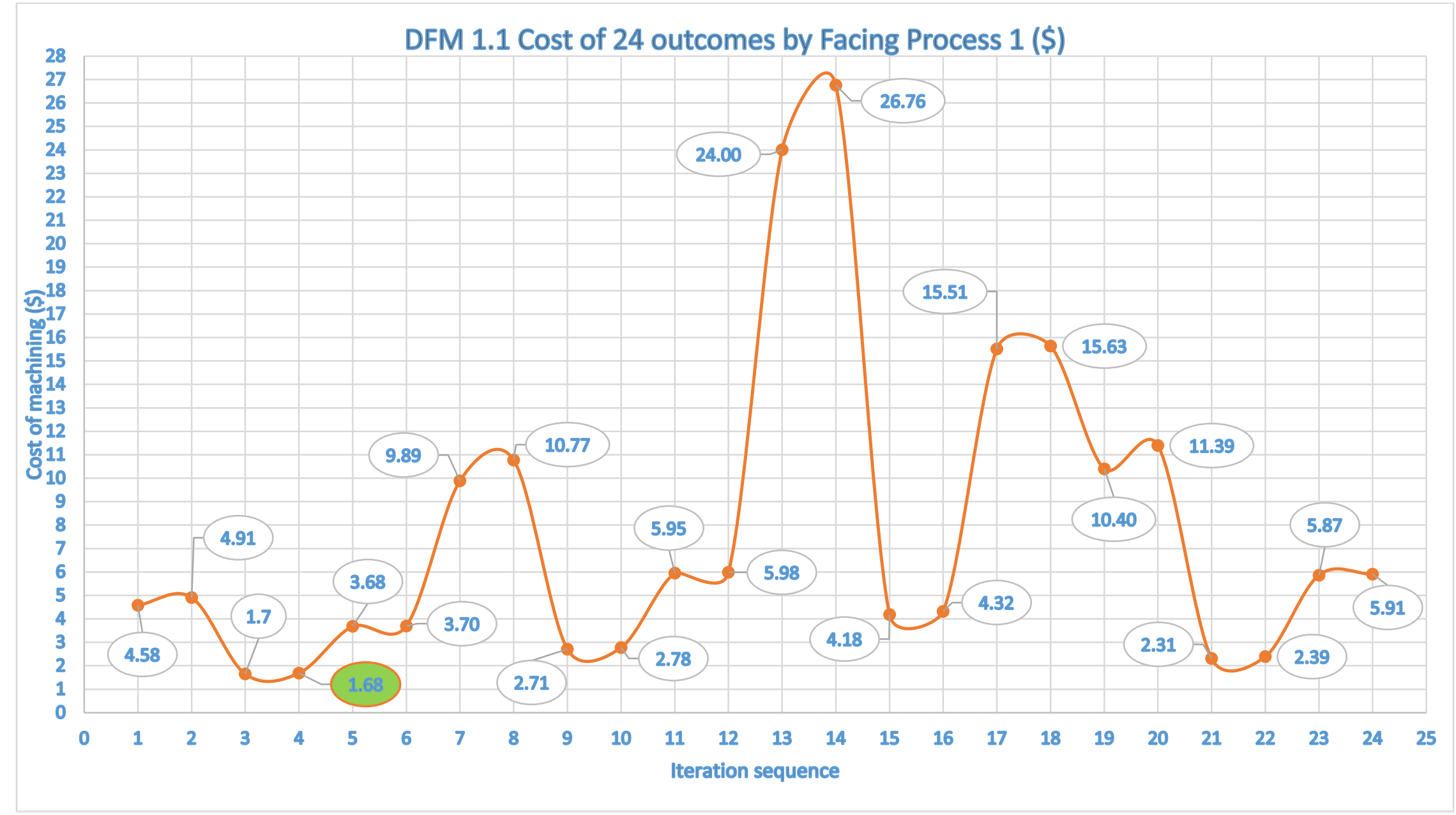

Figure 4.4. The possible outcomes for facing process 1 after applying DFMT1.1 


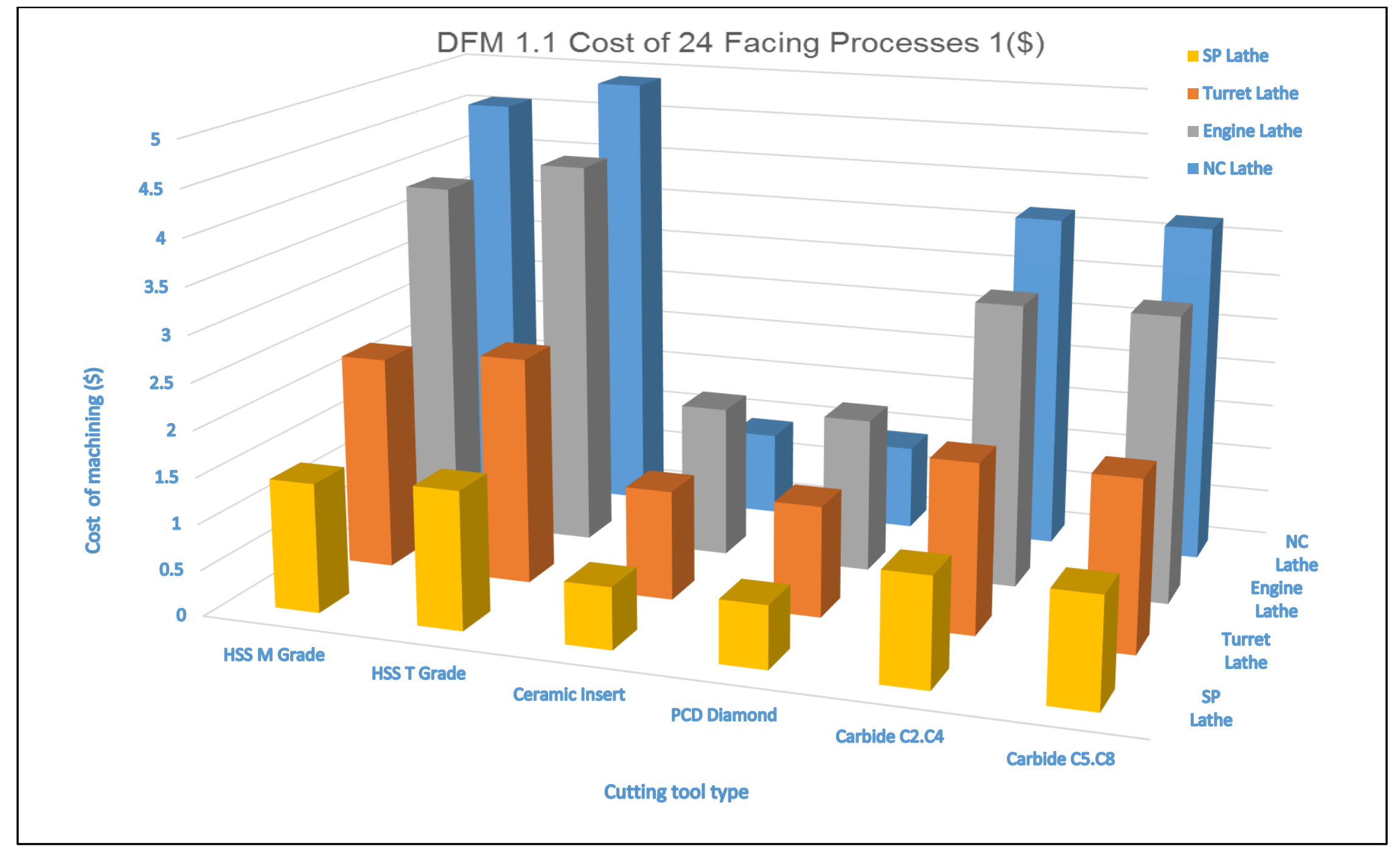

Figure 4.5. The possible outcomes for facing process 1 after applying DFMT1.1 
Figures 4.4 and 4.5 show the results of combinations between the machine elements systems elements (machine tools and cutting tools) for facing process 1 in DFMT1.1. All 24 combinations between the machine tools and cutting tools represented by different lathe machines are shown in these figures. From all of these combinations, the one with lowest cost (\$1.68) was selected; the combination of the selected process was between the NC lathe and PCD cutting tools. The same process of combinations was followed for all machining processes in PP of DFMT1.1 to calculate the DFMO of DFMT1.1. This process was applied on all the DFMT selected in the systematic algorithm.

Thereafter, after applying the steps on all the processes inside the PP of DFMT1.1, the outcomes with the minimum cost for each machining process are arranged together in one table; this table represents the modified PP after applying DFMT1.1. Table 4.5 below shows the improved PP after executing DFMT1.1 with aluminum alloy.

Table 4.5. The better PP after applying the DFMT1.1

\begin{tabular}{|c|c|c|c|c|c|c|c|c|c|}
\hline 吾 & 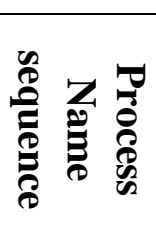 & $\begin{array}{l}\vec{Z} \\
\overline{0} \\
0 \\
\stackrel{0}{0} \\
\Xi\end{array}$ & 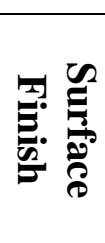 & 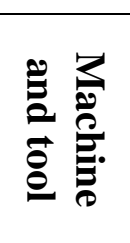 & 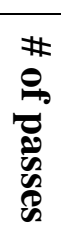 & 逽: & 客: & $\frac{\overrightarrow{0}}{\frac{0}{\vec{\theta}}}$ & 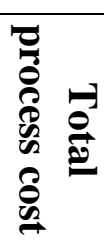 \\
\hline & & & ( $\mu$ in) & & & $(\min )$ & (\$) & (\$) & (\$) \\
\hline 1 & $\begin{array}{l}\text { Facing } \\
\text { side } 1\end{array}$ & Finish & 10 & $\begin{array}{c}\mathrm{NC} \\
\text { Lathe- } \\
\text { PCD }\end{array}$ & 5 & 1.07 & 1.16 & 0.49 & 1.68 \\
\hline 2 & $\begin{array}{c}\text { Facing } \\
\text { side } 2\end{array}$ & Finish & 10 & $\begin{array}{c}\text { SP } \\
\text { Lathe- } \\
\text { PCD }\end{array}$ & 1 & 0.75 & 0.82 & 0.11 & 0.92 \\
\hline 3 & $\begin{array}{c}\text { Turning } \\
1\end{array}$ & Finish & 17 & $\begin{array}{c}\mathrm{NC} \\
\text { Lathe- } \\
\text { PCD }\end{array}$ & 2 & 0.98 & 1.06 & 0.67 & 1.73 \\
\hline 4 & $\begin{array}{c}\text { Turning } \\
2\end{array}$ & Finish & 10 & $\begin{array}{c}\mathrm{NC} \\
\text { Lathe- } \\
\text { PCD }\end{array}$ & 1 & 0.83 & 0.90 & 0.28 & 1.18 \\
\hline
\end{tabular}




\begin{tabular}{|c|c|c|c|c|c|c|c|c|c|}
\hline $5,6,7$ & $\begin{array}{l}\text { Drilling } \\
5 \text { holes }\end{array}$ & Rough & 90 & $\begin{array}{c}\text { Ver Dr } \\
\text { Carbid } \\
\text { e } \\
\text { Solid, } \\
\text { Ver } \\
\text { Dr- } \\
\text { Carbid } \\
\text { e Solid } \\
\text { (C2... } \\
\text { C4), } \\
\text { Ver } \\
\text { Dr- } \\
\text { Carbid } \\
\text { e Solid } \\
\text { (C5... } \\
\text { C7) }\end{array}$ & & 2.46 & 1.64 & 3.54 & 5.19 \\
\hline $8,9,10$ & $\begin{array}{l}\text { Tapping } \\
5 \text { holes }\end{array}$ & Finish & 90 & $\begin{array}{c}\text { SP } \\
\text { Auto } \\
\text { Dr- } \\
\text { HSS T } \\
\text { Grade }\end{array}$ & & 1.51 & 1.01 & 5.10 & 6.11 \\
\hline 11 & $\begin{array}{l}\text { End } \\
\text { milling }\end{array}$ & Rough & 90 & $\begin{array}{c}\mathrm{NC} \\
\text { Mill - } \\
\text { Carbid } \\
\mathrm{e} \\
\text { Insert }\end{array}$ & 3 & 2.30 & 2.49 & 0.30 & 2.78 \\
\hline 12 & T-slot & Finish & 90 & $\begin{array}{c}\mathrm{NC} \\
\text { Mill - } \\
\text { Carbid } \\
\mathrm{e} \\
\text { Insert }\end{array}$ & 2 & 2.23 & 2.42 & 0.24 & 2.65 \\
\hline
\end{tabular}

From Table 4.5, it could be concluded that there are many machining processes that have been modified and eliminated. Two facing processes were used to finish the two surface sides of the cylinder directly, without using surface grinding. Two turning processes were used to get the required surface finish (10 $\mu$ in) on the cylindrical surface of the part by using the PCD tool and without cylindrical grinding. This reduced the machining and production cost and increased the 
production rate. The summarized Table 4.6 was created to understand the change in the cost and production rate after performing DFMT1.1.

Table 4.6. The summarized results of PP for DFMT1.1

\begin{tabular}{|l|c|}
\hline Total Machining Time (min) & 12.13 \\
\hline Total Machining Cost (\$) & 11.49 \\
\hline Total Tool Cost (\$) & 10.72 \\
\hline Production rate per hour & 4.95 \\
\hline Total Cost of Manufacturing One Part (\$) & 22.21 \\
\hline Material Cost (\$) & 19.71 \\
\hline Total Cost for Producing One Part (\$) & 41.95 \\
\hline
\end{tabular}

From the results in Table 4.6, the cost of machining processes to machine one part is $\$ 22.24$, the material cost is $\$ 19.71$, the total cost to produce one part is $\$ 41.95$, and the hourly production rate is 4.95. These cost values appear much lower than machining stainless steel $316 \mathrm{~L}$ in the PPP and higher than the production rate of the PPP. By comparing these values of machining the aluminum alloy 6061 T6 in the PPP, it was found that the cost of machining one part decreased by $41.2 \%$, and the production rate increased by $98 \%$. A significant effectiveness in cost and throughput was obtained by applying DFMT1.1. The next step in the algorithm was performing DFMT1.2 by using the nickel alloy as an alternative raw material.

\subsubsection{DFMT1.2 Using Nickel Alloy as Raw Material}

The preferred properties of nickel alloy were inside the ranges of the alloy properties, which keep the functionality of the part without changing its design. The same steps that were performed in DFMT1.1 were performed in DFMT1.2. After, an enhanced PP was selected. Table 4.7 below explains the final result of an improved PP after utilizing DFMT1.2. 
Table 4.7. The better PP after applying the DFMT1.2

\begin{tabular}{|c|c|c|c|c|c|c|c|c|c|}
\hline 哥 & 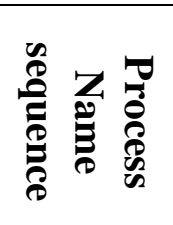 & 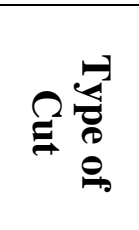 & 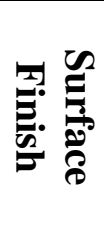 & 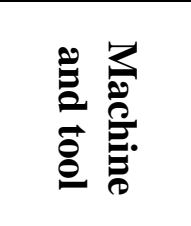 & 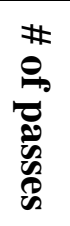 & 逽 & 常 & $\frac{\overrightarrow{0}}{\frac{\partial}{\partial}}$ & 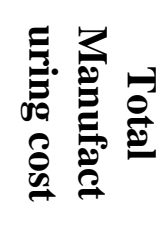 \\
\hline & & & 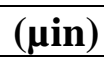 & & & (min) & (\$) & (\$) & (\$) \\
\hline 1 & $\begin{array}{l}\text { Facing } \\
\text { side } 1\end{array}$ & Finish & 10 & $\begin{array}{l}\text { NC Lathe- } \\
\text { PCD }\end{array}$ & 3 & 0.91 & 0.99 & 0.32 & 1.30 \\
\hline 2 & $\begin{array}{l}\text { Facing } \\
\text { side } 2\end{array}$ & Finish & 90 & $\begin{array}{l}\text { NC Lathe- } \\
\text { PCD }\end{array}$ & 3 & 0.91 & 0.99 & 0.32 & 1.30 \\
\hline 3 & Turning & Finish & 10 & $\begin{array}{l}\text { NC Lathe- } \\
\text { PCD }\end{array}$ & 2 & 0.98 & 1.06 & 0.56 & 1.62 \\
\hline $4,5,6$ & $\begin{array}{l}\text { Drilling } \\
5 \text { holes }\end{array}$ & Rough & 90 & $\begin{array}{c}\text { Ver Dr } \\
\text { Carbide } \\
\text { Solid, Ver } \\
\text { Dr- } \\
\text { Carbide } \\
\text { Solid } \\
\text { (C2...C4), } \\
\text { Ver Dr } \\
\text { Carbide } \\
\text { Solid } \\
\text { (C5...C7) }\end{array}$ & & 2.46 & 1.64 & 3.54 & 5.19 \\
\hline $7,8,9$ & $\begin{array}{l}\text { Tapping } \\
5 \text { holes }\end{array}$ & Finish & 90 & $\begin{array}{c}\text { SP Auto } \\
\text { Dr-HSS T } \\
\text { Grade }\end{array}$ & & 1.51 & 1.01 & 5.10 & 6.11 \\
\hline 10 & $\begin{array}{l}\text { End } \\
\text { milling }\end{array}$ & Rough & 90 & $\begin{array}{c}\text { NC Mill- } \\
\text { Carbide } \\
\text { Insert }\end{array}$ & 3 & 2.30 & 2.49 & 0.30 & 2.78 \\
\hline 11 & T-slot & Finish & 90 & $\begin{array}{l}\text { NC Mill- } \\
\text { Carbide } \\
\text { Insert }\end{array}$ & 2 & 2.23 & 2.42 & 0.24 & 2.65 \\
\hline
\end{tabular}

Table 4.7 explains the final results of the modified PP after applying DFMT1.2. It can be observed that the number of processes was reduced by one, because one of the turning processes was eliminated. This reduced the machining and production cost and increased the production rate. 
The summarized Table 4.8 has been created to understand the change in the cost and production rate after performing DFMT1.2.

Table 4.8. The summarized results of PP for DFMT1.2

\begin{tabular}{|l|c|}
\hline Total Machining time (min) & 11.3 \\
\hline Total Machining cost (\$) & 10.58 \\
\hline Total tool cost $\mathbf{( \$ )}$ & 10.38 \\
\hline Total Manufacturing cost $\mathbf{( \$ )}$ & 20.96 \\
\hline Production rate per hour & 5.31 \\
\hline
\end{tabular}

The main goal of this dissertation was to find an improved DFMT with better cost reduction and a better increase in production rate than the PPP.

From the results in Table 4.8, the cost of manufacturing one part is $\$ 20.96$, and the hourly production rate is 5.31. These cost values are lower than the manufacturing cost in applying DFMT1.1 and higher throughput. By comparing the results between DFMT1.1 and DFMT1.2, it was found that the cost of machining one part decreased by $5.76 \%$, and the production rate increased by $7.27 \%$ between the results of the two alternative raw materials using DFMT1.1 and DFMT1.2. As the work with DFMT1 was finished after obtaining the results in Tables 4.6 and 4.8, the work on the algorithm moved to the next sector for applying the second DFMT: DFMT2 (changing quality) with two alternative changes in the next section.

\subsubsection{DFMT2 Modifying Quality}

The algorithm sequence reached the DFMT section, thus the second DFMT was applied by using the original raw material: stainless steel 316L. DFMT2 is considered modifying the quality. This modification can be performed by changing the surface finish and tolerance. Quality means, in this dissertation, the acceptability of the machined part in terms of the part drawing specification. The entire work was seeking to satisfy the part drawing. Modifying the surface finish and tolerance and not arbitrary, but these modifications should be in specific permissible ranges. The maximum and minimum permissible ranges of surface finish were specified by the designer whereby the 
functionality of the part will be maintained on the flat and cylindrical surfaces of the part. The functionality of the part was maintained inside the following ranges:

- Surface finish range must be between 10 to $70 \mu$ in

- $\quad$ and the tolerance must be between \pm 0.02 to \pm 0.005 .

The DFMT2 was applied in two alternative ways, explained in the next two sub-sections.

There are specific ranges of tolerance and surface finish on every feature of the manufacturing part; the functionality of the part is maintained if the features of the part are machined by following these ranges. Combinations have been done between the tolerance and surface finish for the allowable ranges, to obtain a preferred values of surface finish and tolerance with the minimum cost of machining.

\subsubsection{DFMT2.1 First Quality Parameters Modification}

First, combinations were made between the surface finish and tolerance on the flat and cylindrical surfaces of the part. The new surface finish and tolerance values were assigned to machine these two surfaces by using facing and turning processes on machining the stainless steel 316L. The values of surface finish and tolerance that were assigned on both surfaces are $17 \mu$ in and \pm 0.01 , respectively. Then, the DP, MSP, and MSDB were modified according to the modifications made up on DFMT2.1. for example, the DP that should be used inside the MSP on the cylindrical and flat surface will be specified according the new value of surface finish and tolerance. The alternative PP is generated from collecting information from these sections. The final results of this alternative PP and DFMO section were created and shown in Table 4.9 below.

Table 4.9. The better PP after applying the DFMT2.1

\begin{tabular}{|c|c|c|c|c|c|c|c|c|c|}
\hline 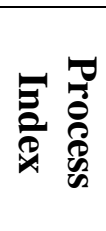 & 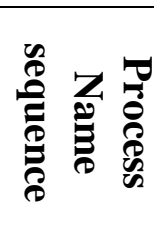 & 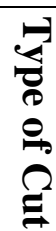 & 氞 & 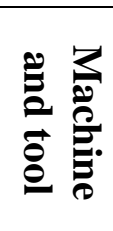 & 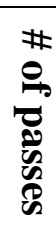 & 芯 & 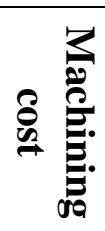 & 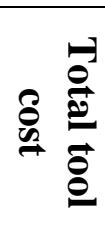 & 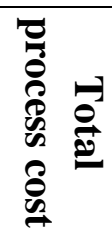 \\
\hline & & & ( $\mu$ in) & & & $(\min )$ & $(\$)$ & (\$) & (\$) \\
\hline
\end{tabular}




\begin{tabular}{|c|c|c|c|c|c|c|c|c|c|}
\hline 1 & $\begin{array}{l}\text { Facing } \\
\text { side } 1\end{array}$ & $\begin{array}{c}\text { Finis } \\
\mathrm{h}\end{array}$ & 17 & $\begin{array}{l}\text { NC Lathe- } \\
\text { PCD } \\
\text { Diamond }\end{array}$ & 5 & 1.07 & 1.16 & 0.49 & 1.68 \\
\hline 2 & $\begin{array}{l}\text { Facing } \\
\text { side } 2\end{array}$ & $\begin{array}{c}\text { Finis } \\
\mathrm{h}\end{array}$ & 17 & $\begin{array}{l}\text { SP Lathe- } \\
\text { PCD } \\
\text { Diamond }\end{array}$ & 1 & 0.76 & 0.51 & 0.17 & 0.68 \\
\hline 3 & $\begin{array}{c}\text { Turning } \\
1\end{array}$ & $\begin{array}{c}\text { Finis } \\
\mathrm{h}\end{array}$ & 17 & $\begin{array}{l}\text { NC Lathe- } \\
\text { PCD } \\
\text { Diamond }\end{array}$ & 2 & 0.98 & 1.06 & 0.67 & 1.73 \\
\hline 4 & $\begin{array}{c}\text { Turning } \\
2\end{array}$ & $\begin{array}{c}\text { Finis } \\
\mathrm{h}\end{array}$ & 17 & $\begin{array}{l}\text { NC Lathe- } \\
\text { PCD } \\
\text { Diamond }\end{array}$ & 1 & 0.83 & 0.90 & 0.28 & 1.18 \\
\hline $5,6,7$ & $\begin{array}{l}\text { Drilling } \\
5 \text { holes }\end{array}$ & $\begin{array}{c}\text { Roug } \\
\mathrm{h}\end{array}$ & 90 & $\begin{array}{c}\text { Ver Dr- } \\
\text { Carbide } \\
\text { Solid, Ver } \\
\text { Dr- } \\
\text { Carbide } \\
\text { Solid } \\
\text { (C2...C4), } \\
\text { Ver Dr } \\
\text { Carbide } \\
\text { Solid } \\
\text { (C5...C7) }\end{array}$ & & 2.46 & 1.64 & 3.54 & 5.19 \\
\hline $8,9,10$ & $\begin{array}{l}\text { Tapping } \\
5 \text { holes }\end{array}$ & $\begin{array}{c}\text { Finis } \\
\mathrm{h}\end{array}$ & 90 & $\begin{array}{c}\text { SP Auto } \\
\text { Dr-HSS T } \\
\text { Grade } \\
\end{array}$ & & 1.51 & 1.01 & 5.10 & 6.11 \\
\hline 11 & $\begin{array}{l}\text { End } \\
\text { milling }\end{array}$ & $\begin{array}{c}\text { Roug } \\
\mathrm{h}\end{array}$ & 90 & $\begin{array}{c}\text { NC Mill } \\
\text { Carbide } \\
\text { Insert }\end{array}$ & 3 & 2.30 & 2.49 & 0.30 & 2.78 \\
\hline 12 & T-slot & $\begin{array}{c}\text { Finis } \\
\mathrm{h}\end{array}$ & 90 & $\begin{array}{l}\text { NC Mill } \\
\text { Carbide } \\
\text { Insert }\end{array}$ & 2 & 2.23 & 2.42 & 0.24 & 2.65 \\
\hline & & & & & Sum & 12.14 & 11.2 & 10.78 & 22.00 \\
\hline
\end{tabular}

The last row in Table 4.9 shows the results of performing DFMT2.1, the total machining cost of the part by machining stainless steel $316 \mathrm{~L}$ was $\$ 22$ and total machining time was 12.14 minutes, thus the production rate was 4.94 part per hour. These results were close to the results of performing DFMT1.1. 


\subsubsection{DFMT2.2 Second Quality Parameters Modification}

Within the allowed ranges of surface finish and tolerance, which are mentioned in the previous sub-section, other values of surface finish and tolerance have been selected to machine the two flat surfaces of the cylinder. The values were $65 \mu$ in for the surface finish and \pm 0.008 for the tolerance. These values were assigned in the drawing on the two flat surfaces of the cylinder. Modifying the surface finish and tolerance value were the reasons to change the machining process by checking the suitability in MPSEL from the facing process to the face milling process. Then, the new values were extracted from the DP, MSP, and MSDB sections to generate the alternative process plan after applying DFMT2.2. Table 4.10 shows the outcomes of this process plan.

Table 4.10. The better PP after applying the DFMT2.2

\begin{tabular}{|c|c|c|c|c|c|c|c|c|c|}
\hline 缼 & 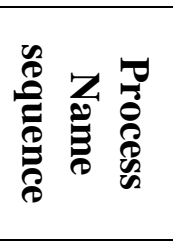 & 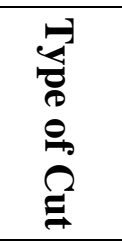 & 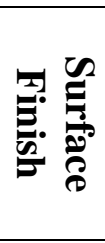 & 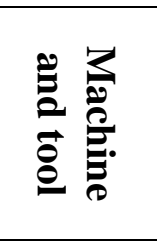 & 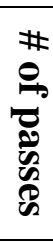 & 蛋 & 苞 & $\frac{\overrightarrow{0}}{\frac{0}{\theta}}$ & 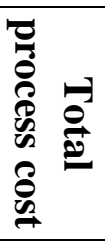 \\
\hline & & & ( $\mu$ in) & & & $(\min )$ & (\$) & (\$) & (\$) \\
\hline 1 & $\begin{array}{c}\text { Face } \\
\text { mill side } \\
1\end{array}$ & Finish & 65 & $\begin{array}{l}\text { NC Mill } \\
\text { Carbide } \\
\text { Insert }\end{array}$ & 2 & 1.05 & 1.14 & 0.55 & 1.69 \\
\hline 2 & $\begin{array}{c}\text { Face } \\
\text { mill side } \\
2\end{array}$ & Finish & 65 & $\begin{array}{l}\text { NC Mill } \\
\text { Carbide } \\
\text { Insert }\end{array}$ & 2 & 1.05 & 1.14 & 0.55 & 1.69 \\
\hline 3 & $\begin{array}{c}\text { Turning } \\
1\end{array}$ & Finish & 17 & $\begin{array}{c}\text { NC } \\
\text { Lathe- } \\
\text { PCD } \\
\text { Diamon } \\
\text { d }\end{array}$ & 2 & 0.98 & 1.06 & 0.67 & 1.73 \\
\hline 4 & $\begin{array}{c}\text { Turning } \\
2\end{array}$ & Finish & 17 & $\begin{array}{c}\mathrm{NC} \\
\text { Lathe- } \\
\text { PCD } \\
\text { Diamon } \\
\text { d }\end{array}$ & 1 & 0.83 & 0.90 & 0.28 & 1.18 \\
\hline
\end{tabular}




\begin{tabular}{|c|c|c|c|c|c|c|c|c|c|}
\hline $5,6,7$ & $\begin{array}{c}\text { Drilling } \\
5 \text { holes }\end{array}$ & Rough & 90 & $\begin{array}{c}\text { Ver Dr- } \\
\text { Carbide } \\
\text { Solid, } \\
\text { Ver Dr } \\
\text { Carbide } \\
\text { Solid } \\
\text { (C2...C4 } \\
\text { ), Ver } \\
\text { Dr } \\
\text { Carbide } \\
\text { Solid } \\
\text { (C5...C7 } \\
\text { ) }\end{array}$ & & 2.46 & 1.64 & 3.54 & 5.19 \\
\hline $8,9,10$ & $\begin{array}{l}\text { Tapping } \\
5 \text { holes }\end{array}$ & Finish & 90 & $\begin{array}{l}\text { SP Auto } \\
\text { Dr HSS } \\
\text { T Grade }\end{array}$ & & 1.51 & 1.01 & 5.10 & 6.11 \\
\hline 11 & $\begin{array}{l}\text { End } \\
\text { milling }\end{array}$ & Rough & 90 & $\begin{array}{c}\text { NC Mill } \\
\text { Carbide } \\
\text { Insert }\end{array}$ & 3 & 2.30 & 2.49 & 0.30 & 2.78 \\
\hline 12 & T-slot & Finish & 90 & $\begin{array}{c}\text { NC Mill } \\
\text { Carbide } \\
\text { Insert }\end{array}$ & 2 & 2.23 & 2.42 & 0.24 & 2.65 \\
\hline & & & & & Sum & 12.41 & 11.79 & 11.23 & 23.02 \\
\hline
\end{tabular}

By comparing the results between the DFMT2.1 and DFMT2.2, the production rate after applying DFMT2.1 was 4.94 and from DFMT2.2 was 4.83, which means the production rate was reduced by $2.23 \%$ and the cost increased by $4.64 \%$. It could be concluded that modifying the surface finish and tolerance on the side surfaces of the part made this change in cost of manufacturing and throughput. The systematic algorithm was finished with DFMT2 and now moved to DFMT3 (changing geometry).

\subsubsection{DFMT3 Modifying Geometry}

The third DFMT was represented by modifying the geometry of the part. The original shape of the raw material and the final part have been analyzed, considering the functionality of the part. A new design has been suggested by the designer after analyzing. This new design was created by modifying the shape of the raw material, the shape of final part, the number of holes on the part, the L/D ratio of the tapped holes, and changing the key and keyway to screw a threaded hole. 


\subsubsection{DFMT3.1 First Modified Geometry}

The first modified geometry of the workpiece and manufactured part are depicted in Figures 4.6 and 4.6 below. The raw material used for the modified geometry was the same material used for the preliminary process plan (stainless steel 316L).

\subsection{Modified Workpiece Dimensions}

The block dimensions of the workpiece are explained in Figure 4.6 below.

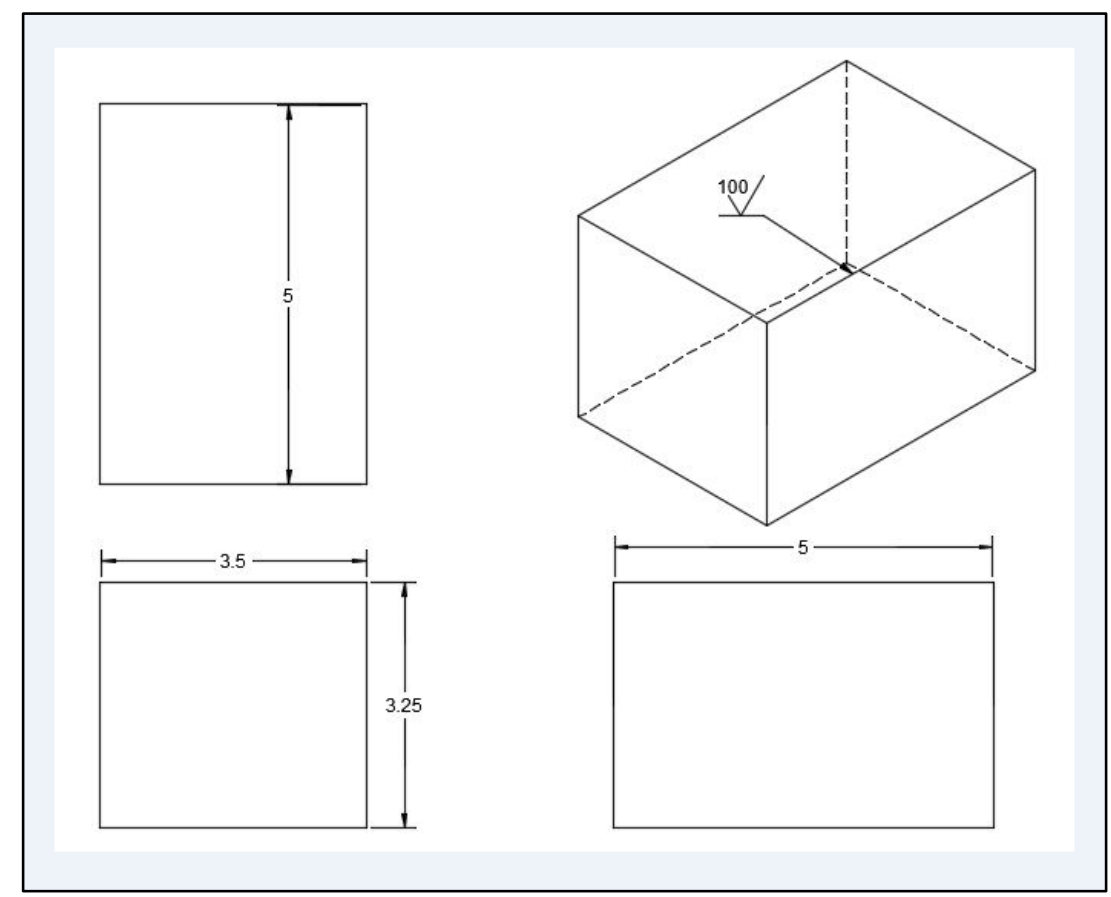

Figure 4.6. 3D drawing of the modified workpiece

The new workpiece block was a rectangular prism with a height of 3.25 inches, a width of 3.5 inches, a length of 5 inches, and a surface roughness of $100 \mu$ in.

\subsection{Final Modified Product Dimensions}

The final product has the following required features and dimensions that are shown in Figure 4.7:

1. Final part block. The block of the final part mush had the following dimensions: height of 3 inches, width of 3 inches, and length of 4.5 inches with a surface roughness of $16 \mu$ in on the front surface, the two sides, and the top. The back surface and the base could be maintained at $100 \mu \mathrm{in}$. 
2. Three holes on the three block surfaces as shown in the drawing. The holes diameter was 0.50 inches and the length was 0.75 inches. All holes had the same dimensions. The holes were tapped (12 TPI), and the inside surface finish of the holes should be $90 \mu \mathrm{in}$. Tolerances can be held to 0.05 inches.

3. A T-slot on front face of the block. The slot width was 0.75 inches and depth was 0.3 inches. The slot neck had a depth of 0.25 inches and width of 0.3 inches. The slot length was 2.5 inches.

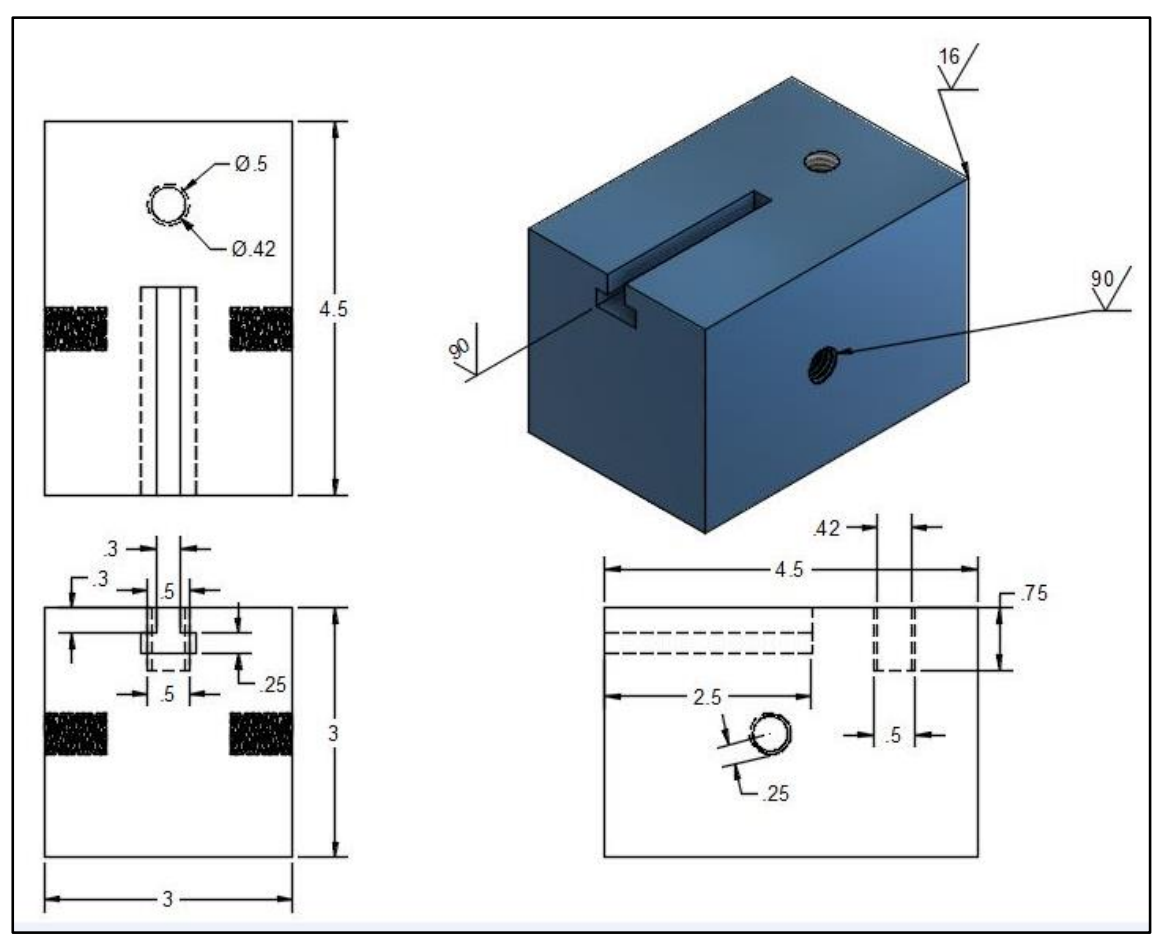

Figure 4.7. 3 views and isometric drawing of the final modified part by DFMT3.1

The information and characteristics of the modified part is shown in Figure 4.7. This information was transformed from the DFMT section to the DP section (the new geometric features, new dimensions, new surface finish and tolerance). Simultaneously, the information was utilized from the sections MSP and MSDB to generate the alternative PP after performing DFMT3.1. The DFMO for this DFMT was acquired and the results are shown in Table 4.11. 
Table 4.11. The better PP after applying the DFMT3.1

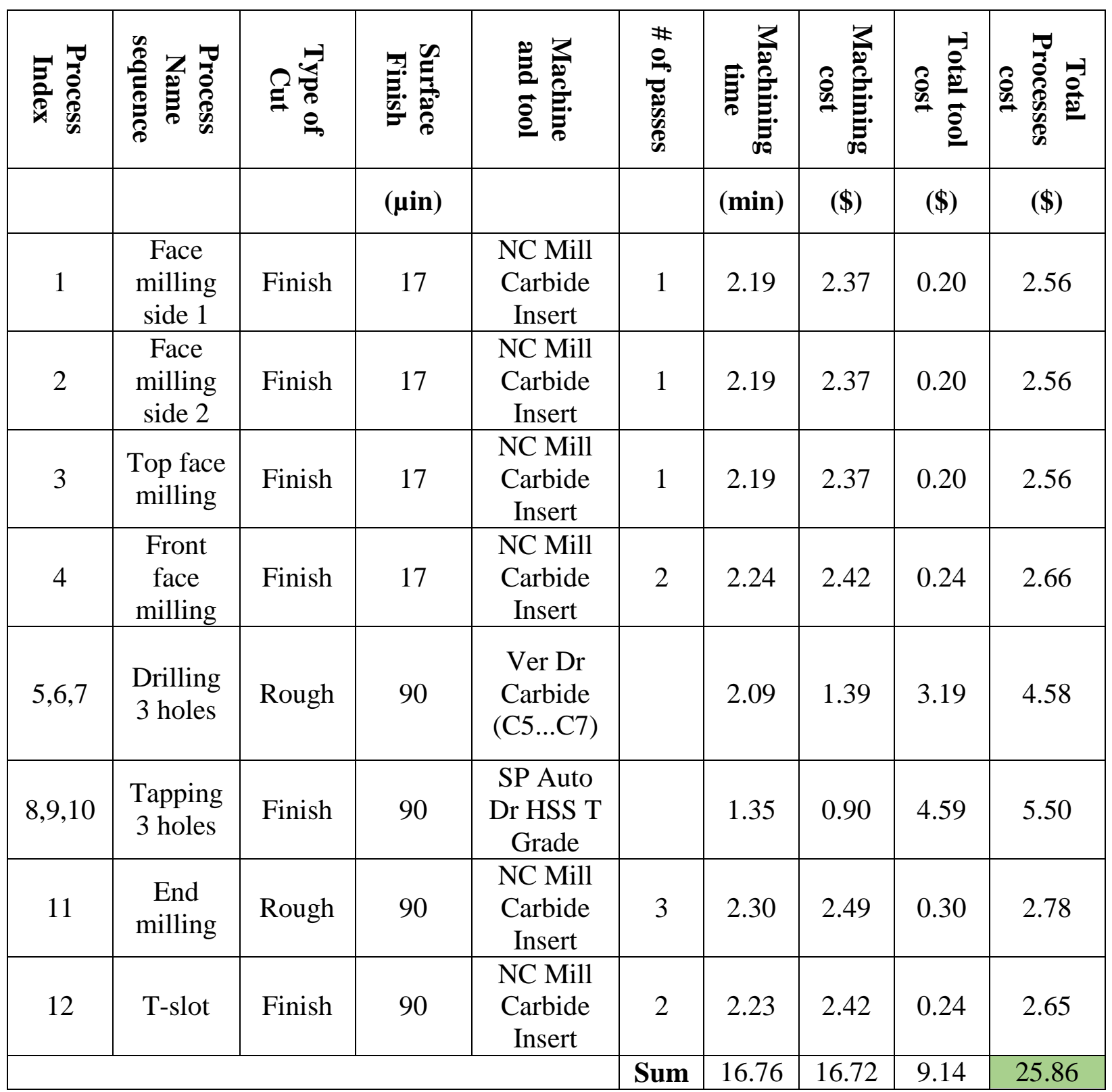

The outcomes of performing DFMT3.1 show that the total manufacturing cost was $\$ 25.86$, and the total machining time was 16.76 minutes, thus the production rate of DFMT3.1 was 3.58 piece/hour. The cost was higher, and the production rate was lower than the cost and production rate of DFMT1 and DFMT2. It is worth mentioning that one work piece from stainless steel 316L in the lot contains 200 pieces is approximately $\$ 78.14$ for the new design. The cost of the 
workpiece material in the PPP was $\$ 144.21$. By comparing these two costs of raw material, the cost was reduced by $45.82 \%$. For the total manufacturing cost and manufacturing time between the PPP and the DFMT3.1 PP, the cost was reduced by $31.62 \%$ and the production rate increased by $43.2 \%$. The alternative modified design of the part is discussed in the next sub-section.

\subsubsection{DFMT3.2 Second Modified Geometry}

In the alternative design of DFMT3.2, the same raw material (stainless steel 316L) was used, the shape and dimensions of the raw material used in DFMT3.1 remained the same. One modification has been made on the final part, the key and keyway feature were replaced by screw and threaded hole as depicted in Figure 4.8 below.

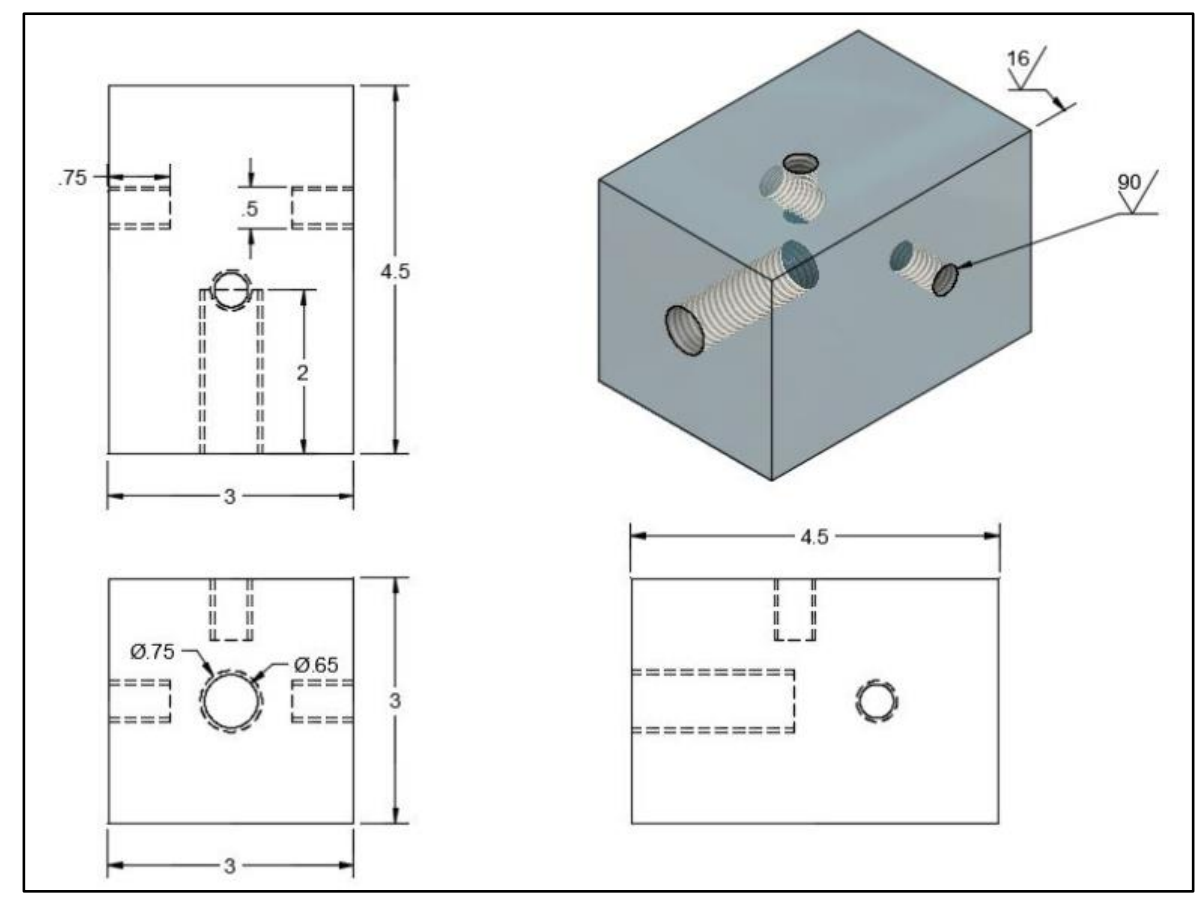

Figure 4.8. 3 views and isometric drawing of the final modified part by DFMT3.2

The difference between the final part in DFMT3.1 and DFMT3.2 was that, instead of using the Tslot on front face of the block, the threaded hole (12 TPI) was used with dimensions: diameter 0.75 inches and length 2 inches. The modified information about DFMT3.2 was transferred to the sections DP, machine element systems, and MSDB to create information about the alternative PP 
of DFMT3.2, then DFMO was obtained by using PPAC interface. The results of DFMT3.2 PP are shown in Table 4.12.

Table 4.12. The better PP after applying the DFMT3.2

\begin{tabular}{|c|c|c|c|c|c|c|c|c|c|}
\hline 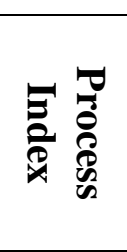 & 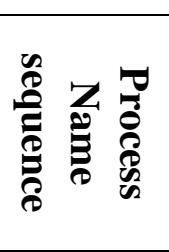 & 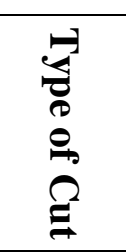 & 象 & 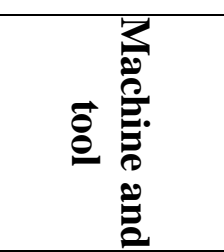 & 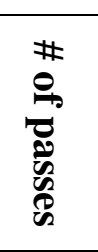 & 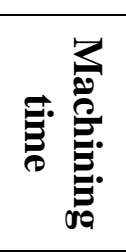 & $\stackrel{2}{\stackrel{2}{2}}$ & $\stackrel{\substack{\overrightarrow{0} \\
\stackrel{0}{0}}}{\stackrel{0}{0}}$ & 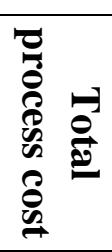 \\
\hline & & & ( $\mu$ in) & & & (min) & (\$) & $(\$)$ & (\$) \\
\hline 1 & $\begin{array}{c}\text { Face } \\
\text { milling } \\
\text { side } 1 \\
\end{array}$ & Finish & 17 & $\begin{array}{c}\text { NC Mill } \\
\text { Carbide } \\
\text { Insert }\end{array}$ & 1 & 2.19 & 2.37 & 0.20 & 2.56 \\
\hline 2 & $\begin{array}{c}\text { Face } \\
\text { milling } \\
\text { side } 2\end{array}$ & Finish & 17 & $\begin{array}{c}\text { NC Mill } \\
\text { Carbide } \\
\text { Insert }\end{array}$ & 1 & 2.19 & 2.37 & 0.20 & 2.56 \\
\hline 3 & $\begin{array}{c}\text { Top face } \\
\text { milling }\end{array}$ & Finish & 17 & $\begin{array}{c}\text { NC Mill } \\
\text { Carbide } \\
\text { Insert }\end{array}$ & 1 & 2.19 & 2.37 & 0.20 & 2.56 \\
\hline 4 & $\begin{array}{c}\text { Front } \\
\text { face } \\
\text { milling }\end{array}$ & Finish & 17 & $\begin{array}{c}\text { NC Mill } \\
\text { Carbide } \\
\text { Insert }\end{array}$ & 2 & 2.24 & 2.42 & 0.24 & 2.66 \\
\hline $5,6,7$ & $\begin{array}{l}\text { Drilling } \\
3 \text { holes }\end{array}$ & Rough & 90 & $\begin{array}{c}\text { Ver Dr- } \\
\text { Carbide } \\
\text { (C5...C7) }\end{array}$ & & 2.09 & 1.39 & 3.19 & 4.58 \\
\hline $8,9,10$ & $\begin{array}{c}\text { Tapping } \\
3 \text { holes }\end{array}$ & Finish & 90 & $\begin{array}{c}\text { SP Auto Dr } \\
\text { HSS T } \\
\text { Grade }\end{array}$ & & 1.35 & 0.90 & 4.59 & 5.50 \\
\hline 11 & $\begin{array}{c}\text { Drilling } \\
\text { front } \\
\text { hole }\end{array}$ & Rough & 90 & $\begin{array}{l}\text { SP AutoDr- } \\
\text { Carbide } \\
\text { Solid } \\
(\mathrm{C} 2 \ldots \mathrm{C} 4)\end{array}$ & & 1.79 & 1.19 & 2.83 & 4.03 \\
\hline 12 & $\begin{array}{c}\text { Tapping } \\
\text { front } \\
\text { hole }\end{array}$ & Finish & 90 & $\begin{array}{c}\text { SP Auto Dr } \\
\text { HSS T } \\
\text { Grade }\end{array}$ & & 1.19 & 0.80 & 4.08 & 4.88 \\
\hline & & & & & Sum & 15.21 & 13.81 & 15.52 & 29.33 \\
\hline
\end{tabular}

The cost of manufacturing the part after applying DFMT3.2 was $\$ 29.33$, the manufacturing time was 15.12 , and production rate was 3.97. This cost was higher than DFMT3.1, at $\$ 25.86$, and the production rate was lower, 3.58. In other words, the cost between DFMT3.1 and DFMT3.2 increased by $13.42 \%$ and the production rate reduced by $10.9 \%$. Modifying the design in DFMT3.1 and DFMT3.2 affected machining process type. Specifically, the facing and turning processes 
were replaced with face milling and side milling. The systematic algorithm was performed on DFMT3, and subsequently on DFMT4 (modifying the selection of machining process/es).

\subsubsection{DFMT4 Modifying the selection of machining Process/es}

The last DFMT applied in the systematic algorithm was modifying the selection of process/es. This DFMT depends on the manufacturer, as the manufacturer can switch from one process to another, to machine specific features of a part. For example, the facing process on the flat surface of the part can be alternately machined by using a face milling process. The number of the process is also matter in this DFMT, instead of machining the cylindrical surface by two turning processes to obtain the desired surface finish, one turning process may be used instead. Modifications in the machining processes are concurrent to checking the suitability of each process in MSP section. In this context, both the number of the processes and the amount of the material to be removed in each process are important. In this DFMT, two alternative modifications in the machining processes and their PPs are performed on the original drawing of the part by using raw material stainless steel 316L.

\subsubsection{DFMT4.1 First Modifications of Selecting Process/es}

The first alternative PP after applying DFMT4 was considered DFMT4.1. In DFMT4.1 and after reanalyzing the PPP, it was possible to machine the two flat surfaces of the part by using the face milling process instead of the facing process, after checking the suitability of the face milling process in the MSP section. Also, in one turning process the cylindrical surface could be machined with $17 \mu$ in surface finish. In the same way and by applying steps 1 to 5 , in the sequence of the algorithm, the alternative PP was generated. The DFMO has been obtained and explained in Table 4.13 .

Table 4.13. The better PP after applying the DFMT4.1

\begin{tabular}{|c|c|c|c|c|c|c|c|c|c|}
\hline 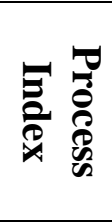 & 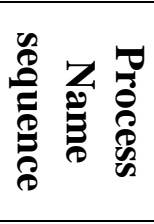 & 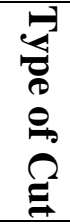 & 四 & 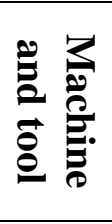 & 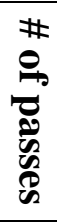 & 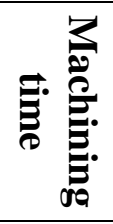 & 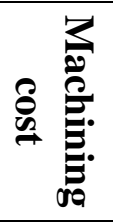 & 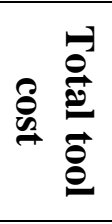 & 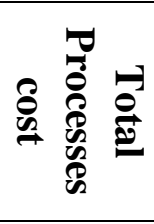 \\
\hline & & & $(\mu \mathrm{in})$ & & & $(\min )$ & (\$) & $(\$)$ & $(\$)$ \\
\hline
\end{tabular}




\begin{tabular}{|c|c|c|c|c|c|c|c|c|c|}
\hline 1 & $\begin{array}{c}\text { Face } \\
\text { Milling } \\
\text { Side } 1\end{array}$ & Finish & 17 & $\begin{array}{c}\text { NC Mill } \\
\text { Carbide } \\
\text { Insert }\end{array}$ & 2 & 1.05 & 1.14 & 0.55 & 1.69 \\
\hline 2 & $\begin{array}{l}\text { Face } \\
\text { Milling } \\
\text { Side } 2\end{array}$ & Finish & 17 & $\begin{array}{l}\text { SP Lathe- } \\
\text { PCD } \\
\text { Diamond }\end{array}$ & 2 & 1.05 & 1.14 & 0.55 & 1.69 \\
\hline 3 & Turning & Finish & 17 & $\begin{array}{c}\text { NC Lathe- } \\
\text { PCD } \\
\text { Diamond }\end{array}$ & 2 & 1.02 & 1.10 & 0.66 & 1.76 \\
\hline $4,5,6$ & $\begin{array}{l}\text { Drilling } \\
3 \text { Holes }\end{array}$ & Rough & 90 & $\begin{array}{c}\text { Ver Dr } \\
\text { Carbide } \\
\text { Solid, Ver } \\
\text { Dr Carbide } \\
\text { Solid } \\
\text { (C2...C4), } \\
\text { Ver Dr } \\
\text { Carbide } \\
\text { Solid } \\
\text { (C5...C7) }\end{array}$ & & 2.46 & 1.64 & 3.54 & 5.19 \\
\hline $7,8,9$ & $\begin{array}{l}\text { Tapping } \\
3 \text { Holes }\end{array}$ & Finish & 90 & $\begin{array}{c}\text { SP Auto Dr } \\
\text { HSS T } \\
\text { Grade }\end{array}$ & & 1.51 & 1.01 & 5.10 & 6.11 \\
\hline 10 & $\begin{array}{l}\text { End } \\
\text { Milling }\end{array}$ & rough & 90 & $\begin{array}{c}\text { NC Mill } \\
\text { Carbide } \\
\text { Insert }\end{array}$ & 3 & 2.30 & 2.49 & 0.30 & 2.78 \\
\hline 11 & T-Slot & finish & 90 & $\begin{array}{l}\text { NC Mill } \\
\text { Carbide } \\
\text { Insert }\end{array}$ & 2 & 2.23 & 2.42 & 0.24 & 2.65 \\
\hline & & & & & Sum & 11.62 & 10.94 & 10.94 & 21.87 \\
\hline
\end{tabular}

The manufacturing cost of the part from DFMT4.1 is $\$ 21.87$ and the production rate is 5.16 parts per hour. These results are convergent with the results of DFMT1 and DFMT2. Another DFMT4 has been applied, named DFMT4.2.

\subsubsection{DFMT4.1 Second Modifications of Selecting Process/es}

In this alternative DFMT, the facing process was used to machine the two flat surfaces of the cylinder with an equal amount of material to be removed from both sides. Moreover, one turning process was used to machine the cylindrical surface with $17 \mu$ in, the modified process plan for DFMT4.2 is shown in Table 4.14 below. 
Table 4.14. The better PP after applying the DFMT4.2

\begin{tabular}{|c|c|c|c|c|c|c|c|c|c|}
\hline 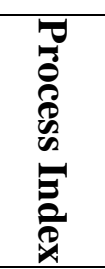 & 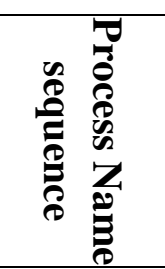 & 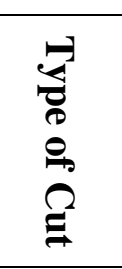 & 国: & 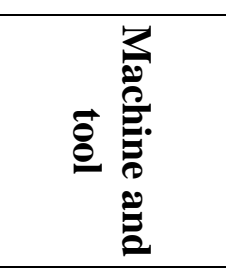 & 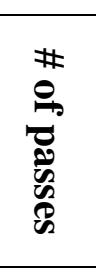 & 言: & 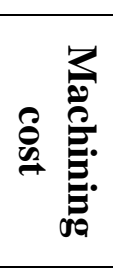 & $\stackrel{\vec{\theta}}{\frac{\vec{\theta}}{\vec{\theta}}}$ & 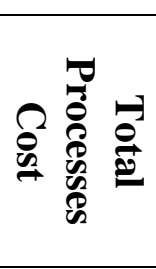 \\
\hline & & & ( $\mu$ in $)$ & & & $(\min )$ & (\$) & (\$) & (\$) \\
\hline 1 & $\begin{array}{l}\text { Facing } \\
\text { Side } 1\end{array}$ & $\begin{array}{c}\text { Finis } \\
\mathrm{h}\end{array}$ & 17 & $\begin{array}{l}\text { NC Lathe- } \\
\text { PCD } \\
\text { Diamond }\end{array}$ & 5 & 1.07 & 1.16 & 0.49 & 1.68 \\
\hline 2 & $\begin{array}{l}\text { Facing } \\
\text { Side } 2\end{array}$ & $\begin{array}{c}\text { Finis } \\
\mathrm{h}\end{array}$ & 17 & $\begin{array}{l}\text { SP Lathe- } \\
\text { PCD } \\
\text { Diamond }\end{array}$ & 1 & 0.75 & 0.82 & 0.11 & 0.92 \\
\hline 3 & $\begin{array}{l}\text { Turning } \\
\text { Cylindri } \\
\text { cal } \\
\text { Surface }\end{array}$ & $\begin{array}{c}\text { Finis } \\
\mathrm{h}\end{array}$ & 17 & $\begin{array}{l}\text { NC Lathe- } \\
\text { PCD } \\
\text { Diamond }\end{array}$ & 2 & 1.02 & 1.10 & 0.66 & 1.76 \\
\hline $4,5,6$ & $\begin{array}{l}\text { Drilling } \\
3 \text { Holes }\end{array}$ & $\begin{array}{c}\text { Roug } \\
\mathrm{h}\end{array}$ & 90 & $\begin{array}{c}\text { Ver Dr } \\
\text { Carbide } \\
\text { Solid, Ver } \\
\text { Dr Carbide } \\
\text { Solid } \\
\text { (C2...C4), } \\
\text { Ver Dr } \\
\text { Carbide } \\
\text { Solid } \\
\text { (C5...C7) }\end{array}$ & & 2.46 & 1.64 & 3.54 & 5.19 \\
\hline $7,8,9$ & $\begin{array}{l}\text { Tapping } \\
3 \text { Holes }\end{array}$ & $\begin{array}{c}\text { Finis } \\
\mathrm{h}\end{array}$ & 90 & $\begin{array}{c}\text { SP Auto Dr } \\
\text { HSS T } \\
\text { Grade }\end{array}$ & & 1.51 & 1.01 & 5.10 & 6.11 \\
\hline 10 & $\begin{array}{l}\text { End } \\
\text { Milling }\end{array}$ & rough & 90 & $\begin{array}{c}\text { NC Mill } \\
\text { Carbide } \\
\text { Insert }\end{array}$ & 3 & 2.30 & 2.49 & 0.30 & 2.78 \\
\hline 11 & T-Slot & finish & 90 & $\begin{array}{c}\text { NC Mill } \\
\text { Carbide } \\
\text { Insert }\end{array}$ & 2 & 2.23 & 2.42 & 0.24 & 2.65 \\
\hline & & & & & Sum & 11.34 & 10.63 & 10.43 & 21.10 \\
\hline
\end{tabular}

The final results in Table 4.14 show that the manufacturing cost of the part from DFMT4.2 is $\$ 21.10$ and the production rate is 5.29. These results are close to the results of DFMT4.1 


\subsection{Summarizing the Results and Discussion}

The systematic algorithm was tested for all the DFMT; every DFMT was applied in two alternative modifications, and for each modification, there is a specific APP. That means nine process plans were obtained from this algorithm: the first one is the PPP, followed by eight alternative PPs. To understand the outcomes of all nine PPs, the important results of each PP was represented by machining time, total tool cost, machining cost, total manufacturing cost, production rate, percentage of production rate reduced/increased cost, and percentage of production rate reduced/increased. All the important outcomes of the nine process plans are depicted in Table 4.15 below. 
Table 4.15. The summarized results of better nine process plan

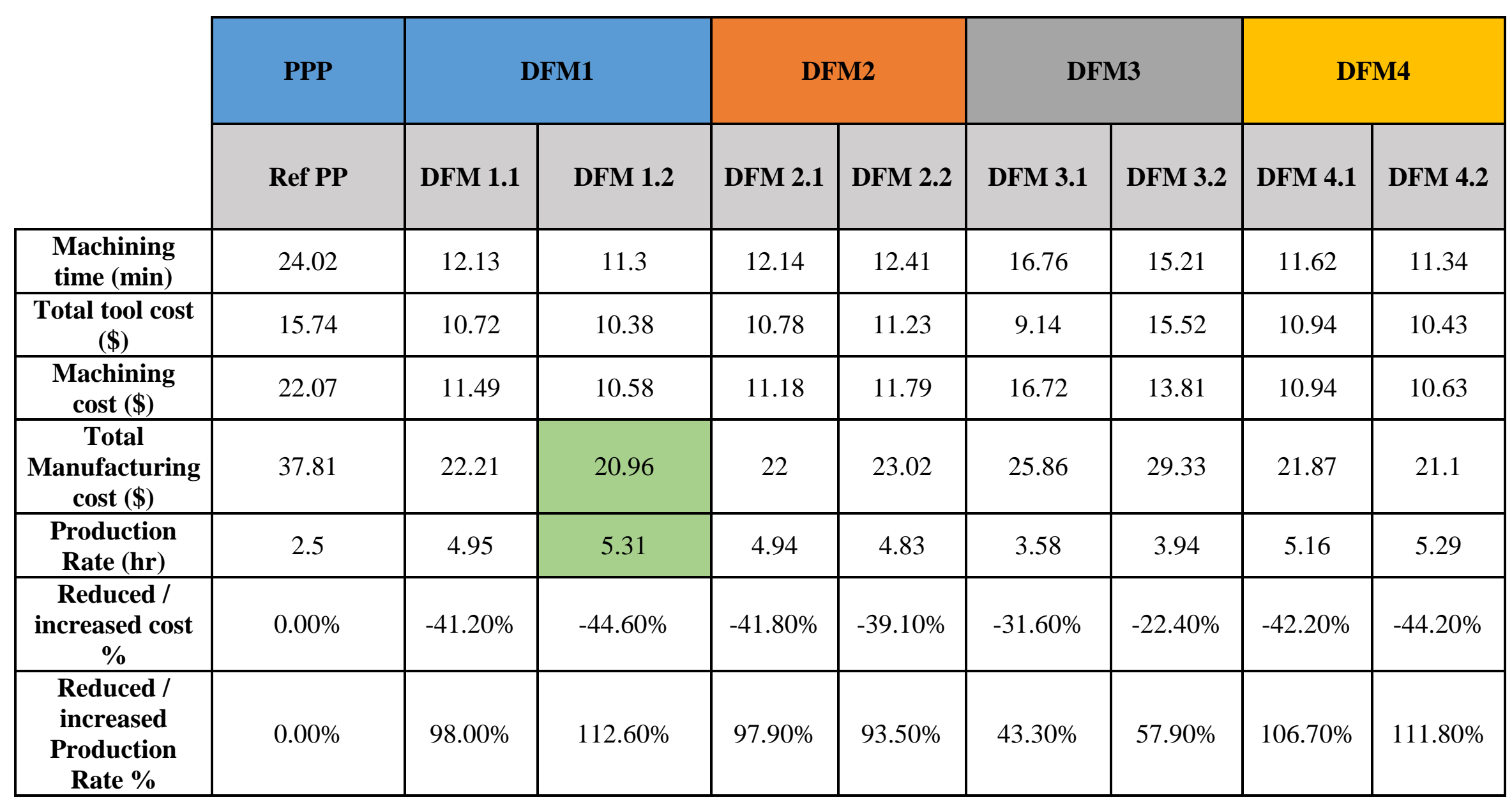


The results of the nine process plans in Table 4.15 is more understandable and a user (facility manager) can decide which PP should be selected according to its preference outcomes, cost of manufacture, and production rate. According to the results, the PP for DFMT1.2 involves using nickel alloy as a raw material. This PP has a minimum machining cost and maximum production rate among all PPs. It is not that the PP for DFMT1.2 should be selected, ignoring the other eight PPs, but the suitable process plan should be selected by considering different factors in addition to the cost and throughput. For example, with the better result for PP with DFMT1.2, the cost of nickel alloy workpiece is very expensive as compared to aluminum alloy workpiece. Moreover, to better understand the results of the nine PPs and determine which has the most effectiveness, the results of the nine PPs are arranged and provided in the custom combination chart of Figure 4.9 below. 


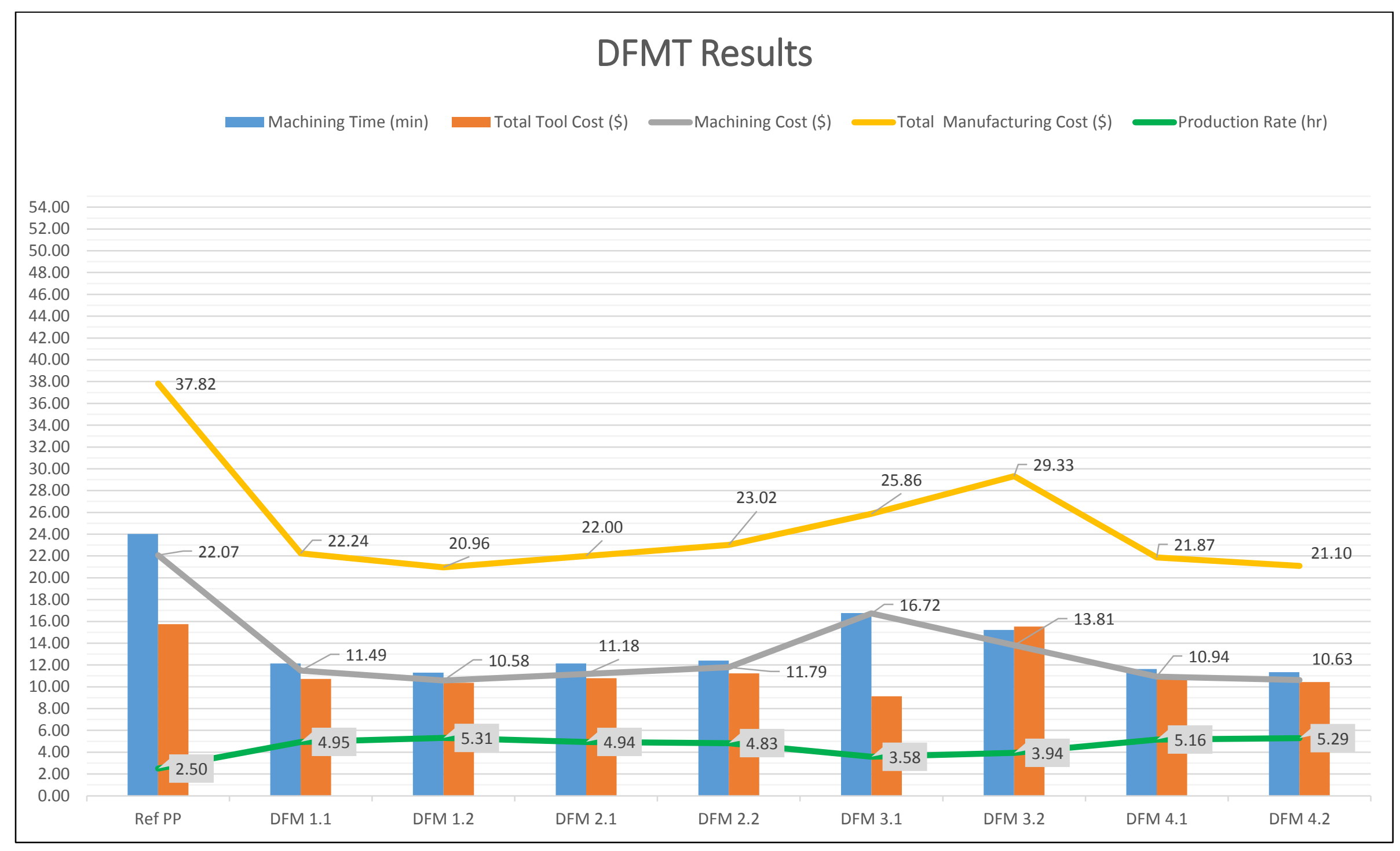

Figure 4.9. Comparison of effectiveness of nine process plans 
In Figure 4.9, five outputs for the nine PPs are shown including machining time (blur bar), total tool cost (orange bar), machining cost (grey line), total manufacturing cost (yellow line), and production rate per hour (green line). This chart and Table 4.15 collectively describe systematic algorithm effectiveness when performed on the floating joint part. From Figure 4.9, it can be observed that the DFMT1.2 had the lowest manufacturing cost and highest production rate among all of the other PPs. This DFMT represents using the nickel alloy as raw material.

\subsection{Sensitivity Analysis}

Sensitivity analysis was performed on different parameters before assigning the systematic algorithm. Some analysis considered alternative modifications on the shape (dimensions) of the workpiece, while further analysis considered different geometric parameters (L/D ratio), machine tool parameters (machine setup time, tool change time), and cutting tool parameters (depth of cut, feed rate, cutting speed). Earlier research showed the effect of some of these parameters[69]-[74]. In this section, alternative modified geometry on the workpiece will be shown with effectiveness on cost reduction and increasing production rate for machining stainless steel alloy.

\subsubsection{Modifying the dimensions of the workpiece}

Several modifications have been made on the original dimensions of the workpiece. The PP has been likewise generated on the new dimensions. These dimension changes are as follows:

1. Modifying the diameter of the workpiece by changing it from 4.5 inches to 4.25 inches dropped the machining cost of stainless steel from $\$ 37.82$ to $\$ 34.05$. Furthermore, the cost of the workpiece will drop down from $\$ 144.21$ to $\$ 128.6$. In this case, two cost saving conditions are obtained: cost of manufacturing was reduced by $9.97 \%$ and the cost of workpiece material was reduced by $10.8 \%$. Another benefit of this modification is that it can be performed without changing the final part.

2. Another modification has been applied to the dimensions of the work piece, this modification is performed by reducing the length of the workpiece from 7 inches to 
6.5 inches. For the cost effectiveness of this modification, the machining was reduced to $\$ 33.25$ and the cost of raw material reduced to $\$ 133.88$. In another words, the cost saving for manufacturing was reduced by $12.83 \%$ and the cost of workpiece was reduced by $7.72 \%$.

3. The third modification involves a combination of the previous modifications. Changing the length of the workpiece from 7 inches to 6.5 inches and changing the diameter of the workpiece from 4.5 inches to 4.25 inches. After performing the PP for this modification, the cost of machining was $\$ 31.67$, and the cost of the workpiece was $\$ 119.4$. For the cost saving of this modification, cost of manufacturing was reduced by $19.42 \%$ and the cost of raw material was reduced by $20.67 \%$.

These results are arranged in Table 4.16 below.

Table 4.16. The summarized results of the suggested modifications

\begin{tabular}{|c|c|c|c|c|c|c|c|c|}
\hline \multirow[b]{2}{*}{ Dimensions } & \multicolumn{2}{|c|}{$\begin{array}{c}\text { Preliminary PP } \\
\text { results }\end{array}$} & \multicolumn{2}{|c|}{$\begin{array}{c}\text { First suggested } \\
\text { results PP results }\end{array}$} & \multicolumn{2}{|c|}{$\begin{array}{l}\text { Second suggested } \\
\text { results PP results }\end{array}$} & \multicolumn{2}{|c|}{$\begin{array}{c}\text { Third suggested results } \\
\text { PP results }\end{array}$} \\
\hline & $L=7$ in & $\mathrm{D}=4.5 \mathrm{in}$ & $L=7$ in & $\mathrm{D}=4.25 \mathrm{in}$ & $L=6.5$ in & $D=4.5$ in & $\mathbf{L}=6.5 \mathrm{in}$ & $D=4.25$ in \\
\hline $\begin{array}{l}\text { Mfg cost } \\
\text { (\$) }\end{array}$ & \multicolumn{2}{|c|}{37.82} & \multicolumn{2}{|c|}{34.05} & \multicolumn{2}{|c|}{33.25} & \multicolumn{2}{|c|}{31.67} \\
\hline $\begin{array}{c}\text { Wp cost } \\
(\$)\end{array}$ & \multicolumn{2}{|c|}{144.41} & \multicolumn{2}{|c|}{128.6} & \multicolumn{2}{|c|}{133.88} & \multicolumn{2}{|c|}{119.4} \\
\hline $\begin{array}{c}\text { \% difference } \\
\text { Mfg cost }\end{array}$ & \multicolumn{2}{|c|}{$0 \%$} & \multicolumn{2}{|c|}{$9.97 \%$} & \multicolumn{2}{|c|}{$12.83 \%$} & \multicolumn{2}{|c|}{$19.42 \%$} \\
\hline $\begin{array}{c}\text { \% difference } \\
\text { Wp cost }\end{array}$ & \multicolumn{2}{|c|}{$0 \%$} & \multicolumn{2}{|c|}{$10.8 \%$} & \multicolumn{2}{|c|}{$7.72 \%$} & \multicolumn{2}{|c|}{$20.67 \%$} \\
\hline
\end{tabular}

To further understand and explain the results depicted in Table 4.16, Figure 4.10 (a histogram) was created. 


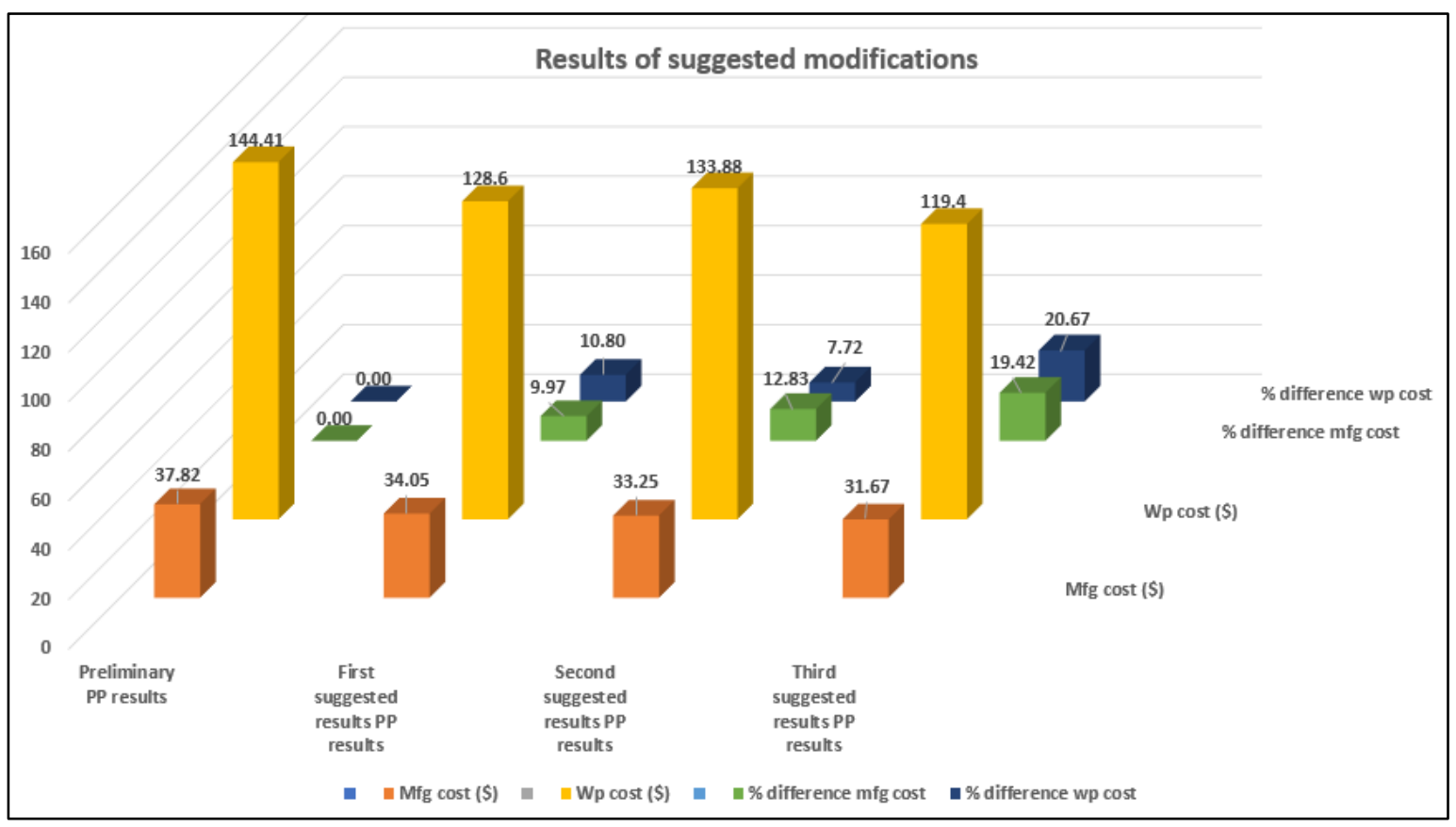

Figure 4.10. Comparison of effectiveness of three design modifications

In Figure 4.10, the results of the three suggested modifications are more understandable. Additional modifications could be made, even by modifying the cross-sectional area of the workpiece from circle to square. The major benefit of these design modifications is that the part does not need to be redesigned and reanalyzed, because these particular modifications do not influence the shape or the functionality of the final part.

\subsubsection{Analyzing L/D ratio}

More analysis was performed on the relationship between the diameter and length of the holes (L/D ratio). This analysis has been executed on both drilling and tapping processes.

In Table 4.16 and Table 4.17 the changes in drilling process parameters are explained.

Table 4.17. Changing $D$ and $L$ together in drilling process

\begin{tabular}{|c|c|c|c|c|c|c|c|}
\hline $\mathbf{D}$ & $\mathbf{L}$ & $\mathbf{L} / \mathbf{D}$ & $\begin{array}{c}\text { Number } \\
\text { of holes }\end{array}$ & $\begin{array}{c}\text { Sum } \\
\text { length of } \\
\text { holes }\end{array}$ & $\begin{array}{c}\text { Speed } \\
\mathbf{( r p m )}\end{array}$ & $\begin{array}{c}\text { Surface } \\
\text { finish }\end{array}$ & $\begin{array}{c}\text { Cost of } \\
\text { drilling } \\
\mathbf{( \$ )}\end{array}$ \\
\hline 0.3 & 0.5 & 1.6667 & 5 & 2.5 & 104.85 & 17 or 90 & 5.75 \\
\hline 0.2 & 0.4 & 2 & 5 & 2 & 69.9 & 17 or 90 & 4.81 \\
\hline
\end{tabular}




\begin{tabular}{|c|c|c|c|c|c|c|c|}
\hline 0.15 & 0.4 & 2.6667 & 5 & 2 & 52.425 & 17 or 90 & 4.81 \\
\hline 0.2 & 0.5 & 2.5 & 5 & 2.5 & 69.9 & 17 or 90 & 5.75 \\
\hline 0.15 & 0.3 & 2 & 5 & 1.5 & 52.425 & 17 or 90 & 3.88 \\
\hline 0.3 & 0.5 & 1.6667 & 4 & 2 & 104.85 & 17 or 90 & 4.73 \\
\hline 0.2 & 0.4 & 2 & 4 & 1.6 & 69.9 & 17 or 90 & 3.99 \\
\hline 0.15 & 0.4 & 2.6667 & 4 & 1.6 & 52.425 & 17 or 90 & 3.99 \\
\hline 0.2 & 0.5 & 2.5 & 4 & 2 & 69.9 & 17 or 90 & 4.73 \\
\hline 0.15 & 0.3 & 2 & 4 & 1.2 & 52.425 & 17 or 90 & 3.24 \\
\hline 0.3 & 0.5 & 1.6667 & 3 & 1.5 & 104.85 & 17 or 90 & 3.72 \\
\hline 0.2 & 0.4 & 2 & 3 & 1.2 & 69.9 & 17 or 90 & 3.16 \\
\hline 0.15 & 0.4 & 2.6667 & 3 & 1.2 & 52.425 & 17 or 90 & 3.16 \\
\hline 0.2 & 0.5 & 2.5 & 3 & 1.5 & 69.9 & 17 or 90 & 3.72 \\
\hline 0.15 & 0.3 & 2 & 3 & 0.9 & 52.425 & 17 or 90 & 2.6 \\
\hline
\end{tabular}

Table 4.18. Fixed $D$ values and changing $L$ together in drilling process

\begin{tabular}{|c|c|c|c|c|c|c|c|}
\hline $\mathbf{D}$ & $\mathbf{L}$ & $\mathbf{L} / \mathbf{D}$ & $\begin{array}{c}\text { Number } \\
\text { of holes }\end{array}$ & $\begin{array}{c}\text { Sum } \\
\text { length of } \\
\text { holes } \\
\text { (inch) }\end{array}$ & $\begin{array}{c}\text { Speed } \\
(\mathbf{r p m})\end{array}$ & $\begin{array}{c}\text { Surface } \\
\text { finish } \\
(\boldsymbol{\mu} \text { in) }\end{array}$ & $\begin{array}{c}\text { Cost of } \\
\text { drilling } \\
\mathbf{( \$ )}\end{array}$ \\
\hline 0.3 & 1 & 3.3333 & 5 & 5 & 104.85 & 17 or 90 & 10.41 \\
\hline 0.3 & 0.95 & 3.1667 & 5 & 4.75 & 104.85 & 17 or 90 & 9.95 \\
\hline 0.3 & 0.9 & 3 & 5 & 4.5 & 104.85 & 17 or 90 & 9.48 \\
\hline 0.3 & 0.85 & 2.8333 & 5 & 4.25 & 104.85 & 17 or 90 & 9.01 \\
\hline 0.3 & 0.8 & 2.6667 & 5 & 4 & 104.85 & 17 or 90 & 8.55 \\
\hline 0.3 & 0.75 & 2.5 & 5 & 3.75 & 104.85 & 17 or 90 & 8.08 \\
\hline 0.3 & 0.7 & 2.3333 & 5 & 3.5 & 104.85 & 17 or 90 & 7.61 \\
\hline 0.3 & 0.65 & 2.1667 & 5 & 3.25 & 104.85 & 17 or 90 & 7.15 \\
\hline 0.3 & 0.6 & 2 & 5 & 3 & 104.85 & 17 or 90 & 6.68 \\
\hline 0.3 & 0.55 & 1.8333 & 5 & 2.75 & 104.85 & 17 or 90 & 6.21 \\
\hline 0.3 & 0.5 & 1.6667 & 5 & 2.5 & 104.85 & 17 or 90 & 5.75 \\
\hline 0.3 & 0.45 & 1.5 & 5 & 2.25 & 104.85 & 17 or 90 & 5.28 \\
\hline 0.3 & 0.4 & 1.3333 & 5 & 2 & 104.85 & 17 or 90 & 4.81 \\
\hline 0.3 & 0.35 & 1.1667 & 5 & 1.75 & 104.85 & 17 or 90 & 4.35 \\
\hline 0.3 & 0.3 & 1 & 5 & 1.5 & 104.85 & 17 or 90 & 3.88 \\
\hline 0.3 & 0.25 & 0.8333 & 5 & 1.25 & 104.85 & 18 or 90 & 3.41 \\
\hline 0.3 & 0.2 & 0.6667 & 5 & 1 & 104.85 & 19 or 90 & 2.95 \\
\hline 0.3 & 0.15 & 0.5 & 5 & 0.75 & 104.85 & 20 or 90 & 2.48 \\
\hline & & & & & & & \\
\hline
\end{tabular}


In Table 4.17, both $\mathrm{D}$ and $\mathrm{L}$ have been modified; it could be observed that when the values of $\mathrm{L}$ are constant, the cost of the process was approximately constant even when the value of $\mathrm{D}$ was variable. In Table 4.17, the value of $\mathrm{D}$ was constant, and values of $\mathrm{L}$ are variable. The cost is reduced with reduction of the $\mathrm{L}$ value. Thus, modifying $\mathrm{D}$ does not affect the cost of machining by using the same type of drilling bit. Modifying $L$ has the most effectiveness on the process cost. Tables 4.19 and 4.20 show the modifications in tapping process parameters.

Table 4.19. Changing $D$ and $L$ in tapping process

\begin{tabular}{|c|c|c|c|c|c|c|c|}
\hline $\mathbf{D}$ & $\mathbf{L}$ & $\mathbf{L} / \mathbf{D}$ & $\begin{array}{c}\text { Number } \\
\text { of holes }\end{array}$ & $\begin{array}{c}\text { Sum } \\
\text { ength of } \\
\text { holes }\end{array}$ & $\begin{array}{c}\text { Speed } \\
\mathbf{( r p m )}\end{array}$ & $\begin{array}{c}\text { Surface } \\
\text { finish }\end{array}$ & $\begin{array}{c}\text { Cost of } \\
\text { tapping } \\
\mathbf{( \$ )}\end{array}$ \\
\hline 0.3 & 0.5 & 1.6667 & 5 & 2.5 & 60 & 17 or 90 & 5.36 \\
\hline 0.2 & 0.4 & 2 & 5 & 2 & 60 & 17 or 90 & 4.47 \\
\hline 0.15 & 0.4 & 2.6667 & 5 & 2 & 60 & 17 or 90 & 4.47 \\
\hline 0.2 & 0.5 & 2.5 & 5 & 2.5 & 60 & 17 or 90 & 5.34 \\
\hline 0.15 & 0.3 & 2 & 5 & 1.5 & 60 & 17 or 90 & 3.6 \\
\hline 0.3 & 0.5 & 1.6667 & 4 & 2 & 60 & 17 or 90 & 4.49 \\
\hline 0.2 & 0.4 & 2 & 4 & 1.6 & 60 & 17 or 90 & 3.78 \\
\hline 0.15 & 0.4 & 2.6667 & 4 & 1.6 & 60 & 17 or 90 & 3.77 \\
\hline 0.2 & 0.5 & 2.5 & 4 & 2 & 60 & 17 or 90 & 4.47 \\
\hline 0.15 & 0.3 & 2 & 4 & 1.2 & 60 & 17 or 90 & 3.08 \\
\hline 0.3 & 0.5 & 1.6667 & 3 & 1.5 & 60 & 17 or 90 & 3.62 \\
\hline 0.2 & 0.4 & 2 & 3 & 1.2 & 60 & 17 or 90 & 3.08 \\
\hline 0.15 & 0.4 & 2.6667 & 3 & 1.2 & 60 & 17 or 90 & 3.08 \\
\hline 0.2 & 0.5 & 2.5 & 3 & 1.5 & 60 & 17 or 90 & 3.61 \\
\hline 0.15 & 0.3 & 2 & 3 & 0.9 & 60 & 17 or 90 & 2.56 \\
\hline
\end{tabular}

Table 4.20. Fixed $D$ values and changing $L$ together in tapping process

\begin{tabular}{|c|c|c|c|c|c|c|c|}
\hline $\mathbf{D}$ & L & L/D & $\begin{array}{c}\text { Number } \\
\text { of holes }\end{array}$ & $\begin{array}{c}\text { Sum } \\
\text { length of } \\
\text { holes }\end{array}$ & $\begin{array}{c}\text { Speed } \\
(\mathbf{r p m})\end{array}$ & $\begin{array}{c}\text { Surface } \\
\text { finish }\end{array}$ & $\begin{array}{c}\text { Cost of } \\
\text { tapping } \\
(\mathbf{\$})\end{array}$ \\
\hline 0.3 & 1 & 3.3333 & 5 & 5 & 60 & 17 or 90 & 9.72 \\
\hline 0.3 & 0.95 & 3.1667 & 5 & 4.75 & 60 & 17 or 90 & 9.28 \\
\hline 0.3 & 0.9 & 3 & 5 & 4.5 & 60 & 17 or 90 & 8.85 \\
\hline 0.3 & 0.85 & 2.8333 & 5 & 4.25 & 60 & 17 or 90 & 8.41 \\
\hline
\end{tabular}




\begin{tabular}{|c|c|c|c|c|c|c|c|}
\hline 0.3 & 0.8 & 2.6667 & 5 & 4 & 60 & 17 or 90 & 7.97 \\
\hline 0.3 & 0.75 & 2.5 & 5 & 3.75 & 60 & 17 or 90 & 7.54 \\
\hline 0.3 & 0.7 & 2.3333 & 5 & 3.5 & 60 & 17 or 90 & 7.1 \\
\hline 0.3 & 0.65 & 2.1667 & 5 & 3.25 & 60 & 17 or 90 & 6.67 \\
\hline 0.3 & 0.6 & 2 & 5 & 3 & 60 & 17 or 90 & 6.232 \\
\hline 0.3 & 0.55 & 1.8333 & 5 & 2.75 & 60 & 17 or 90 & 5.79 \\
\hline 0.3 & 0.5 & 1.6667 & 5 & 2.5 & 60 & 17 or 90 & 5.36 \\
\hline 0.3 & 0.45 & 1.5 & 5 & 2.25 & 60 & 17 or 90 & 4.92 \\
\hline 0.3 & 0.4 & 1.3333 & 5 & 2 & 60 & 17 or 90 & 4.49 \\
\hline 0.3 & 0.35 & 1.1667 & 5 & 1.75 & 60 & 17 or 90 & 4.05 \\
\hline 0.3 & 0.3 & 1 & 5 & 1.5 & 60 & 17 or 90 & 3.62 \\
\hline 0.3 & 0.25 & 0.8333 & 5 & 1.25 & 60 & 18 or 90 & 3.18 \\
\hline 0.3 & 0.2 & 0.6667 & 5 & 1 & 60 & 19 or 90 & 2.74 \\
\hline
\end{tabular}

Tables 4.19 and 4.20 for tapping process give the same conclusion, which is obtained from Tables 4.17 and 4.18 of drilling process. The cost of tapping process is constant when the $\mathrm{L}$ value is constant, and the cost is reduced when the $\mathrm{L}$ values are reduced. More analysis has been done on drilling and tapping by changing T-slot to threaded hole as well. The results are depicted in Tables 4.21 and 4.22, which support the same conclusions.

Table 4.21. Changing $D$ and $L$ together in drilling process

\begin{tabular}{|c|c|c|c|c|c|c|c|}
\hline $\mathbf{D}$ & $\mathbf{L}$ & $\mathbf{L} / \mathbf{D}$ & $\begin{array}{c}\text { Number } \\
\text { of holes }\end{array}$ & $\begin{array}{c}\text { Sum } \\
\text { length of } \\
\text { holes }\end{array}$ & $\begin{array}{c}\text { Speed } \\
\mathbf{( r p m )}\end{array}$ & $\begin{array}{c}\text { Surface } \\
\text { finish }\end{array}$ & $\begin{array}{c}\text { Cost of } \\
\text { drilling } \\
\mathbf{( \$ )}\end{array}$ \\
\hline 0.8 & 2.5 & 3.125 & 1 & 2.5 & 279.6 & 17 or 90 & 5.43 \\
\hline 0.775 & 2.5 & 3.2258 & 1 & 2.5 & 270.86 & 17 or 90 & 5.43 \\
\hline 0.75 & 2.5 & 3.3333 & 1 & 2.5 & 262.13 & 17 or 90 & 5.43 \\
\hline 0.725 & 2.5 & 3.4483 & 1 & 2.5 & 253.39 & 17 or 90 & 5.43 \\
\hline 0.7 & 2.5 & 3.5714 & 1 & 2.5 & 244.65 & 17 or 90 & 5.43 \\
\hline 0.675 & 2.5 & 3.7037 & 1 & 2.5 & 235.91 & 17 or 90 & 5.43 \\
\hline 0.65 & 2.5 & 3.8462 & 1 & 2.5 & 227.18 & 17 or 90 & 5.43 \\
\hline 0.625 & 2.5 & 4 & 1 & 2.5 & 218.44 & 17 or 90 & 5.43 \\
\hline 0.6 & 2.5 & 4.1667 & 1 & 2.5 & 209.7 & 17 or 90 & 5.43 \\
\hline 0.575 & 2.5 & 4.3478 & 1 & 2.5 & 200.96 & 17 or 90 & 5.43 \\
\hline 0.8 & 2 & 2.5 & 1 & 2 & 279.6 & 17 or 90 & 4.49 \\
\hline 0.775 & 2 & 2.5806 & 1 & 2 & 270.86 & 17 or 90 & 4.49 \\
\hline 0.75 & 2 & 2.6667 & 1 & 2 & 262.13 & 17 or 90 & 4.49 \\
\hline 0.725 & 2 & 2.7586 & 1 & 2 & 253.39 & 17 or 90 & 4.49 \\
\hline
\end{tabular}




\begin{tabular}{|c|c|c|c|c|c|c|c|}
\hline 0.7 & 2 & 2.8571 & 1 & 2 & 244.65 & 17 or 90 & 4.49 \\
\hline 0.675 & 2 & 2.963 & 1 & 2 & 235.91 & 17 or 90 & 4.49 \\
\hline 0.65 & 2 & 3.0769 & 1 & 2 & 227.18 & 17 or 90 & 4.49 \\
\hline 0.625 & 2 & 3.2 & 1 & 2 & 218.44 & 17 or 90 & 4.49 \\
\hline 0.6 & 2 & 3.3333 & 1 & 2 & 209.7 & 17 or 90 & 4.49 \\
\hline 0.575 & 2 & 3.4783 & 1 & 2 & 200.96 & 17 or 90 & 4.49 \\
\hline
\end{tabular}

Table 4.22. Changing $D$ and fixing $L$ in tapping process

\begin{tabular}{|c|c|c|c|c|c|c|c|}
\hline $\mathbf{D}$ & $\mathbf{L}$ & $\mathbf{L} / \mathbf{D}$ & $\begin{array}{c}\text { Number } \\
\text { of holes }\end{array}$ & $\begin{array}{c}\text { Sum } \\
\text { length of } \\
\text { holes }\end{array}$ & $\begin{array}{c}\text { Speed } \\
\mathbf{( r p m )}\end{array}$ & $\begin{array}{c}\text { Surface } \\
\text { finish }\end{array}$ & $\begin{array}{c}\text { Cost of } \\
\text { tapping } \\
\mathbf{( \$ )}\end{array}$ \\
\hline 0.8 & 2 & 2.5 & 1 & 2 & 70 & 17 or 90 & 5.99 \\
\hline 0.775 & 2 & 2.5806 & 1 & 2 & 70 & 17 or 90 & 5.99 \\
\hline 0.75 & 2 & 2.6667 & 1 & 2 & 70 & 17 or 90 & 5.98 \\
\hline 0.725 & 2 & 2.7586 & 1 & 2 & 70 & 17 or 90 & 5.98 \\
\hline 0.7 & 2 & 2.8571 & 1 & 2 & 70 & 17 or 90 & 5.98 \\
\hline 0.675 & 2 & 2.963 & 1 & 2 & 70 & 17 or 90 & 5.98 \\
\hline 0.65 & 2 & 3.0769 & 1 & 2 & 70 & 17 or 90 & 5.97 \\
\hline 0.625 & 2 & 3.2 & 1 & 2 & 70 & 17 or 90 & 5.97 \\
\hline 0.6 & 2 & 3.3333 & 1 & 2 & 70 & 17 or 90 & 5.97 \\
\hline 0.575 & 2 & 3.4783 & 1 & 2 & 70 & 17 or 90 & 5.96 \\
\hline
\end{tabular}

More analysis was performed in accordance with cutting tool parameters and machine tool parameters, such as feed rate, depth of cut, tool cost, tool life, cutting speed, and machine setup time. These analyses support the conclusion that the feed rate and tool life have the maximum effect on cost and production rate among all the MP.

\subsection{Conclusion}

In this work, the systematic algorithm was performed on the case study, which was suggested in the beginning of this chapter. Four DFMT were executed in the algorithm and all the results are organized and summarized. The proposed systematic algorithm will be repeated if the outcomes of four DFMT were not satisfactory until the final preferred results are determined. These steps can be repeated with more modifications on DFMT, or combined with two or more DFMT, until the desired outcomes are obtained. The algorithm might need to combine three or four of the DFMT. 
In this chapter, two potential alternative modifications were applied on every DFMT without any combination. The results were compared after applying the algorithm on all of the DFMT. In every DFMT all the possible outcomes between the suitable machine tool and cutting tool were considered and the minimum process cost was selected. The DFMT were applied in this sequence: 1. changing raw material, 2. modifying quality, 3. modifying geometry, and 4. modifying the selection of process/es. The reason for considering this sequence is related to the degree of effectiveness and applicability of the DFMT on cost and production rate. This degree of effectiveness was obtained after massive heuristic work done by the researcher. Also, this sequence is related to its applicability. For instance, modifying the quality of the part (moving joint) is easier than modifying the geometry of the part. However, it is recommended to apply all the DFMT, then generating a table (as shown in Table 4.15) to decide which DFMT will be selected according the manufacturing availability and applicability.

The raw material was the first option in the DFMT and it has the minimum manufacturing cost with DFMT1.2, but it is not always the best choice because of the cost of the nickel alloy and availability. The modifying the selection of process/es DFMT could be changed inherently with any other DFMT. For example, modifying the design of the part shape from cylinder to block will eliminate the turning process and switch it to the milling process. However, it is recommended to apply the DFMT4 separately without modifying the design of the part. The fifth DFMT, changing environmental consideration (pressure, temperature, corrosion resistance, stiffness, strength, etc.), was terminated because it is related to first DFMT (changing raw material), and it depends on various properties of part material which are related to the functionality of the part.

It can be concluded from Figure 4.9 that the results of applying DFMT1.2 has the minimum cost among the rest of the DFMT, but that does not necessarily suggest selecting it and ignoring the other. By considering the cost of the nickel alloy workpiece, a user (manufacturing facility management) may switch to alternative DFMT. After applying and obtaining all the outcomes of DFMT, these results should be analyzed according to each DFMT's performance applicability and availability. MPSEL and PPAC software were used to select the suitable machine elements systems and machining parameters, then to obtain 
PP and DFMO. The output of these two software platforms were checked manually by calculating the results, using the economic equations $(1,2,3,4,5$, and 6) in Chapter three. The results between the software output and manual check were tested and they were compatible. For example, the three suggested modifications on the design in section 4.4.2 could be applied to the Aluminum alloy that will reduce the cost more than applying them on stainless steel and will be considered a combination between DFMT1 and DFMT3 without modifying the design. 


\section{Chapter 5: Conclusion, Contributions, Limitations, and Proposed Future Work}

\subsection{Introduction}

In this dissertation, chapter one and two presented the introduction and the literature review for this this work. Chapter three explains in detail, the systematic algorithm and methodology of the work. The systematic algorithm was tested in Chapter four, and the outcomes were summarized and discussed in the end of this chapter. Chapter five contains the conclusion and the contributions of this work, and then discusses the limitations and need for future work.

To utilize the result from the systematic algorithm, which is proposed in this research, manufacturing facilities should apply the algorithm step by step on all the DFMT. Then, the table of the results and the graphic charts should be obtained. Then, users (manufacturing facility management) decide about which output they should go with. The final decision depends on the selected process plan manufacturing cost and production rate. More considerations should be followed by the companies to select the desired process plan which are: cost and availability of the raw material, machinability of the raw material, manufacturing considerations and the desired material properties. From all these considerations, the management of the manufacturing facilities can decide which process plan will be for plan A, B, and C. The user will be able to analyze the impact of various DFMT with respect to product, process, and system level parameters and generate desirable alternatives.

\subsection{Conclusion}

This study included investigation for several DFMT in the machining domain. The results of analyzing the DFMT showed significant influence on cost reduction and production rates. Little work has analyzed the significance of DFMT with their inherent machine elements systems and machining parameters to investigate which DFMT has the main influence on cost reduction and increasing throughput, and under which circumstances. 


\subsubsection{The Findings of the Systematic Algorithm}

The systematic algorithm was suggested in this work, from which all findings are drawn. These findings suggest that further beneficial outcomes and variety might be obtained by applying this algorithm.

The order of performing the DFMT is critical, and it is recommended by the researcher that the appropriate DFMT sequence be followed: 1) Modifying the selection of raw material, 2) Modifying quality, 3) Modifying geometry, and 4) Modifying the selection of the process/es. This sequence has been set according to heuristic work performed by the researcher.

Working on the first two DFMT (modifying the selection of raw material and modifying quality) in advance increased the influence of the systematic algorithm. These two DFMT could be applied without any minor or major modifications in the workpiece or final design. With parts such as the moving joint, a user can perform the two DFMT by following the specific ranges of material properties in Appendix D, with respect to suitable ranges of surface finish and tolerance.

The proposed systematic algorithm is explained in detail in Chapter three and tested in Chapter four. The systematic algorithm guides and instructs the user to gradually apply the DFMT. The results showed that the algorithm has an influence on cost reduction and increasing production rate. The algorithm provides several outcomes in which every outcome represents an option that can be performed as an alternative PP. When the manufacturing facility aims to reduce manufacturing costs by modifying PP, significant time may be saved through application of the algorithm, especially given its guidance towards the suitable alternative solutions.

The final results after applying the systematic algorithm are explained in Table 4.15 and Figure 4.9. This table and figure will help users (manufacturing facility management) to reach suitable decisions regarding which DFMT should be applied. The sensitivity analysis in section 4.5 showed a positive impact on reducing the cost of manufacturing. More specifically, the dimensions of the workpiece were modified by reducing the diameter, length, or both. The advantage of these modifications is that they can be performed without any need for redesigning the final part, or concern about functionality of that part. 


\subsubsection{Suggested Method for Modifying the DFMT}

The use of the tables in Appendix D to assign alternative raw material by using material properties, will be beneficial in minimizing time needed to determine suitable alternative material. Modifying the selection of raw material has significant impact on DFMO without changing the designs of workpiece and final part. It is assumed that with every preliminary manufactured part, there are specific assigned ranges of material properties that the functionality of a part should be maintained within. These material properties include several categories, such as electrical, thermal, mechanical, and environmental properties. The material properties for specific metal alloys (ferrous and non-ferrous) have been extracted from Ashby's charts [78], [79]. By using data from these tables in Appendix D, two alternate raw materials could be employed in this dissertation case study instead of the original raw material. Inside the algorithm, this selection method proved reliable. In addition, the decision of modifying the raw material will not take excessive time.

The modifying quality DFMT is second in the order of applying the DFMT. By analyzing the contact faces between features or different parts, specific ranges of surface finish and tolerance can be assigned. In this context, the two interaction features must fit inside each other within these ranges, in addition to keeping the functionality of the part.

Modifying geometry, which is the third DFMT, does require reanalysis of the part design, with attention to maintaining functionality. This DFMT has a significant impact on reducing the cost of workpiece as well, but it is more difficult to apply. In other words, modifying the quality is easier than redesigning the part.

The fourth DFMT involves modifying the selection of process/es. This technique can be performed separately on a preliminary process plan or can be inherited with any DFMT. Modifying the selection of raw material will allow the use of different machining process/es and modifying quality and design will modify the selection of the process/es or the process sequence of PP. DFMT4 is considered as a floating DFMT between the other three DFMTs. It achieves the combinations between DFMT with the other three DFMTs. For this reason, it took the fourth order because DFMT4 already exists. It is not obligatory to apply this sequence on the DFMT, but it is recommended to employ according to the DFMT 
availability and applicability. It is better if all the DFMT are applied in the suggested sequence.

\subsubsection{Suggested Case Study}

Manufacturing parts such as the moving joint, which was suggested as a case study, have minimal interaction features between faces. However, on the suggested part, only the holes and the keyway have interactions with the studs and the key, respectively. Thus, modifying the quality of the cylindrical surface and two side surfaces of the part will be relatively easy, and does not require substantial design reanalysis.

\subsubsection{Work Development}

The work suggested in the proposal defense involved performing one DFMT, then modifying the Machining Parameters inside of it to obtain the lower cost, shown in the scheme below.

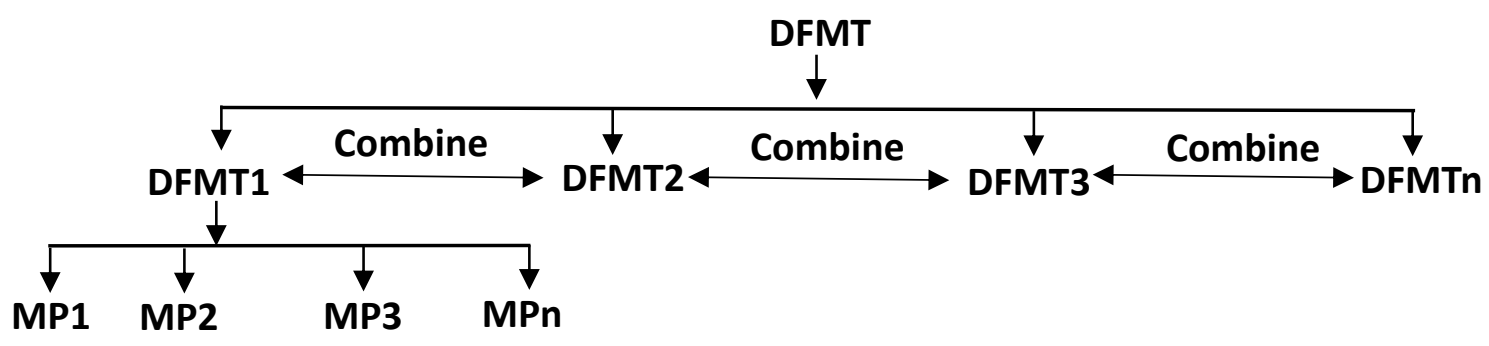

This change was supposed to be arbitrary, without any systematic work. Then, another DFMT would be applied with arbitrary changes to machining parameters, and so forth. Then, combinations between two or more DFMT could be performed. The arbitrary nature of the changes to machining parameters were insufficient for the researcher and as such, these changes should be performed systematically. The solution was established by creating data in Appendix A and B to organize the information of machine elements systems with machining parameters. These modifications between machine elements systems and machining parameters should be restricted by specific values, as represented by the tables in these two Appendixes. Every machine tool should have specific values for its machining parameters, such as machine setup time, tool change time, and rapid traverse rate. In the 
same way, every used cutting tool should have specific values for its machining parameters, such as tool cost, tool life, depth of cut, cutting speed, and feed rate. Thus, the changes between machine elements systems and machining parameters must not be arbitrary and should be restricted by their suitability, which are obtained from MPSEL.

\subsubsection{Developed Software in Systematic Algorithm}

The PPAC software interface was developed by the researcher to determine the DFMO of every PP. This coded spreadsheet was used to apply all the possible combinations between the machine elements systems (machine tool and cutting). The PPAC could perform the combinations with relative ease and in a short amount of time. One or more parameters can be modified easily and without reentering all the inputs. For every modification on DFMT there were six or seven possible PP proposed, and from these PP, the PP with the minimum manufacturing cost was selected. It is worth mentioning, for every PP, there are several machining processes, for every machining process there are several combinations ( 4 to 24 combinations), and for every combination PPAC must be run one time after inserting the suitable parameter values. To perform all those functions while executing the algorithm, massive time for calculation and running is required. The PPAC played the main role in shortening the time of this work. Moreover, calculating the feed rate, cutting speed, and depth of cut by using the Speed_Feed_Selection developed spreadsheet saved substantial time in this calculation, without any requirement for calculating the attributes of the PP from specific resources.

For every cutting tool type and grade there is a specific tool geometry. The tool geometry is already described and coded inside MPSEL software. That means the tool geometry is considered in this work to check the suitability of the cutting tool with the machine tool, DP, and the raw material used.

\subsection{Contributions}

There are several contributions made by this research:

- Methodology for selecting alternative raw materials was developed in this dissertation. The methodology was adopted by creating tables of material properties 
for several metal alloys [78], [79]. This methodology has been tested in the proposed systematic algorithm and has proven its reliability. The selection of alternative raw material involves considering specific ranges of material properties, in order that within these ranges the functionality of the part is preserved. The alternative raw material can be selected by considering theses ranges.

- The systematic algorithm was tool used to format all of the work in this dissertation. This algorithm provided guidance for testing and analysis of all the DFMT. It additionally organized the information between several sections involved within the algorithm (DP, MSDB, PP, and DFMO). All possible outcomes from this algorithm have been organized and discussed after performing it. The structure and execution of the algorithm are explained in detail in chapters three and four. In addition to the algorithm's role in formatting the work, it also significantly reduces the time needed to analyze and perform the DFMT.

- A spreadsheet software interface named PPAC has been developed to calculate the outcomes of every process plan (DFMO). This process involved coding the Excel sheet using Visual Basic for the application (VBA), to create this software interface. The software interface was beneficial within the algorithm because of its flexibility, and its time efficiency in changing the variables of calculating machining cost and time. More specifically, this software saved substantial time in performing a large number of iterations for every machining process.

- Sensitivity analysis has been performed on the preliminary work. This analysis was provided the framework for creating the systematic algorithm. Investigations were made on the structure of the systematic algorithm (DFMT, MSDB, DFMO, MSP, and DP). All the machine elements systems and machining parameters were tested and combined, based on this work. Important notes were developed about the influence of the algorithm structures. Then, the systematic algorithm was created, which is considered to be the backbone of the work. 


\subsection{Limitations}

- There was difficulty in finding some data in the tables of Appendix D that is not available in peer-reviewed resources.

- The systematic algorithm proved its reliability and organized the work, but it still needs a significant amount of time to perform.

- There is difficulty in using several software platforms at the same time and transferring the information between them.

- Machine element systems, represented by machine tools and cutting tools information, needs to be updated consistently because this information frequently changes. Examples include: tool type, tool cost, machine tool type, setup time, feed, and speed.

- This algorithm was performed on the machining processes only and it has only been applied to prismatic parts.

\subsection{Proposed Future Work}

Possibilities for future work include:

- Considering more DFMT factors and more machining parameters, as well as the combinations between them.

- Expanding the work to general manufacturing processes and more complicated parts.

- Considering more metallic and non-metallic materials in the manufacturing field.

- There is a need to build a whole program that works on the systematic algorithm and connects all the algorithm's sections (DFMT, DP, MSP, MSDB, PP, and DFMO). Then, this software should show the final results, after the user decision has been made.

- Expanding the systematic algorithm and increasing the inputs and outputs of it.

- Increasing the ranges of machine tools and cutting tools used, with use of five to six axis CNC machines. 


\section{Literature Cited}

[1] V. Smil, Made in the USA: The Rise and Retreat of American Manufacturing. MIT Press, 2013.

[2] R. Heizer and B. Render, Operation Management, Sustainability and Supply Chain management. Pearson, UK, 2013.

[3] D. M. Hutton, "The Difference Engine: Charles Babbage and the Quest to Build the First Computer," Kybernetes, vol. 31, no. 6, 2002.

[4] J. Heizer, Operations Management, 11/e. Pearson Education India, 2016.

[5] M. P. Groover, Fundamentals of modern manufacturing: materials processes, and systems. John Wiley \& Sons, 2007.

[6] A. S. M. Handbook, "Volume 16: Machining," ASM International Handbook Committee, ASM International, Electronic, 1989.

[7] E. P. De Garmo, J. T. Black, and R. A. Kohser, DeGarmo's materials and processes in manufacturing. John Wiley \& Sons, 2011.

[8] R. A. Tenkorang, "Concurrent Engineering (CE): A Review Literature Report," in Proceedings of the World Congress on Engineering and Computer Sciences, San Francisco, 2011.

[9] I. Basu, N. Biswas, S. N. Biswas, and S. Sarkar, "A Study on Concurrent Engineering-Based Design and Product Development," International Journal of Recent advances in Mechanical Engineering, vol. 2, no. 1, pp. 15-20, 2013.

[10] A. S. M. I. H. Committee, ASM handbook: Materials selection and design, vol. 20. CRC Press, 1997.

[11] D. Montgomery, Introduction to statistical quality control. John Wiley \& Sons (New York), 2009.

[12] S. B. Gershwin, Manufacturing systems engineering. Prentice Hall, 1994. 
[13] M. Sandberg, "Design for manufacturing: methods and applications using knowledge engineering," Lule $\{a ̊\}$ tekniska universitet, 2007.

[14] M. F. Hassan and S. M. Megahed, Current Advances in Mechanical Design and Production VII. Elsevier, 2000.

[15] G. Boothroyd, "Design for manufacture and assembly: The Boothroyd-Dewhurst experience," in Design for X, Springer, 1996, pp. 19-40.

[16] G. Boothroyd and P. Dewhurst, Product design for manufacture and assembly, Third Edit. Taylor \&Francis Group 6000 Broken Sound Parkway NW, Suite 300, 2011.

[17] K. Krishnaiah and P. Shahabudeen, Applied design of experiments and Taguchi methods. PHI Learning Pvt. Ltd., 2012.

[18] V. K. Jain, Advanced machining processes. Allied publishers, 2009.

[19] R. E. Walpole, R. H. Myers, S. L. Myers, and K. Ye, Probability and statistics for engineers and scientists. Pearson Education, 2014.

[20] "5 Factors That Affect Design for Manufacturability (DFM).” [Online]. Available: http://news.ewmfg.com/blog/5-factors-that-affect-design-for-manufacturability-dfmvideo. [Accessed: 01-Jan-2017].

[21] S. N. Broadberry, "Comparative productivity levels in manufacturing since the industrial revolution: lessons from Britain, America, Germany and Japan,” Structural Change and Economic Dynamics, vol. 6, no. 1, pp. 71-95, 1995.

[22] a. Gunasekaran, "Implementation of productivity improvement strategies in a small company," Technovation, vol. 18, no. 5. pp. 362-363, 1998.

[23] W. Gu and M. Ho, “A Comparison of Productivity Growth in Manufacturing between Canada and the United States, 1961-95," The Canada-US Manufacturing Productivity Gap, pp. 21-22, 2000.

[24] S. H. Huang, J. P. Dismukes, J. Shi, and Q. Su, "Manufacturing system modeling 
for productivity improvement," Journal of Manufacturing Systems, vol. 21, no. 4, p. $249,2002$.

[25] S. H. Huang et al., "Manufacturing productivity improvement using effectiveness metrics and simulation analysis," International Journal of Production Research, vol. 41, no. 3, pp. 513-527, 2003.

[26] E. Kabir, S. M. M. I. Boby, and M. Lutfi, "Productivity Improvement by using SixSigma," International Journal of Engineering and Technology, vol. 3, no. 12, pp. 56-84, 2013.

[27] K. Hemanand, D. Amuthuselvan, S. C. Raja, and G. Sundararaja, "Improving Productivity of manufacturing division using lean concepts and development of Material gravity feeder-A Case Study," International Journal of Lean Thinking, vol. 3, no. 2, pp. 117-134, 2012.

[28] N. Roy, S. Saha, T. Bhowmick, and S. C. Goldar, "Productivity Improvement of a Fan Manufacturing Company by using DMAIC Approach: A Six-Sigma Practice," Global Journal of Research In Engineering, vol. 13, no. 4, 2013.

[29] M. Mandloi and J. Abhishek Yadav, "Productivity Improvement by Lean Manufacturing an Automobile Industry with the Help of Method Study," Global Journal of Research In Engineering, vol. 14, no. 4, 2014.

[30] B. Esmaeilian, S. Behdad, and B. Wang, "The evolution and future of manufacturing: A review," Journal of Manufacturing Systems, vol. 39, pp. 79-100, 2016.

[31] A. S. N. Reddy, P. S. Rao, and G. Rajyalakshmi, "Productivity Improvement Using Time Study Analysis in a Small Scale Solar Appliances Industry- a Case Study,” vol. 11, no. 1, pp. 666-674, 2016.

[32] F. Schreiber, M. Manns, and J. Morales, "Design of an additively manufactured soft ring-gripper," Procedia Manufacturing, vol. 28, pp. 142-147, 2019.

[33] K. Kristjansdottir, S. Shafiee, L. Hvam, C. Forza, and N. H. Mortensen, "The main 
challenges for manufacturing companies in implementing and utilizing configurators," Computers in Industry, vol. 100, pp. 196-211, 2018.

[34] K. Lameche, N. M. Najid, P. Castagna, and K. Kouiss, "Modularity in the design of reconfigurable manufacturing systems," IFAC-PapersOnLine, vol. 50, no. 1, pp. 3511-3516, 2017.

[35] I. Palcic, R. Koren, and B. Buchmeister, "Technical innovation concepts in Slovenian manufacturing companies," Procedia Engineering, vol. 100, pp. 141$149,2015$.

[36] T. Nishiguchi, Y. Koizumi, Y. Maeda, M. Masuda, K. Nagayama, and K. Okamura, "Improvement of productivity in aspherical precision machining with in-situ metrology," CIRP Annals-Manufacturing Technology, vol. 40, no. 1, pp. 367-370, 1991.

[37] S. Enache, E. Strajescu, C. Opran, C. Minciu, and M. Zamfirache, "Mathematical model for the establishment of the materials machinability," CIRP AnnalsManufacturing Technology, vol. 44, no. 1, pp. 79-82, 1995.

[38] X. Yan, K. Shirase, M. Hirao, and T. Yasui, "NC program evaluator for higher machining productivity," International Journal of Machine Tools and Manufacture, vol. 39, no. 10, pp. 1563-1573, 1999.

[39] R. Pasko, L. Przybylski, and B. Slodki, "High speed machining (HSM)--The effective way of modern cutting," in Proceedings of 7th DAAAM International Workshop CA Systems And Technologies, 2002, pp. 72-79.

[40] S. C. Veldhuis, G. K. Dosbaeva, and K. Yamamoto, "Tribological compatibility and improvement of machining productivity and surface integrity," Tribology International, vol. 42, no. 6, pp. 1004-1010, 2009.

[41] M. Kuttolamadom, S. Hamzehlouia, and L. Mears, "Effect of machining feed on surface roughness in cutting 6061 aluminum," SAE International Journal of Materials and Manufacturing, vol. 3, no. 2010-1-218, pp. 108-119, 2010. 
[42] P. C. Kumar, "Set up Reduction A perfect way for productivity improvement of computer numerical control (CNC) set up in manufacturing company," Journal of Mechanical Engineering Research, vol. 5, no. 8, pp. 166-170, 2013.

[43] R. Malhotra, I. Saxena, K. Ehmann, and J. Cao, "Laser-induced plasma micromachining (LIPMM) for enhanced productivity and flexibility in laser-based micromachining processes," CIRP Annals-Manufacturing Technology, vol. 62, no. 1, pp. 211-214, 2013.

[44] S. Agarwal, "Optimizing machining parameters to combine high productivity with high surface integrity in grinding silicon carbide ceramics," Ceramics International, vol. 42, no. 5, pp. 6244-6262, 2016.

[45] M. Baumers, P. Dickens, C. Tuck, and R. Hague, "The cost of additive manufacturing: machine productivity, economies of scale and technology-push," Technological Forecasting and Social Change, vol. 102, pp. 193-201, 2016.

[46] A.-K. Reichler et al., "Incremental Manufacturing: Model-based part design and process planning for Hybrid Manufacturing of multi-material parts," Procedia CIRP, vol. 79, pp. 107-112, 2019.

[47] N. Costa, L. Patrl'licio, N. Morelli, and C. L. Magee, "Bringing service design to manufacturing companies: integrating PSS and service design approaches," Design Studies, vol. 55, pp. 112-145, 2018.

[48] R. S. Srinivasan, K. L. Wood, and D. A. McAdams, "Functional tolerancing: A design for manufacturing methodology," Research in Engineering Design, vol. 8, no. 2, pp. 99-115, 1996.

[49] A. M. Bayoumi, "Design for manufacture and assembly (DFMA): concepts, benefits and applications current advances in mechanical design and production," in 7th Cairo University International MDP Conference, 2000.

[50] W. Chiang, A. Pennathur, and A. Mital, "Designing and manufacturing consumer products for functionality: a literature review of current function definitions and 
design support tools," Integrated Manufacturing Systems, vol. 12, no. 6, pp. 430448, 2001.

[51] K. L. Edwards, "Towards more strategic product design for manufacture and assembly: priorities for concurrent engineering," Materials \& design, vol. 23, no. 7, pp. 651-656, 2002.

[52] J. W. Herrmann et al., "New directions in design for manufacturing," in Proceedings of the ASME Design Engineering Technical Conferences, 2004.

[53] L. M. Wong, G. G. Wang, and D. Strong, "A New Design for Production (DFP) Methodology with Two Case Studies," Concurrent Engineering, vol. 12, no. 4, pp. 263-273, 2004.

[54] Z. Zhao and J. J. Shah, "Domain independent shell for DfM and its application to sheet metal forming and injection molding," Computer-Aided Design, vol. 37, no. 9, pp. 881-898, 2005.

[55] M. Bird and A. K. Kochhar, "Sustainable Design of Manufacturing Systems Assessment of Current Practices in Different Parts of a Multi-National Automotive Organization," IFAC Proceedings Volumes, vol. 42, no. 4, pp. 1760-1765, 2009.

[56] O. Kerbrat, P. Mognol, and J.-Y. Hascoët, "A new DFM approach to combine machining and additive manufacturing," Computers in Industry, vol. 62, no. 7, pp. 684-692, 2011.

[57] A. L. T. Ramos and F. Lorini, "Architecture Information Context in a Design For Manufacturing (DFM) Framework," IFAC Proceedings Volumes, vol. 46, no. 7, pp. 110-115, 2013.

[58] J. Vallhagen, J. Madrid, R. Söderberg, and K. Wärmefjord, “An approach for producibility and DFM-methodology in aerospace engine component development," Procedia CIRP, vol. 11, pp. 151-156, 2013.

[59] F. Andersson, A. Hagqvist, E. Sundin, and M. Björkman, "Design for manufacturing of composite structures for commercial aircraft-the development of a 
DFM strategy at SAAB aerostructures," Procedia CIRP, vol. 17, pp. 362-367, 2014.

[60] D. S. Cochran, M. U. Jafri, A. K. Chu, and Z. Bi, "Incorporating design improvement with effective evaluation using the Manufacturing System Design Decomposition (MSDD)," Journal of Industrial Information Integration, vol. 2, pp. 65-74, 2016.

[61] A. Sharma, V. Bandari, K. Ito, K. Kohama, M. Ramji, and H. S. BV, "A new process for design and manufacture of tailor-made functionally graded composites through friction stir additive manufacturing," Journal of Manufacturing Processes, vol. 26, pp. 122-130, 2017.

[62] C. Song, A. Wang, Z. Wu, Z. Chen, Y. Yang, and D. Wang, "The design and manufacturing of a titanium alloy beak for Grus japonensis using additive manufacturing," Materials \& Design, vol. 117, pp. 410-416, 2017.

[63] E. Ostrosi and A.-J. Fougères, "Intelligent virtual manufacturing cell formation in cloud-based design and manufacturing," Engineering Applications of Artificial Intelligence, vol. 76, pp. 80-95, 2018.

[64] E. Alabort, D. Barba, and R. C. Reed, "Design of metallic bone by additive manufacturing," Scripta Materialia, vol. 164, pp. 110-114, 2019.

[65] A. W. Gebisa and H. G. Lemu, "Design for manufacturing to design for Additive Manufacturing: Analysis of implications for design optimality and product sustainability," Procedia Manufacturing, vol. 13, pp. 724-731, 2017.

[66] M. E. Thatcher, "The impact of technology on product design, productivity, and profits: A duopoly model of price-quality competition," in System Sciences, 2004. Proceedings of the 37th Annual Hawaii International Conference on, 2004, p. 10 pp.

[67] S. Prasad, T. Zacharia, and J. Babu, "Design for Manufacturing (DFM) approach for Productivity Improvement in Medical Equipment Manufacturing," Inernational 
Journal of Emerging Technology and Advanced Engineering, vol. 4, no. 4, pp. 79$85,2008$.

[68] R. H. Mueller, "Design for warranty cost reduction," in Reliability and Maintainability Symposium, 2008. RAMS 2008. Annual, 2008, pp. 200-205.

[69] S. B. Raja and N. Baskar, "Application of particle swarm optimization technique for achieving desired milled surface roughness in minimum machining time," Expert Systems with Applications, vol. 39, no. 5, pp. 5982-5989, 2012.

[70] N. Qehaja, K. Jakupi, A. Bunjaku, M. Bruçi, and H. Osmani, "Effect of machining parameters and machining time on surface roughness in dry turning process," Procedia Engineering, vol. 100, pp. 135-140, 2015.

[71] E. Leal-Muñoz, E. Diez, H. Perez, and A. Vizan, "Accuracy of a new online method for measuring machining parameters in milling," Measurement, 2018.

[72] S. Lata, R. Rana, and Hitesh, "Investigation of Chip-Tool Interface Temperature: Effect of Machining Parameters and Tool Material on Ferrous and Non-Ferrous Metal," Materials Today: Proceedings, vol. 5, no. 2, pp. 4250-4257, 2018.

[73] S. Kosaraju, M. V. Kumar, and N. Sateesh, "Optimization of Machining Parameter in Turning Inconel 625," Materials Today: Proceedings, vol. 5, no. 2, pp. 53435348, 2018.

[74] P. Chandra, C. R. P. Rao, and V. Kiran, R, Ravi kumard, "Influence Of Machining Parameter On Cutting Force And Surface Roughness While Turning Alloy Steel," Materials Today: Proceedings, vol. 5, no. 5, pp. 11794-11801, 2018.

[75] A. Jacob, K. Windhuber, D. Ranke, and G. Lanza, "Planning, Evaluation and Optimization of Product Design and Manufacturing Technology Chains for New Product and Production Technologies on the Example of Additive Manufacturing," Procedia CIRP, vol. 70, pp. 108-113, 2018.

[76] X. F. Zha and H. Du, "Manufacturing process and material selection in concurrent collaborative design of MEMS devices," Journal of Micromechanics and 
Microengineering, vol. 13, no. 5, p. 509, 2003.

[77] J. Kaspar, D. Baehre, and M. Vielhaber, "Material selection based on a product and production engineering integration framework," Procedia CIRP, vol. 50, pp. 2-7, 2016.

[78] M. F. Ashby, "Materials selection in mechanical design," MRS Bull, vol. 30, no. 12, p. $995,2005$.

[79] M. F. Ashby, H. Shercliff, and D. Cebon, Materials: engineering, science, processing and design. Butterworth-Heinemann, 2013.

[80] "How to Sharpen Tungsten Carbide." [Online]. Available: https://www.ehow.com/how_7822285_sharpen-tungsten-carbide.html.

[81] “Performance Carbide.” [Online]. Available: http://perfcarb.com/.

[82] B. Denkena, T. Grove, M. Theuer, and Y. Liu, "Resource Efficient Regrinding of Cemented Carbide Milling Tools," Procedia CIRP 69 (2018), vol. 69, pp. 882-887, 2018 .

[83] B. Gopalakrishnan, "Expert systems for machining parameter selection: design aspects," Advanced manufacturing engineering, vol. 2, no. 2, pp. 59-63, 1990.

[84] “RTS Cutting Tools." [Online]. Available: https://www.rtscut.com/high-speed-steelcutting-tools.html.

[85] “Global High-speed Steel Cutting Tools Market 2019-2023,” 2019. [Online]. Available: https://www.technavio.com/report/global-high-speed-steel-cutting-toolsmarket-industryanalysis?utm_source=t9\&utm_medium=bw_wk13\&utm_campaign=businesswire.

[86] "Norseman ${ }^{\mathrm{TM}}$ Drill and Tool Company."

[87] "Global High Speed Steel (HSS) Metal Cutting Tools Industry," 2018. [Online]. Available: https://www.prnewswire.com/news-releases/global-high-speed-steel-hssmetal-cutting-tools-industry-300679332.html. 
[88] "Global High Speed Steel (HSS) Metal Cutting Tools Market Report 2018." [Online]. Available: https://www.wiseguyreports.com/reports/3350458-global-highspeed-steel-hss-metal-cutting-tools-market-report-2018.

[89] M. D. Center, Machining data handbook, vol. 1. MDC, 1980.

[90] "McMaster-Carr Supply Company. Supplier Company for Maintenance, Repair and Operations materials and supplies.”[Online]. Available: Index @ Www.Mcmaster.Com. 


\section{Appendix}

\section{Appendix A}

Table A.1: The information of the used turning tools (Single Point Cutting Tool)

\begin{tabular}{|c|c|c|c|c|}
\hline Tool & $\begin{array}{l}\text { Cost } \\
(\$)\end{array}$ & Tool Life & $\begin{array}{l}\text { Number of Times } \\
\text { Sharpened/Indexed } \\
\text { before Discarding }\end{array}$ & $\begin{array}{c}\text { Time to } \\
\text { Resharpen }\end{array}$ \\
\hline HSS G.P. & 6 & $3 \min$ & 5 & $5 \mathrm{~min}$ \\
\hline HSS (M grade) & 7 & $4.5 \mathrm{~min}$ & 5 & $5 \mathrm{~min}$ \\
\hline HSS ( $T$ grade) & 8 & $4 \mathrm{~min}$ & 5 & $5 \mathrm{~min}$ \\
\hline Carbide G.P. & 13 & $4 \mathrm{~min}$ & 8 & $5 \mathrm{~min}$ \\
\hline Carbide (C2..C4) & 14 & $5 \mathrm{~min}$ & 8 & $5 \mathrm{~min}$ \\
\hline Carbide (C5..C8) & 15 & $5 \mathrm{~min}$ & 8 & $5 \mathrm{~min}$ \\
\hline Ceramic Insert & 50 & $6 \mathrm{~min}$ & 3 (\# of edges) & $* * *$ \\
\hline PCD (diamond) & 100 & $10 \mathrm{~min}$ & 3 (\# of edges) & $* * *$ \\
\hline
\end{tabular}

Table A.2: The information of the end mill tools

\begin{tabular}{|c|c|c|c|c|c|}
\hline $\begin{array}{c}\text { Tool } \\
\text { End Mill }\end{array}$ & $\begin{array}{l}\text { Cost } \\
(\$)\end{array}$ & $\begin{array}{l}\text { Number } \\
\text { of teeth }\end{array}$ & $\begin{array}{l}\text { Tool } \\
\text { Life }\end{array}$ & $\begin{array}{l}\text { Number of Times } \\
\text { Sharpened/Indexed } \\
\text { Before Discarding }\end{array}$ & $\begin{array}{l}\text { Time to } \\
\text { Resharpen }\end{array}$ \\
\hline HSS (2 Flute) & 8 & 2 & 3 feet & 5 & 10 \\
\hline HSS (M grade) & 9 & 2 & 4 feet & 5 & 10 \\
\hline HSS ( $T$ grade) & 10 & 2 & 5 feet & 5 & 10 \\
\hline Carbide (2 Flute) & 15 & 2 & 6 feet & 5 & 10 \\
\hline Carbide (C2..C4) & 15 & 2 & 7 feet & 5 & 10 \\
\hline Carbide (C5..C8) & 15 & 2 & 8 feet & 5 & 10 \\
\hline Carbide Insert & 8 & 2 & 6 feet & 2 (\# of edges) & $* * *$ \\
\hline
\end{tabular}


Table A.3: The information of the T-slot mill tools

\begin{tabular}{|l|c|c|c|c|c|}
\hline $\begin{array}{c}\text { Tool } \\
\text { T-Slot Mill } \\
\text { (Dia 0.75 x 0.3) }\end{array}$ & $\begin{array}{c}\text { Cost } \\
(\$)\end{array}$ & $\begin{array}{c}\text { Number } \\
\text { of } \\
\text { Teeth }\end{array}$ & $\begin{array}{c}\text { Tool } \\
\text { Life }\end{array}$ & $\begin{array}{c}\text { Number of Times } \\
\text { Sharpened/Indexed } \\
\text { Before Discarding }\end{array}$ & $\begin{array}{c}\text { Time to } \\
\text { Resharpen }\end{array}$ \\
\hline HSS (8 Flute) & 30 & 8 & 3 feet & 5 & 10 \\
\hline HSS (M grade) & 30 & 8 & 4 feet & 5 & 10 \\
\hline HSS (T grade) & 30 & 8 & 5 feet & 5 & 10 \\
\hline Carbide tipped & 70 & 8 & 6 feet & 5 & 10 \\
\hline Carbide (C2..C4) & 70 & 8 & 7 feet & 5 & 10 \\
\hline Carbide (C5..C8) & 70 & 8 & 8 feet & 5 & \\
\hline
\end{tabular}

Table A.4: The information of the face/side mill tools Table A.4: The information of the face/side mill tools

\begin{tabular}{|l|c|c|c|c|c|}
\hline $\begin{array}{c}\text { Tool } \\
\text { Face / Side Mill }\end{array}$ & $\begin{array}{c}\text { Cost } \\
(\$)\end{array}$ & $\begin{array}{c}\text { Number } \\
\text { of } \\
\text { Teeth }\end{array}$ & $\begin{array}{c}\text { Tool } \\
\text { Life }\end{array}$ & $\begin{array}{c}\text { Number of Times } \\
\text { Sharpened/Indexed } \\
\text { before Discarding }\end{array}$ & $\begin{array}{c}\text { Time to } \\
\text { Resharpen }\end{array}$ \\
\hline HSS (2 Flute) & 30 & 16 & 3 feet & 5 & 10 \\
\hline HSS (M grade) & 30 & 16 & 4 feet & 5 & 10 \\
\hline HSS (T grade) & 30 & 16 & 5 feet & 5 & 10 \\
\hline Carbide tipped & 100 & 6 & 6 feet & 5 & 10 \\
\hline Carbide (C2..C4) & 100 & 6 & 7 feet & 5 & 10 \\
\hline Carbide (C5..C8) & 100 & 6 & 8 feet & 5 & 10 \\
\hline Carbide Insert & 8 & 12 & 6 feet & 2 (\# of edges) & $* * *$ \\
\hline
\end{tabular}


Table A.5: The information of the used drilling tools

\begin{tabular}{|l|c|c|c|c|}
\hline $\begin{array}{c}\text { Tool } \\
\text { Twist Drill }\end{array}$ & $\begin{array}{c}\text { Cost } \\
(\$)\end{array}$ & Tool Life & $\begin{array}{c}\text { Number of Times } \\
\text { Sharpened/Indexed } \\
\text { Before Discarding }\end{array}$ & $\begin{array}{c}\text { Time to } \\
\text { Resharpen }\end{array}$ \\
\hline HSS (TiN coat) & 5 & 4 inches & 5 & 8 \\
\hline HSS (M grade) & 5 & 4 inches & 5 & 8 \\
\hline HSS (T grade) & 5 & 4 inches & 5 & 8 \\
\hline Carbide Tipped & 10 & 6 inches & 5 & 8 \\
\hline Carbide (C2..C4) & 10 & 6 inches & 5 & 8 \\
\hline Carbide (C5..C8) & 10 & 6 inches & 5 & 8 \\
\hline Carbide Solid & 20 & 8 inches & 5 & 8 \\
\hline Carbide Solid (C2..C4) & 20 & 8 inches & 5 & 5 \\
\hline Carbide Solid (C5..C8) & 20 & 8 inches & 5 & 8 \\
\hline
\end{tabular}

Table A6: The information of the tapping tools

\begin{tabular}{|l|c|c|c|c|}
\hline $\begin{array}{c}\text { Tool } \\
\text { Spiral Point Plug. } \\
12 \text { TPI }\end{array}$ & Cost $\$$ ) & Tool Life & $\begin{array}{c}\text { Number of Times } \\
\text { Sharpened/Indexed } \\
\text { Before Discarding }\end{array}$ & $\begin{array}{c}\text { Time to } \\
\text { Resharpen }\end{array}$ \\
\hline HSS (coated) & 8 & 4 inches & 5 & 15 \\
\hline HSS (M grade) & 8 & 6 inches & 5 & 15 \\
\hline HSS (T grade) & 8 & 8 inches & 5 & 15 \\
\hline Solid carbide & 60 & 10 inches & 5 & 15 \\
\hline Carbide Solid (C2..C4) & 60 & 10 inches & 5 & 15 \\
\hline Carbide Solid (C5..C8) & 60 & 10 inches & 5 & 15 \\
\hline
\end{tabular}


Table A.7: The information of grinding tools

\begin{tabular}{|c|c|c|c|c|}
\hline $\begin{array}{c}\text { Tool } \\
\text { Wheel }\end{array}$ & Cost $(\$)$ & Tool Life & $\begin{array}{c}\text { Number of Times } \\
\text { Sharpened/Indexed } \\
\text { Before Discarding }\end{array}$ & $\begin{array}{c}\text { Time to } \\
\text { Resharpen }\end{array}$ \\
\hline $\begin{array}{c}\text { Grinding wheel } \\
8 ” \times 2 "\end{array}$ & 45 & 7 min & 5 & 5 \\
\hline
\end{tabular}

\section{Appendix B}

Table B: Parameters of the Machines

\begin{tabular}{|c|c|c|c|c|c|c|c|c|c|c|c|}
\hline $\begin{array}{l}\text { Machine } \\
\text { Parameter } \\
\text { s }\end{array}$ & $\begin{array}{l}\text { Engine } \\
\text { Lathe }\end{array}$ & $\begin{array}{l}\mathrm{NC} \\
\text { lathe }\end{array}$ & $\begin{array}{l}\text { Turret } \\
\text { Lathe }\end{array}$ & $\begin{array}{l}\text { SP } \\
\text { auto }\end{array}$ & $\begin{array}{l}\text { Cyl } \\
\text { Gr } \\
\mathrm{mc}\end{array}$ & $\begin{array}{l}\text { NC } \\
\text { Mill }\end{array}$ & $\begin{array}{l}\mathrm{Rad} \\
\mathrm{Dr} \\
\mathrm{Mc}\end{array}$ & $\begin{array}{l}\text { Sur } \\
\text { Gr } \\
\mathrm{Mc}\end{array}$ & $\begin{array}{l}\text { Turr } \\
\text { Dr } \\
\text { Mc }\end{array}$ & $\begin{array}{l}\text { Ver } \\
\text { Dr } \\
\text { Mc }\end{array}$ & $\begin{array}{l}\text { Ver } \\
\text { Mill }\end{array}$ \\
\hline a (inch) & 0.5 & 0.5 & 0.8 & 0.5 & 0.5 & 1 & 0.5 & 0.5 & 1 & 0.5 & 1 \\
\hline e (inch) & 0.5 & 0.5 & 0.5 & 0.5 & 0.5 & 1 & ** & 0.5 & $* *$ & ** & 1 \\
\hline Feed & $\begin{array}{l}@ \\
\text { ipr }\end{array}$ & $\begin{array}{l}\text { @ } \\
\text { ipr }\end{array}$ & $\begin{array}{l}\text { @ } \\
\text { ipr }\end{array}$ & $\begin{array}{l}@ \\
\text { ipr }\end{array}$ & $\begin{array}{l}0.02 \\
\text { ipm }\end{array}$ & $\begin{array}{l}@ \\
\text { ipt }\end{array}$ & $\begin{array}{l}@ \\
\text { ipr }\end{array}$ & $\begin{array}{l}2.5 \\
\text { ipm }\end{array}$ & $\begin{array}{l}@ \\
\text { ipr }\end{array}$ & $\begin{array}{l}@ \\
\text { ipr }\end{array}$ & $\begin{array}{l}@ \\
\text { ipt }\end{array}$ \\
\hline $\begin{array}{c}\text { Labor } \\
\text { Rate } \\
(\$ / \mathrm{hr})\end{array}$ & 20 & 65 & 45 & 40 & 55 & 65 & 35 & 55 & 40 & 40 & 40 \\
\hline $\begin{array}{c}\mathrm{R} \\
\text { (inch/min) }\end{array}$ & 50 & 200 & 70 & 80 & 150 & 200 & 40 & 45 & 25 & 15 & 60 \\
\hline $\begin{array}{l}\text { Speed } \\
(\mathrm{RPM})\end{array}$ & @ & @ & @ & @ & 2000 & @ & @ & 3500 & @ & @ & @ \\
\hline $\begin{array}{c}\text { Load/ } \\
\text { Unload } \\
\text { Time } \\
\text { Each. } \\
\text { (min) }\end{array}$ & 3 & 0.5 & 1 & 0.5 & 3 & 2 & 2 & 3 & 1 & 1 & 4 \\
\hline
\end{tabular}




\begin{tabular}{|c|c|c|c|c|c|c|c|c|c|c|c|}
\hline $\begin{array}{c}\text { Tool } \\
\text { Change } \\
\text { Time } \\
\text { (min) }\end{array}$ & 3 & 0.5 & 1 & .75 & 15 & 0.5 & 1 & 15 & 0.5 & 1 & 4 \\
\hline $\begin{array}{c}\text { Desired } \\
\text { Depth of } \\
\text { Cut (inch) }\end{array}$ & $@$ & $@$ & $@$ & $@$ & 0.01 & $@$ & - & 0.01 & - & - & $@$ \\
\hline $\begin{array}{c}\text { Machine } \\
\text { Setup } \\
\text { Time } \\
\text { (min) }\end{array}$ & 10 & 35 & 15 & 20 & 20 & 10 & 15 & 15 & 15 & 15 & 15 \\
\hline
\end{tabular}

\section{Appendix C}

Table C: Speed feed selection (Sample tool data)

\begin{tabular}{|c|c|c|c|c|}
\hline Machine & Tool Material & $\begin{array}{c}\text { Recommended } \\
\text { Speed (RPM) }\end{array}$ & $\begin{array}{c}\text { Recommended } \\
\text { Feed (ipr) }\end{array}$ & $\begin{array}{l}\text { Depth } \\
\text { of Cut } \\
\text { (inch) }\end{array}$ \\
\hline Engine Lathe & & $600-1000$ & 0.012 & 0.2 \\
\hline (turning) & Ceramic Insert & & & \\
\hline Engine Lathe & & $230-250$ & 0.004 & \\
\hline (drilling) & HSS (TiN coot) & & & \\
\hline Engine Lathe & & $340-375$ & 0.006 & 0.1 \\
\hline (boring) & Carbide Insert & & & \\
\hline
\end{tabular}




\begin{tabular}{|c|c|c|c|c|c|}
\hline NC Lathe & & & $395-425$ & 0.025 & 0.2 \\
\hline (turning) & HSS & $\nabla$ & & & \\
\hline NC Lathe & & & $445-475$ & 0.006 & \\
\hline (drilling) & Carbide Solid & $\nabla$ & & & \\
\hline NC Lathe & & & $450-475$ & 0.004 & 0.1 \\
\hline (boring) & HSS & $\nabla$ & & & \\
\hline Turret Lathe & & & $330-350$ & 0.02 & 0.2 \\
\hline (turning) & Carbide Insert & $\nabla$ & & & \\
\hline Turret Lathe & & & $280-310$ & 0.006 & \\
\hline (drilling) & HSS (TiN coat) & $\nabla$ & & & \\
\hline Turret Lathe & & & $400-435$ & 0.006 & 0.1 \\
\hline (boring) & Carbide Insert & $\nabla$ & & & \\
\hline SP Auto & & & $390-410$ & 0.02 & 0.15 \\
\hline (turning) & Carbide Tipped & $\nabla$ & & & \\
\hline
\end{tabular}




\begin{tabular}{|c|c|c|c|c|c|}
\hline SP Auto & & & $350-375$ & 0.004 & \\
\hline (drilling) & HSS (TiN coat) & $\nabla$ & & & \\
\hline Radial Drill & & & $740-760$ & 0.004 & \\
\hline (axial / nonaxial) & Carbide Tipped & $\nabla$ & & & \\
\hline Vertical Drill & & & $1290-1310$ & 0.004 & \\
\hline (axial / nonaxial) & HSS (TiN coat) & $\nabla$ & & & \\
\hline Turret Drill & & & $930-950$ & 0.003 & \\
\hline (axial / nonaxial) & HSS (TiN coat) & $\nabla$ & & & \\
\hline NC Mill & & & $2780-2800$ & $0.008 \mathrm{ipt}$ & 0.2 \\
\hline & HSS & $\nabla$ & & & \\
\hline Ver / Hor Mill & & & $2200-2230$ & $0.008 \mathrm{ipt}$ & 0.2 \\
\hline & HSS & $\mathbf{\nabla}$ & & & \\
\hline
\end{tabular}




\section{Appendix D}

Table D1: Suggested alloys properties' values

\begin{tabular}{|c|c|c|c|c|c|c|c|c|c|c|c|c|c|c|c|c|c|}
\hline \multirow{3}{*}{ Index } & \multirow{3}{*}{ Engineering Alloys } & \multicolumn{16}{|c|}{ Properties } \\
\hline & & \multicolumn{4}{|c|}{$\rho v s E$} & \multicolumn{4}{|c|}{$\rho v s \sigma f$} & \multicolumn{4}{|c|}{$\rho$ vs Kic } & \multicolumn{4}{|c|}{$E v s \eta$} \\
\hline & & Min & $\operatorname{Max}$ & Min & Max & Min & $\operatorname{Max}$ & Min & $\operatorname{Max}$ & Min & $\operatorname{Max}$ & Min & $\operatorname{Max}$ & Min & Max & Min & $\operatorname{Max}$ \\
\hline 1 & Aluminum Alloys & 2.6 & 2.8 & 78.8 & 89.5 & 2.6 & 2.76 & 55 & 718 & 2.6 & 2.7 & 15 & 74 & 78.8 & 89.5 & $5.60 \mathrm{E}-05$ & $1.80 \mathrm{E}-03$ \\
\hline 2 & Steel Alloys & 7.9 & 8.6 & 312 & 364 & 8.35 & 8.76 & 365 & 1000 & 8.3 & 9 & 31 & 365 & 312 & 364 & $2.20 \mathrm{E}-05$ & $3.16 \mathrm{E}-03$ \\
\hline 3 & Copper Alloys & 8.4 & 9.2 & 152 & 258 & 8.35 & 9.2 & 55 & 718 & 8.7 & 9.5 & 703 & 417 & 152 & 258 & $1.80 \mathrm{E}-05$ & $2.20 \mathrm{E}-03$ \\
\hline 4 & Zinc Alloys & 7.3 & 7.9 & 84 & 100 & 7.5 & 7.9 & 94.7 & 645 & 7.3 & 7.9 & 20 & 100 & 84 & 100 & $1.50 \mathrm{E}-03$ & $6.80 \mathrm{E}-03$ \\
\hline 5 & Nickel Alloys & 8.6 & 9.2 & 388 & 391 & 8.55 & 9.2 & 83 & 1562 & 8.5 & 9.6 & 81 & 232 & 388 & 391 & & \\
\hline 6 & Titanium Alloys & 4.9 & 5.7 & 94 & 197 & 5 & 5.5 & 493 & 2125 & 4.8 & 5.7 & 78.8 & 206 & 94 & 197 & $6.80 \mathrm{E}-05$ & E-3 \\
\hline 7 & Cast Iron & 8 & 8.4 & 100 & 259 & 8 & 8.4 & 381 & 887 & 8 & 8.6 & 7.8 & 36.5 & 100 & 259 & $2.60 \mathrm{E}-03$ & 0.0316 \\
\hline
\end{tabular}

\begin{tabular}{|c|c|c|c|c|c|c|c|c|c|c|c|c|c|c|c|c|c|}
\hline \multirow{3}{*}{ Index } & \multirow{3}{*}{ Engineering Alloys } & \multicolumn{16}{|c|}{ Properties } \\
\hline & & \multicolumn{4}{|c|}{$C R \rho$ vs $E$} & \multicolumn{4}{|c|}{$C R \rho$ vs $\sigma f$} & \multicolumn{4}{|c|}{ a vs $\lambda$} & \multicolumn{4}{|c|}{ of vs Kic } \\
\hline & & Min & $\operatorname{Max}$ & Min & $\operatorname{Max}$ & Min & $\operatorname{Max}$ & Min & $\operatorname{Max}$ & Min & $\operatorname{Max}$ & Min & $\operatorname{Max}$ & Min & $\operatorname{Max}$ & Min & $\operatorname{Max}$ \\
\hline 1 & Aluminum Alloys & 10 & 45 & 78.8 & 89.5 & 10 & 45 & 55 & 718 & $4.20 \mathrm{E}-05$ & $1.00 \mathrm{E}-04$ & 82 & 415 & 55 & 718 & 15 & 74 \\
\hline 2 & Steel Alloys & 8 & 77.5 & 312 & 364 & 8.3 & 77.5 & 365 & 1000 & $3.20 \mathrm{E}-06$ & $7.50 \mathrm{E}-06$ & 55 & 73 & 365 & 1000 & 31 & 365 \\
\hline 3 & Copper Alloys & 49 & 83 & 152 & 258 & 49 & 83 & 55 & 718 & $2.70 \mathrm{E}-05$ & $1.15 \mathrm{E}-04$ & 235 & 550 & 55 & 718 & 703 & 417 \\
\hline 4 & Zinc Alloys & 29 & 60.6 & 84 & 100 & 29 & 60.6 & 94.7 & 645 & $3.70 \mathrm{E}-05$ & $5.60 \mathrm{E}-05$ & 91 & 235 & 94.7 & 645 & 20 & 100 \\
\hline 5 & Nickel Alloys & 128 & 409 & 388 & 391 & 128 & 409 & 83 & 1562 & $3.20 \mathrm{E}-06$ & $7.50 \mathrm{E}-06$ & 73 & 92 & 83 & 1562 & 81 & 232 \\
\hline 6 & Titanium Alloys & 212 & 606 & 94 & 197 & 212 & 606 & 493 & 2125 & $2.40 \mathrm{E}-06$ & $5.60 \mathrm{E}-06$ & 7.2 & 12 & 493 & 2125 & 78.8 & 206 \\
\hline 7 & Cast Iron & 7 & 11 & 100 & 259 & 6.6 & 11 & 381 & 887 & 9.33E-06 & 8.67E-05 & 55 & 70.3 & 381 & 887 & 7.8 & 36.5 \\
\hline
\end{tabular}




\begin{tabular}{|c|c|c|c|c|c|c|c|c|c|c|c|c|c|}
\hline \multirow{3}{*}{ Index } & \multirow{3}{*}{ Engineering Alloys } & \multicolumn{12}{|c|}{ Properties } \\
\hline & & \multicolumn{4}{|c|}{$\lambda \operatorname{vs} \alpha$} & \multicolumn{4}{|c|}{$E$ vs $\alpha$} & \multicolumn{4}{|c|}{$\alpha v s \eta$} \\
\hline & & Min & $\operatorname{Max}$ & Min & $\operatorname{Max}$ & Min & $\operatorname{Max}$ & Min & $\operatorname{Max}$ & Min & $\operatorname{Max}$ & Min & $\operatorname{Max}$ \\
\hline 1 & Aluminum Alloys & 82 & 415 & 35.3 & 49.3 & 78.8 & 89.5 & 35.3 & 49.3 & 35.3 & 49.3 & $8.70 \mathrm{E}-03$ & $1.20 \mathrm{E}-03$ \\
\hline 2 & Steel Alloys & 55 & 73 & 10 & 38 & 312 & 364 & 10 & 38 & 10 & 38 & $8.70 \mathrm{E}-03$ & $5.60 \mathrm{E}-02$ \\
\hline 3 & Copper Alloys & 235 & 550 & 47.5 & 41 & 152 & 258 & 47.5 & 41 & 47.5 & 41 & $5.60 \mathrm{E}-03$ & $2.40 \mathrm{E}-03$ \\
\hline 4 & Zinc Alloys & 91 & 235 & 43.75 & 60.6 & 84 & 100 & 43.75 & 60.6 & 43.75 & 60.6 & $9.30 \mathrm{E}-03$ & $3.15 \mathrm{E}-03$ \\
\hline 5 & Nickel Alloys & 73 & 92 & 9.4 & 26.8 & 388 & 391 & 9.4 & 26.8 & 9.4 & 26.8 & $4.87 \mathrm{E}-03$ & $1.54 \mathrm{E}-03$ \\
\hline 6 & Titanium Alloys & 7.2 & 12 & 8.9 & 10 & 94 & 197 & 8.9 & 10 & 8.9 & 10 & $4.87 \mathrm{E}-03$ & $1.30 \mathrm{E}-03$ \\
\hline 7 & Cast Iron & 55 & 70.3 & 9.5 & 32.5 & 100 & 259 & $9 . .5$ & 32.5 & $9 . .5$ & 32.5 & $3.16 \mathrm{E}-03$ & $5.60 \mathrm{E}-03$ \\
\hline
\end{tabular}

\begin{tabular}{|c|c|c|c|c|c|c|c|c|c|c|c|c|c|}
\hline \multirow{3}{*}{ Index } & \multirow{3}{*}{$\begin{array}{c}\text { Engineering } \\
\text { Alloys }\end{array}$} & \multicolumn{12}{|c|}{ Properties } \\
\hline & & \multicolumn{4}{|c|}{$T v s \sigma f(T)$} & \multicolumn{4}{|c|}{$H$ vs $K a$} & \multicolumn{4}{|c|}{$q \rho$ vs $E$} \\
\hline & & Min & $\operatorname{Max}$ & Min & $\operatorname{Max}$ & Min & $\operatorname{Max}$ & Min & Max & Min & $\operatorname{Max}$ & Min & Max \\
\hline 1 & Aluminum Alloys & 257 & 512 & 94 & 775 & 50 & 150 & $1 \mathrm{E}-12$ & $5.01 \mathrm{E}-12$ & 831 & 1000 & 78.8 & 89.5 \\
\hline 2 & Steel Alloys & 68.2 & 920 & 68 & 894 & 135 & 185 & $3.16 \mathrm{E}-14$ & $3.16 \mathrm{E}-14$ & 606 & 1562 & 312 & 364 \\
\hline 3 & Copper Alloys & & & & & 40 & 201 & $2.00 \mathrm{E}-12$ & $3.16 \mathrm{E}-13$ & 803 & 2125 & 152 & 258 \\
\hline 4 & Zinc Alloys & 258 & 383 & 152.9 & 576 & 80 & 100 & & & 578 & 775 & 84 & 100 \\
\hline 5 & Nickel Alloys & 741 & 1280 & 576 & 1000 & 80 & 360 & & & & & 388 & 391 \\
\hline 6 & Titanium Alloys & 575 & 1000 & 68 & 894 & 150 & 200 & & & 4093 & 5500 & 94 & 197 \\
\hline 7 & Cast Iron & & & & & 110 & 600 & $3.98 \mathrm{E}-16$ & $1 \mathrm{E}-14$ & 634 & 1843 & 100 & 259 \\
\hline
\end{tabular}




\begin{tabular}{|c|c|c|c|c|c|c|c|c|c|c|c|c|c|}
\hline \multirow{3}{*}{ Index } & \multirow{3}{*}{$\begin{array}{l}\text { Engineering } \\
\text { Alloys }\end{array}$} & \multicolumn{12}{|c|}{ Properties } \\
\hline & & \multicolumn{4}{|c|}{$q \rho v s \sigma f$} & \multicolumn{4}{|c|}{ Evs Kic } & \multicolumn{4}{|c|}{ Tmax vs $\sigma y$} \\
\hline & & Min & $\operatorname{Max}$ & Min & $\operatorname{Max}$ & Min & $\operatorname{Max}$ & Min & $\operatorname{Max}$ & Min & $\operatorname{Max}$ & Min & Max \\
\hline 1 & Aluminum Alloys & 831 & 1000 & 55 & 718 & 78.8 & 89.5 & 15 & 74 & 146 & 234 & 55 & 640 \\
\hline 2 & Steel Alloys & 550 & 1562 & 365 & 1000 & 312 & 364 & 31 & 365 & 809 & 1127 & 292 & 1000 \\
\hline 3 & Copper Alloys & 803 & 2125 & 55 & 718 & 152 & 258 & 703 & 417 & 85 & 387 & 55 & 640 \\
\hline 4 & Zinc Alloys & 578 & 775 & 94.7 & 645 & 84 & 100 & 20 & 100 & 90 & 678 & 77 & 118 \\
\hline 5 & Nickel Alloys & & & 83 & 1562 & 388 & 391 & 81 & 232 & 350 & 1127 & 85 & 1055 \\
\hline 6 & Titanium Alloys & 4093 & 5500 & 493 & 2125 & 94 & 197 & 78.8 & 206 & 300 & 800 & 450 & 1105 \\
\hline 7 & Cast Iron & 634 & 1843 & 381 & 887 & 100 & 259 & 7.8 & 36.5 & 395 & 538 & 357 & 871 \\
\hline
\end{tabular}

\begin{tabular}{|c|c|c|c|c|c|c|c|c|c|c|c|c|c|}
\hline \multirow{3}{*}{ Index } & \multirow{3}{*}{$\begin{array}{c}\text { Engineering } \\
\text { Alloys }\end{array}$} & \multicolumn{12}{|c|}{ Properties } \\
\hline & & \multicolumn{4}{|c|}{$H p . \rho$ vs $E$} & \multicolumn{4}{|c|}{$H p . \rho v s \sigma f$} & \multicolumn{4}{|c|}{$\rho e v s \lambda$} \\
\hline & & Min & $\operatorname{Max}$ & Min & $\operatorname{Max}$ & Min & $\operatorname{Max}$ & Min & $\operatorname{Max}$ & Min & $\operatorname{Max}$ & Min & $\operatorname{Max}$ \\
\hline 1 & Aluminum Alloys & 706122 & 761224 & 78.8 & 89.5 & 706122 & 761224 & 55 & 718 & 2223 & 3334 & 82 & 415 \\
\hline 2 & Steel Alloys & 797959 & 834693 & 312 & 364 & 797959 & 834693 & 365 & 1000 & 4445 & 5278 & 55 & 73 \\
\hline 3 & Copper Alloys & 779591 & 816326 & 152 & 258 & 779591 & 816326 & 55 & 718 & 1667 & 3056 & 235 & 550 \\
\hline 4 & Zinc Alloys & 430612 & 577551 & 84 & 100 & 430612 & 577551 & 94.7 & 645 & 3334 & 4445 & 91 & 235 \\
\hline 5 & Nickel Alloys & 1551020 & 1918367 & 388 & 391 & 1551020 & 1918367 & 83 & 1562 & & & 73 & 92 \\
\hline 6 & Titanium Alloys & 131500000 & 145000000 & 94 & 197 & 1367346 & 145000000 & 493 & 2125 & 5556 & 7222 & 7.2 & 12 \\
\hline 7 & Cast Iron & 155102 & 191837 & 100 & 259 & 155102 & 191837 & 381 & 887 & & & 55 & 70.3 \\
\hline
\end{tabular}




\begin{tabular}{|c|c|c|c|c|c|c|c|c|c|}
\hline & \multirow{3}{*}{$\begin{array}{l}\text { Engineering } \\
\text { Alloys }\end{array}$} & \multicolumn{8}{|c|}{ Properties } \\
\hline & & \multicolumn{4}{|c|}{$\rho e v s \sigma y$} & \multicolumn{4}{|c|}{$\sigma t s v s \sigma e$} \\
\hline & & Min & Max & Min & $\operatorname{Max}$ & Min & $\operatorname{Max}$ & Min & $\operatorname{Max}$ \\
\hline 1 & Aluminum Alloys & 191 & 334 & 82 & 718 & 336 & 857 & 82 & 381 \\
\hline 2 & Steel Alloys & 571 & 714 & 280 & 2800 & 668 & 1710 & 493 & 831 \\
\hline 3 & Copper Alloys & 96 & 238 & 61 & 604 & 194 & 668 & 83 & 212 \\
\hline 4 & Zinc Alloys & 288 & 476 & 82 & 712 & 85 & 621 & 55 & 325 \\
\hline 5 & Nickel Alloys & 667 & 809 & 532 & 3160 & 667 & 3605 & 212 & 943 \\
\hline 6 & Titanium Alloys & 619 & 762 & 892 & 1720 & 881 & 2421 & 775 & 859 \\
\hline 7 & Cast Iron & & & 357 & 871 & 715 & 834 & 184 & 662 \\
\hline
\end{tabular}


Table D2: List of materials properties that have been selected

\begin{tabular}{|c|c|c|c|}
\hline No & Property Name & Nomenclature & Property Unit \\
\hline 1 & Density & $\rho$ & $\left(\mathrm{Mg} / \mathrm{m}^{3}\right)$ \\
\hline 2 & Young Modulus & $\mathrm{E}$ & (Gpa) \\
\hline 3 & Strength / Elastic limit & $\sigma f$ & (Mpa) \\
\hline 4 & Fracture Toughness & Kic & $\left(\mathrm{Mpa}^{\mathrm{m}}{ }^{1 / 2}\right)$ \\
\hline 5 & loss coefficient at $30 \mathrm{C} 0$ & $\eta$ & $1 / \mathrm{C}^{0}$ \\
\hline 6 & Relative cost per unit volume & $\mathrm{CR} \rho$ & $\left(\mathrm{Mg} / \mathrm{m}^{3}\right)$ \\
\hline 7 & Thermal Diffusivity & $\mathrm{a}$ & $\left(\mathrm{m}^{2} / \mathrm{s}\right)$ \\
\hline 8 & Thermal Conductivity & $\lambda$ & $(\mathrm{W} / \mathrm{m} . \mathrm{K})$ \\
\hline 9 & $\begin{array}{l}\text { Linear Expansion Coefficient } \\
\text { (Thermal expansion) }\end{array}$ & $\alpha$ & $\begin{array}{c}(\mu \text { strain } / \mathrm{K})\left(\mathrm{K}^{-1}\right) \\
\left(\mathrm{c}^{-1}\right)\end{array}$ \\
\hline 10 & Normalized Strength & $\sigma \mathrm{t} / \mathrm{E}$ & \\
\hline 11 & Temperature & $\mathrm{T}$ & $\mathrm{k}$ \\
\hline 12 & Strength at Temperature & $\sigma_{f}(T)$ & (Mpa) \\
\hline 13 & Hardness & $\mathrm{H}$ & Bhn \\
\hline 14 & Wear Rate Constant & $\mathrm{Ka}$ & $\left(\mathrm{m}^{2} / \mathrm{N}\right)$ \\
\hline 15 & Energy Content & $q \rho$ & $\left(\mathrm{GJ} / \mathrm{m}^{3}\right)$ \\
\hline 16 & $\begin{array}{l}\text { Maximum Service } \\
\text { Temperature }\end{array}$ & $\mathrm{T}$ & $\mathrm{C}^{0}$ \\
\hline 17 & Strength & $\sigma_{\mathrm{y}}$ or $\sigma_{\mathrm{el}}$ & (Mpa) \\
\hline 18 & $\begin{array}{l}\text { Production (Embodied) energy } \\
\text { per cubic meter }\end{array}$ & Нp. $\rho$ & $(\mathrm{MJ} / \mathrm{m} 3)$ \\
\hline 19 & Electrical resistivity & $\rho e$ & $(\mu-\Omega . c m)$ \\
\hline 20 & tensile strength & ots & (Mpa) \\
\hline 21 & Endurance Limit & $\sigma e$ & (Mpa) \\
\hline
\end{tabular}




\section{Appendix E}

\section{Cutting Speeds for Tapping:}

Engine Lathe:

HSS TiN Coat: $10 \sim 15$ fpm

Carbide Tipped: $15 \sim 20 \mathrm{fpm}$

Carbide Solid: $20 \sim 25$ fpm

NC Lathe:

HSS TiN Coat: 25 35 fpm

Carbide Tipped: $35 \sim 45$ fpm

Carbide Solid: $45 \sim 55$ fpm

Turret Lathe:

HSS TiN Coat: 20 30 fpm

Carbide Tipped: $30 \sim 40 \mathrm{fpm}$

Carbide Solid: $40 \sim 50$ fpm

SP Auto:

HSS TiN Coat: 20 30 fpm

Carbide Tipped: $30 \sim 40$ fpm

Carbide Solid: $40 \sim 50$ fpm 
Radial Drill:

HSS TiN Coat: $35 \sim 45$ fpm

Carbide Tipped: $45 \sim 55$ fpm

Carbide Solid: $55 \sim 65$ fpm

Vertical Drill:

HSS TiN Coat: $40 \sim 50$ fpm

Carbide Tipped: $50 \sim 60 \mathrm{fpm}$

Carbide Solid: 60 70 fpm

Turret Drill:

HSS TiN Coat: $35 \sim 45$ fpm

Carbide Tipped: $45 \sim 55$ fpm

Carbide Solid: $55 \sim 65 \mathrm{fpm}$ 